\title{
NISTIR 88-4008
}

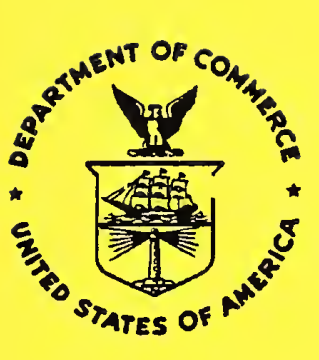

\section{Corrosion of Metallic Fasteners in Low-Sloped Roofs: A Review of Available Information and Identification of Research Needs}

"Walter J. Rossiter, Jr.

** Michael A. Streicher

"Willard E. Roberts

\author{
*U.S. DEPARTMENT OF COMMERCE \\ National Institute of Standards and Technology \\ (Formerly National Bureau of Standards) \\ National Engineering Laboratory \\ Center for Building Technology \\ Gaithersburg, MD 20899 \\ ${ }^{* *}$ Webster Farm \\ Wilmington, DE 19803
}

February 1989

Prepared for

U.S. Department of Energy

Office of Energy Utilization Research

Energy Conservation Utilization and Technologies Program 1000 Independence Ave., S.W.

Washington, DC 20585 



\section{Corrosion of Metallic Fasteners in Low-Sloped Roofs: A Review of Available Information and Identification of Research Needs}

"Walter J. Rossiter, Jr.

*"Michael A. Streicher

"Willard E. Roberts

*U.S. DEPARTMENT OF COMMERCE

National Institute of Standards and Technology

(Formerly National Bureau of Standards)

National Engineering Laboratory

Center for Building Technology

Gaithersburg, MD 20899

${ }^{*}$ Webster Farm

Wilmington, DE 19803

February 1989

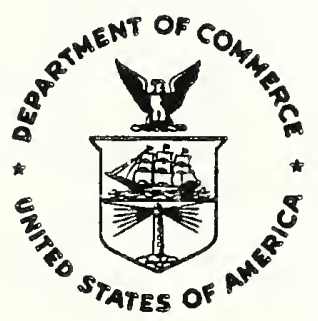

National Bureau of Standards became the National institute of Standards and Technology on August 23, 1988, when the Omnibus Trade and Competitiveness Act was signed. NIST retains all NBS functions. Its new programs will encourage improved use of technology by U.S. industry.

Prepared for

U.S. Department of Energy

Office of Energy Utilization Research

Energy Conservation Utilization and Technologies Program

1000 Independence Ave., S.W.

Washington, DC 20585

\section{U.S. DEPARTMENT OF COMMERCE \\ C. William Verity, Secretary \\ Ernest Ambler, Acting Under Secretary for Technology}

NATIONAL INSTITUTE OF STANDARDS 


\section{ABSTRACT}

The use of mechanical fasteners for securing membranes or both insulation and membranes to the structural deck of low-sloped roofing systems is a common practice in the United states. The fasteners have been observed to corrode in service in the presence of moisture. Depending upon the extent of corrosion, loss of securement may result, making the roofing vulnerable to damage during high winds. Systematic studies to elicit the factors affecting the corrosion of fasteners in service have not been conducted.

This paper presents the results of a study conducted to summarize available information on the corrosion issue, and to identify research needed to correct problems. On the basis of the available information, it was not possible to estimate the extent of the corrosion problem. In particular, the incidence of loss of fastener securement due to corrosion could not be established because of the inaccessibility of installed fasteners within roofs. In reviewing factors affecting fastener corrosion, water was the only one that stood out on the basis of the information obtained. Uniform corrosion (rust on some or all of the surface) was the predominant type that inspectors have observed in service. Nevertheless, some evidence of localized corrosion processes (e.g., crevice corrosion) has also been observed. Both types of corrosion may lead to loss of fastener securement in service. The results of the study indicated that there are three major gaps in the knowledge base: 1) evaluation test procedures for the corrosion resistance of fasteners are limited and need to be improved, 2) a data base on field performance of fasteners is lacking, and 3) non-destructive diagnostic procedures for assessing the condition of in-place fasteners are not available. Research needed to overcome these limitations was identified.

Key words: corrosion; durability; metallic fasteners; low-sloped roofs; membrane attachment; research needs; review; roof performance; securement 
ABSTRACT

LIST OF TABLES ................... . V v

LIST OF FIGURES. . . . . . . . . . . . . . . . . v

EXECUTIVE SUMMARY. . . . . . . . . . . . . . . vi vi

1. INTRODUCTION. . . . . . . . . . . . . 1

1.1 Background ................ 3

1.2 Objective. . . . . . . . . . . . . . 8

1.3 Scope.................. . . 8

2. THE LITERATURE. ............... . 10

2.1 Summary of Norwegian Study . . . . . . . . 10

2.2 Summary of Trade Literature........... 12

3. FOREIGN BUILDING RESEARCH INSTITUTES. . . . . . 14

4. INFORMATION FROM QUESTIONNAIRES . . . . . . . . 16

5. MATERIALS AND CORROSION PROTECTION FOR FASTENERS, STRESS PLATES, AND BATTEN BARS. . . . . . . . . . 19

5.1 Commentary on Corrosion Concerns . . . . . . 22

6. DISCUSSION OF THE SULFUR DIOXIDE/WATER VAPOR TEST • 28

6.1 Summary of the Test Method . . . . . . . . . 28

6.2 Significance of the Method . . . . . . . . . 29

6.3 Advantages of the Method ............ 30

6.4 Limitations of the Method... . . . . . . . 30

7. RECOMMENDATIONS FOR RESEARCH. . . . . . . . . 34

8. CONCLUSIONS AND RECOMMENDATIONS . . . . . . . . . 39

8.1 Conclusions. ............... . . 40

8.2 Recommendations.:. . . . . . . . . . . 41

9. REFERENCES. . . . . . . . . . .... 42

10. ACKNOWLEDGMENTS ............... . . 45 
APPENDIX A. DEFINITIONS OF CORROSION TERMS USED IN THIS REPORT. . . . . . . . . . . . . AI

APPENDIX B. NORWEGIAN RECOMMENDATIONS ON FASTENER CORROSION . . . . . . . . . . . . . BI

APPENDIX C. SUMMARY OF RESPONSES FROM ABROAD ON QUESTIONS REGARDING FASTENER CORROSION. . . . Cl

APPENDIX D. QUESTIONNAIRE RESULTS . . . . . . . . DI

\section{LIST OF TABLES}

Page

Table 1. Summary of Number of Questionnaires sent and Returned .............. 16

Table 2. Fastener Materials for Low-sloped Roofing systems. . . . . . . . . . . . . 20

Table 3. Stress Plate and Batten Strip Materials for Low-sloped Roofing... . . . . . . 21

Table Bl. Corrosion Resistance for Metallic Fasteners as Given in the Norwegian Recommendations. . .

\section{LIST OF FIGURES}

$\underline{\text { Page }}$

Figure 1. Typical Fasteners and Stress Plates Currently Used in Low-Sloped Roofing. . . . .

Figure 2. The Use of Fasteners to Secure Roof Components to Decks: A) First Layer of Insulation, and B) Insulation and Membrane. . . . . . . .

Figure 3. Fasteners That Experienced Corrosion In Service. . . . . . . . . . . . . .

Figure 4. Cross-Section of a-Mechanically-Attached Single-Ply Membrane System Installed over An Existing Built-Up Membrane System. The Fastener Experienced Marked Thinning of the Shank in the Area Within the Insulation ... 50 


\section{EXECUTIVE SUMMARY}

\section{BACKGROUND AND OBJECTIVES}

The potential for corrosion-induced problems of a major portion of the Nation's low-sloped roofing systems is of serious concern to the U.S. roofing industry. In recent years, mechanical fasteners have gained acceptance for use as an alternative to hot asphalt (or other type of adhesive) to secure membrane and insulation components to the structural deck, particularly against removal by wind uplift forces. However, while mechanical fasteners generally provide improved immediate attachment versus that obtained with hot asphalt on some decks, particularly steel, corrosion of the fasteners may eventually lead to loss of securement and in time make the system vulnerable to high winds.

The objectives of the study are: 1) to summarize available information related to the corrosion of fasteners in low-sloped roofing systems, 2) to estimate, if possible, the nature and magnitude of current and future problems, and 3) to determine the need for research to correct the problems identified, and if appropriate, to recommend a research program. The study was limited to an assessment of existing information on the potential for fasteners used in low-sloped roofing systems to corrode in service. Emphasis was placed on the performance of metallic screw-type fasteners for attaching insulation and/or membranes primarily to decks, because this type of fastener application is the most common, and has raised the most concern regarding corrosion. Sources of information consulted included the archival and trade literature, discussions with researchers familiar with building and roofing performance including foreign building research institutes, and contacts with individuals associated with roofing practice such as contractors, owners, consultants, and manufacturers' representatives. Questionnaires addressing the extent of the potential problem and factors influencing it were prepared for completion by contractors, consultants, and manufacturers' representatives.

\section{RESULTS}

In summarizing the major findings of the study, three main areas are addressed: 1) the field performance of fastener systems, 2) fastener system materials and the possibility of corrosion, and 3) evaluation techniques for corrosion resistance. The summary is based on the review of the literature, the result of the questionnaires, and discussions with individuals having experience with the corrosion of fastener issue including manufacturers, contractors and consultants. The authors' review of the types of fasteners, stress plates, and batten bars used for low-sloped roofing, and also their analysis of the sulfur dioxide/water vapor test contributed to the summary. 
1) Field Performance of Fastener systems

- The use of mechanical fasteners has been generally accepted as a method for attaching insulation and membranes to steel decks as well as other decks. Mechanical attachment has resulted in improved securement to steel decks over that obtained using adhesive methods such as the application of hot asphalt. A major driving force behind the use of mechanical fasteners for these decks was the insurance industry's (particularly Factory Mutual Research Corp.) desire to minimize wind losses due to poor attachment when asphalt or other adhesives were used.

- The use of mechanical fasteners has not eliminated all roof securement problems. Mechanical fasteners have been observed to corrode in service. This has been generally evidenced by rusting and thinning in the presence of moisture. In a few cases, there has been evidence of localized corrosion. This has included crevice corrosion where the fastener has been in contact with the deck or the stress distribution plate. As is obvious, if a sufficient number of fasteners on a roof fail by corrosion, the securement of the roof against wind uplift is in jeopardy.

- Most reports of incidents of corrosion are anecdotal. The anecdotes have included instances of wind damage. Figures and records on the magnitude of corrosion-related problems including wind damage are not available. Furthermore, no systematic field evaluations have been conducted in the United states to assess the performance of either new or early-generation fasteners. Technical reports on the subject are not available. Nevertheless, concerns about the magnitude of the problem have motivated the insurance industry to develop requirements intended to enhance the corrosion resistance of fasteners.

- The action taken by the insurance industry was to recommend the sulfur dioxide/water vapor test procedure for evaluating the corrosion resistance of fasteners, stress plates, and batten bars. Factory Mutual Research Corporation put into effect, in December 1988, a requirement that these components meet the evaluation criteria of the sulfur dioxide/water vapor test.

- Many individuals in the roofing industry believe that the use of the test will improve fastener performance by eliminating those that may perform marginally in service, and by providing a method for selecting those that will perform satisfactorily. Nevertheless, it has been stated more than once that the relationship between fastener performance in the sulfur dioxide/water vapor test and longterm field performance is not known. 
- In attempting to elucidate the specific factors affecting the corrosion of fasteners in roofing systems, water was the only factor that stood out on the basis of the information obtained. While mechanisms governing corrosion of metallic fasteners are generally known, the specific contributions due to factors such as roof design and roofing materials generally did not surface. On basic principles, if water (with possible chloride content) is not present, then corrosion will not occur. Much information on field performance was consistent with this principle. Trade articles and anecdotes from individuals having field experience suggest that fasteners have corroded where the roof is wet, and have not done so where it is dry.

Information from the authors' questionnaires indicated that, when examined, corroded fasteners were often in contact with water and that the roof was generally leaking. Moreover, all sources of information were in general agreement that re-roofing projects without tear-off, where an existing system was recovered with a new mechanically attached membrane system, was the predominant type of roofing project in which corroded fasteners were observed. In the latter case, the mechanical fasteners of the new system were driven through the existing system that maybe was wet and abrasive.

- Although re-roofing projects without tear-off were seen to be the predominant type of project having corroded fasteners, some observations of corrosion of fasteners have also been made in cases of projects involving new roofing and re-roofing with tear-off. Roofs of ages ranging from one to more than ten years have experienced corrosion of fasteners. Moreover, corrosion of fasteners has occurred in roofs of all types of membranes, insulations, and decks.

\section{2) Fasteners, Stress Plates, Batten Strips and coatings}

- Because of the corrosion issue, the industry is in a state of rapid change regarding the materials and/or coatings used for fasteners, stress plates, and batten strips. Zinc-coated carbon-steel fasteners and stress plates, which predominated until recently, are now seldom used. The major type of fastener is now polymer-coated (e.g., fluorocarbon or epoxy) carbon steel. Stainless steel fasteners (e.g., Type 410 and 304 ) are also being offered. In the case of stress plates, zinc-aluminum alloy coated carbon steel and plastic stress plates are widely available. These new materials have been introduced to provide products having improved corrosion resistance. 
- Most of the corroded fasteners observed to date have been carbon steel, either bare or coated. Evidence of both general and localized corrosion processes have been noted. Two reports of corrosion of stainless steel fasteners were received in the questionnaires.

- Analysis, based on well-known corrosion experiences with the materials from which these newer fasteners are being produced, indicates that the new products may not be corrosion free. Some (particularly stainless steels) may undergo corrosion processes, such as galvanic effects (e.g., between the stainless steels and the carbon steel deck and stress plates), chloride pitting, chloride stress corrosion cracking, and hydrogen embrittlement (see Appendix A). These corrosion processes are generally different from those previously experienced on roofs. In the case of the polymer-coated carbon steel fasteners, a factor that is expected to influence its corrosion resistance in service is the ability of the coating to remain in place through the rigors of screw-application through the various components of the roof (e.g., embrittled membranes or residual gravel on an existing system, or insulation boards). Field evaluation of the new fasteners to obtain data on their performance, particularly with regard to these specific corrosion processes, is lacking and needs to be obtained. In particular, the field studies should address whether or not corrosion processes that may be postulated for the newer fasteners are, in fact, occurring in service.

3) Evaluation Techniques for Corrosion Resistance

- Until recently, the roofing industry did not use a standardized test method for evaluating the corrosion resistance of fasteners. In response to the desire in the industry for improved corrosion resistance, the standardized sulfur dioxide/water vapor test (Kesternich Test) was proposed and adopted by the industry for fasteners. Factory Mutual Research Corporation (FMRC) is evaluating fasteners according to this method. An FMRC approval requirement became effective December 1988.

- Considerations of the advantages and limitations of the test indicate that its applicability for assessing the corrosion resistance of fasteners is limited. It is useful for checking the integrity of coatings on carbon steel fasteners. Nevertheless, if a coated fastener passes the test, it is not assured that the coating integrity will be maintained during application and service. The test does not address abrasion resistance and adhesion of the coating system to the substrate. In addition, with regard to other limitations, the sulfur dioxide/water vapor test, which is free of chloride additions, is not designed to evaluate whether the fasteners are adequately resistant to corrosion processes such as galvanic corrosion, chloride pitting, chloride stress corrosion cracking, and hydrogen 
embrittlement. As has been indicated above, these processes need to be considered when evaluating potential corrosion of the fastener products in service.

\section{CONCLUSIONS}

From the review of the available information and analyses made in this study, the following conclusions have been derived:

1. Fasteners have been observed to corrode in service in the presence of water, and in some cases, with the loss of fastener securement. All sources of information on this point are in agreement, and numerous examples are given in our sources.

2. On the basis of the available information, it was not possible to estimate the extent of the fastener corrosion problem. In particular, the incidence of loss of fastener securement due to corrosion could not be established because of the inaccessibility of installed fasteners within roofs.

3. However, in almost all cases, the corrosion of fasteners was reported to occur in wet insulation, and in roofs that had often leaked. In some cases, severe corrosion and loss of securement was reported to have occurred in less than two years of service.

4. In the future, unless corrosion resistant fastener systems are used, corrosion of fasteners in wet roofs is likely to continue. The incidence can be expected to be related to the number of wet roofs. Two factors are important in reducing the extent of future problems with metallic fasteners: 1) for new construction, installation of wet materials should be avoided and the spread of water due to unexpected leaks during service should be minimized, and 2) for reroofing without tear-off, application of fasteners through wet insulation and abrasive membranes in the existing system should be avoided.

5. New coating systems, such as polymeric coatings and base coats to adhere them to carbon steel, have been introduced in response to efforts by industry to provide fastener systems with improved corrosion resistance. The introduction of such coatings has produced a need for new or improved evaluation methods for important properties affecting fastener corrosion resistance. Such properties include adhesion, porosity, and abrasion resistance required to maintain the coating during installation.

6. New materials, such as stainless steels also introduced in response to efforts by industry to provide fastener systems with improved corrosion resistance, have brought with them additional corrosion mechanisms different from those encountered with carbon steel. For example, various stainless steels may be subject to pitting, crevice 
corrosion, and stress corrosion cracking in the presence of dissolved chloride salts.

7. Improvements to the sulfur dioxide/water vapor (Kesternich) test and new approaches for evaluating corrosion resistance of fasteners are needed.

8. A method is needed to evaluate the abrasion resistance of coated fasteners. Current evaluation procedures for corrosion resistance do not consider abrasion resistance of coated fasteners. Loss of protective coating by abrasion, particularly during installation, would expose the steel substrate of the fastener to the roof environment.

\section{RECOMMENDATIONS}

Based on the findings of the study, recommendations are made for research to overcome the limitations identified regarding the use of fasteners in low-sloped roofing. The results of the study indicated that there are at least three needs: (1) improved evaluation test procedures for the corrosion resistance of fasteners, (2) a data base on field performance, and (3) nondestructive diagnostic procedures for assessing in-place condition of fasteners.

Suggestions for research in the three areas are given in section 7 of the main text of the report. Completion of the recommended research will help facilitate the assessment and use of fastener systems which will perform satisfactorily in wet roofing environments. 



\section{INTRODUCTION}

A primary goal associated with the construction of low-sloped roofing systems is to provide satisfactory long-term performance, perhaps for 20 years or more. Experience has shown that the economics and technology of roofing construction makes such a goal feasible. For the owner, no matter what type of system is installed, durability at an acceptable cost is the major item of importance. The roof represents a significant investment, for it is a prime barrier protecting the building and its contents from the weather, as well as contributing to thermal efficiency. Those involved in the roof construction cycle, such as architectengineers, material manufacturers, and contractors, play an important role, because durability is dependent on proper design, rational selection of materials, and good workmanship and installation.

Many factors can adversely affect the long-term performance of roofs. These include weather, biological agents, mechanical stress, incompatibility of materials, installation practices, and maintenance procedures [1]. Recent advances in materials and roofing technology have led to improvements in long-term roofing performance [2]. However, unexpected problems and failures continue to occur, resulting in less than satisfactory long-term performance. This is probably why some roofinr systems introduced in the mid-1970s are no longer available [3]. Because of its importance, the question of roof durability has received considerable discussion, and methods for providing improved techniques for evaluating the durability of roof systems and 
components are often proposed [e.g., 4-6]. Considerable work still needs to be performed to make possible reliable predictions of long-term performance on the basis of short-term tests $[1,4]$.

This report describes a state-of-the-art review of a relatively recently recognized problem; namely, the corrosion of metallic fasteners in low-sloped roofing. In recent years, mechanical fasteners have gained acceptance for use as an alternative to hot asphalt (or other type of adhesive) to secure membrane and insulation components to the structural deck, particularly against removal by uplift forces [7]. Figure 1 is a photograph of some typical fasteners and stress plates. While generally providing improved immediate attachment versus that obtained with hot asphalt on some decks, particularly steel, fastener corrosion caused by the presence of moisture leading to loss of attachment can make the system vulnerable to high winds.

One definition of corrosion is the "undesirable deterioration of a metal or alloy, i.e., an interaction of a metal with its environment that adversely affects those properties of the metal which are to be preserved" [8] (see Appendix A for definitions of corrosion terms used in this report). With regard to the environment of the components of low-sloped roofs, a major factor is water (or moisture) with or without dissolved chemicals (e.g., salts and acids). In the case of roofing fasteners, the property to be preserved is the fastener's ability to secure the system to the structural deck. Corrosion of fasteners in service has been manifested in several ways [9-16]. These include general uniform 
corrosion (rusting) and localized corrosion such as progressive thinning which can lead to loss of fastener securement, or crevice corrosion (Appendix A) where the fastener is in contact with the deck. Crevice corrosion may lead to separation of the fastener from the deck. It is apparent that, if these corrosion processes resulting in loss of fastener securement occur, the roof will likely become susceptible to damage by high winds.

\subsection{Background}

Energy efficient, low-sloped roofing systems, in many cases, are characterized as having two layers of rigid board insulation with staggered joints. In the case of built-up roofing on metal decks, it is now customary that the first (bottom) layer of insulation be secured in place with the use of metallic mechanical fasteners; the second (top) layer is, in turn, adhered to the first layer, normally using hot asphalt (Figure $2 \mathrm{~A}$ ). In the cases of some single-ply systems, a single thick layer of insulation board (or perhaps more) and single-ply membrane are both directly secured to the deck using fasteners (Figure 2B).

The practice of attaching the first insulation-board layer to steel decks using metallic fasteners was prescribed in Factory Mutual Research Corp. (FMRC) Data Sheet 1-28, issued in May, 1983 [7]. It was introduced to assure adequate resistance of the membrane system to uplift forces. As described in the FMRC Data Sheet, during the period from 1971 to 1980,30 percent of all windstorm losses (Factory Mutual System) occurred to steel deck roofs. This represented over 1200 occurrences with losses of 
more than $\$ 83$ million. The main roof components involved in these losses were the insulation, membrane, and perimeter flashing. FMRC indicated that, in cases where the insulation lifted from the steel deck, usually the adhesive had been "scantily applied" [7]. In contrast, it was also indicated that "loss experience ... has been favorable when insulation fasteners were used to secure the insulation."

Hasan [9] has outlined the evolution of roofing practices that resulted in inadequate amounts of adhesive being applied on steel decks to secure insulations in place. In brief, when asphalt (or other type of adhesive) was used to attach insulation to steel decks, the amount of asphalt applied was purposely limited to help achieve an acceptable fire-rating of the resulting roofing systems.

Several articles in the trade literature over the last two to three years have addressed the use of mechanical fasteners for securing low-sloped roofing [9-17]. This relatively recent practice appears successful in reducing wind damage of the magnitude expexienced in the 70s [9-17]. However, as also indicated in the same articles, the success has not been accomplished without introducing the potential for another important problem, i.e., the corrosion of the metallic fasteners and steel decks leading to the loss of securement of the membrane system. Bradford [10] expressed concern in January 1986, stating that the problem "appears to be of calamitous proportions." 
In spite of the voiced concerns and warnings, the magnitude of the problem has not been studied in the U.S. Most of the information available is anecdotal, whereby specific experiences with corroded fasteners are described, or concerns that the fasteners may corrode to the point of loosing attachment are voiced. Some trade articles, and even one manufacturer's literature, have included photos of corroded fasteners.

Figure 3 presents some fasteners that experienced corrosion in service. Note that one of the fasteners depicted was cleaned, which showed that the corrosion was generally uniform over the surface. In contrast, another fastener totally failed through thinning of the shank; whereas another experienced localized thinning of the shank that did not completely corrode through. In the latter case, the fastener was about 15 months old, and had been installed through an existing insulated built-up membrane system (Figure 4). The locus of the thinning of the shank was the area within the insulation which may have been wet.

Concerns over the potential corrosion of fasteners have provided impetus for industry associations to address the issue. In February 1986, ARMA, NRCA, RIC/TIMA, and SPRI'l released a joint statement indicating that the scope of the corrosion issue had not been determined [18]. They recommended that only "corrosion resistant type fasteners" be used to attach insulation and

$1_{\text {Asphalt Roofing Manufacturers Association (ARMA), National }}$ Roofing Contractors Association (NRCA), Roof Insulation Committee of the Thermal Insulation Manufacturers Association (RIC/TIMA), and Single-Ply Roofing Institute (SPRI) . 
roofing in new and re-roofing constructions. The joint statement brought attention to an industry developed test procedure [19] for evaluating the corrosion resistance of fasteners. The industry procedure was based on modification of the German DIN 50 018 standard test [20]. This latter procedure consists of exposure of specimens to cycles of alternating dry and sulfur dioxide/water vapor environments. The sulfur dioxide portion of the cycle is conducted at $104^{\circ} \mathrm{F}\left(40^{\circ} \mathrm{C}\right)$, and the drying portion at room temperature.

In April 1986, Factory Mutual Research Corporation (FMRC) published requirements for the corrosion resistance of mechanical fasteners, stress plates, and batten bars [21]. The FMRC requirements (or approval criteria) are that these components "not develop more than 15 percent corrosion on the surface area" in the FMRC test procedure which is essentially the same as the cyclic sulfur dioxide/water vapor test mentioned above. The FMRC method is "designed to assess the potential damage to metal fasteners used for mechanically attached roof covers and mechanical fasteners used for attachment of insulation." The effective date for the corrosion requirement for systems conforming to the FMRC Approval Standard for Class I Roof Covers (Class Number 4470) was December 1, 1988. In anticipation of this date, considerable testing of fasteners according to the FMRC procedure has been taking place to determine conformance to the corrosion requirements. 
The use of the sulfur dioxide/water vapor test procedure for evaluating corrosion resistance has been included in the roofing trade literature in articles on fastener performance $[9,10,13-$ 16]. These articles have expressed optimism that the use of fasteners subjected to the procedure will overcome corrosion problems. For example, Bradford [10] stated in 1986 that the use of fasteners which passed the test "could solve most, if not all, of the problems in new construction..." The trade articles also indicate that many currently available fasteners are coated to provide sufficient protection which allows them to pass the test; whereas the many of the fasteners available a few years back have not always performed satisfactorily in the test. Nevertheless, in spite of the optimism, it has been pointed out that the relationship between fastener performance in the test and in service has not been established $[9,14]$.

The potential for corrosion-induced problems of a major portion of the Nation's low-sloped roofing systems is of serious concern to the U.S. roofing industry. Thus, the Department of Energy (DOE) requested the National Institute of standards and Technology (NIST) (formerly, National Bureau of Standards/NBS), working with Dr. Michael A. Streicher, a corrosion consultant, to conduct a study summarizing the extent of the problem and the factors affecting corrosion of fasteners in service, and to recommend needed research in those areas where problems are identified. This report presents the results of the study. DOE was interested in supporting this study, because many of the roofs that may be potentially affected by fastener corrosion are 
insulated. Insulated low-sloped roofing systems, that perform less than satisfactorily, may be energy inefficient, and therefore not contribute fully to the Nation's energy conservation efforts $[22,23]$. Since the beginnings of the energy-conservation era, the U.S. roofing industry has acknowledged that "good roofs save energy" [24].

\section{2 objectives}

The objectives of the study are: 1) to summarize available information related to the corrosion of fasteners in low-sloped roofing systems, 2) to estimate, if possible, the nature and magnitude of current and future problems, and 3) to determine the need for research to correct the problems identified, and if appropriate, to recommend a research program.

\subsection{Scope}

The study was limited to an assessment of existing information on the potential for fasteners used in low-sloped roofing systems to corrode in service. Laboratory investigations were not conducted as part of the study. Information obtained was summarized to provide an overview of the extent of the problem. Factors addressed included the frequency and severity of corrosion problems, time scale for their development, the effect of various roofing materials and systems on the problem, and suspected causes of problems.

Emphasis was placed on the performance of metallic screw-type fasteners for attaching insulation and/or membranes primarily to 
decks, because this type of fastener application is the most common, and has raised the most concern regarding corrosion. The use of nail-type fasteners for securing plies of felt to nailable decks (e.g., wood, lightweight fills) and related applications was beyond the scope of the study. In addition, other concerns with the use of screw-type fastener such as back-out and overtorquing during application were beyond the scope of the study.

Sources of information included the axchival and trade literature, researchers familiar with building and roofing performance including foreign building research institutes, and individuals associated with roofing practice such as contractors, owners, consultants, and manufacturers' representatives. Questionnaires addressing the extent of the potential problem and factors influencing it were sent to contractors, consultants, and manufacturers' representatives for their completion.

A five-member industry review panel, comprised of representatives from the NRCA, two single-ply sheet manufacturers, and a fastener producer, was assembled to provide assistance during the study. The panel met three times with the investigators. The panel's assistance included critiquing the initial work plan, suggesting sources of information on the corrosion issue, and commenting on the study findings. 


\section{THE LITERATURE}

The archival chemical and engineering literature, as well as roofing trade publications and manufacturers' literature, were searched as a source of information about corrosion of fasteners. From experience, it was expected that quantitative data on the extent of the corrosion issue had not been published. With one exception, the articles treating the subject were in the trade press and were qualitative in nature $[9-18,25]$. One report by Paulsen [26] of the Norwegian Building Research Institute described the results of a field survey of mechanically fastened roofs.

\subsection{Summary of Norwegian study}

Paulsen's field survey [26] provides data on in-service performance. It was conducted to provide information on the "decisive factors" affecting selection of a fastener system. He obtained information not only on fastener corrosion, but also on fastener pull-out resistance and the general overall condition of the roofs. Forty-eight buildings were included in the survey out of 290 candidates. Twenty-five had polymeric membranes, and 23 had bituminous membranes. The buildings were geographically distributed throughout Norway, and had a variety of different decks, but primarily expanded polystyrene and mineral wool insulation. The ages of the roofs ranged from zero (new) to ten years, although many were less than five years old. In general, all membranes surveyed were reported to be "good and fulfill their function today, and no serious defects have been recorded" [26]. Paulsen cut the membranes to expose the fasteners. 
With regard to corrosion, Paulsen [26] reported that "many cases of corrosion on metallic fasteners where found, sometimes on new roofs." From his tabulated data, evidence of surface corrosion was observed on metallic fasteners for 25 of the 48 roofs. The protection on these fasteners was given as electroplated zinc. Further comments on the extent of the observed corrosion were not given. It is noted that, in the case of 15 roofs where corrosion on fasteners was observed, the insulation was described as being dry at the time of the inspection. However, the report did not discuss the possibility that the insulations may have contained moisture at other times.

Twelve observations of corrosion of metallic stress plates were reported. This was fewer than for the fasteners. In all but one case, the stress plates had a zinc coating (type not defined). On one roof, the stress plate had an aluminum/zinc coating.

Paulsen recommended [26] that the corrosion protection of fasteners must be improved where there is risk for prolonged periods of moisture from condensation, alone or in combination with corrosion promoting substances. He proposed that corrosion testing be conducted according to the FMRC 4470 sulfur dioxide/ water vapor procedure. He also proposed that, for organic coatings on steel, a temperature/humidity test at $194{ }^{\circ} \mathrm{F}\left(9{ }^{\circ} \mathrm{C}\right)$ and $100 \% \mathrm{RH}$ be conducted. Under these conditions, the coating should not peel or blister. For the sulfur dioxide/water vapor tests, he recommended a classification system of fastener selection consisting of three categories, depending upon fastener 
environment. The system is given in Appendix B. As is evident from Table BI in the Appendix, only one category of fastener use includes 15 cycles in the sulfur dioxide/water vapor test. In contrast, in the United States, all fasteners meeting the requirements of the sulfur dioxide/water vapor test (FMRC 4470) must undergo 15 cycles of testing. In 1988, Paulsen's proposals were included in a Norwegian design sheet that was published by the Norwegian Building Research Institute in cooperation with the Norwegian Roofing Research Group [27].

In completing this summary of the Norwegian recommendations, it is noted that a critique and discussion of the sulfur. dioxide/water vapor test for evaluating corrosion resistance of fasteners is given in section 6 of this report. The need for additional evaluation methods is examined in the proposed research agenda in section 7 .

\subsection{Summary of Trade Literature}

The following are the major points obtained from a review of articles in roofing trade publications $[9-17,28]$ :

- Most importantly, several articles $[10-12,14,18,28]$ raised the concern that the corrosion of fasteners in service over the long-term will lead in future years to unwanted wind damage. The extent of the current problem and its future magnitude are not known, and statistics on the number of mechanically fastened roofs experiencing corrosion problems and the factors affecting observed instances of corrosion have not generally been described.

- The review of the trade literature indicated that no systematic surveys on the extent of the corrosion problem have been conducted. Nevertheless, the articles are generally in agreement that a major factor is the use of mechanically fastened membranes in re-roofing applications where the existing system is not removed but recovered. In 
these cases, the fasteners for the new membrane are driven through the old system, which is likely wet and maybe abrasive, and contributes to rapid corrosion of the new fasteners. Thus, many articles include recommendations that fasteners should not be applied through existing wet insulation. These articles also often indicate that this practice occurs in spite of the recommendations against it.

- As a safeguard against corrosion, the trade literature recommends the use of "corrosion resistant" fasteners. In general, in these articles, "corrosion resistant" fasteners were regarded as those passing the sulfur dioxide/water vapor test. The articles do not generally comment on the abrasion resistance of coated fasteners, and in particular, the possible removal of the coating by abrasion and its effect on the sulfur dioxide/waster vapor test. 
3. FOREIGN BUILDING RESEARCH INSTITUTES

Low-sloped roofing practices from country to country around the world have many common characteristics, and often raise many common concerns [29]. Although not universal throughout Europe, mechanically fastened systems have been installed in some European countries, for example, Norway as was reported above. Consequently, during the course of the study, requests were made of foreign building research institutes asking whether the potential for corrosion of fasteners was of concern, were any reports available on the subject, and were any standard test methods available or under development. In response to the requests, information was received from 10 countries. The responses were primarily received by letter, although in a few cases, conversations were held by phone or in person.

For each country contacted, a summary of the response is given in Appendix C. The key points are as follows:

- With the exception of Norway, no reports were received from abroad, and little other information was provided.

- Most respondents indicated that corrosion of fasteners is not a concern in their country. This belief is generally based on the fact that few mechanically fastened systems are being installed in the country of the respondent.

- Many respondents indicated that they are aware of the questions being raised in the United States on the fastener corrosion issue. They stated that they are following the situation here, and await any information that is developed. 
- The European Union of Agrément (UEAtC) has under development a directive for the assessment of mechanically fastened roofing systems. Requirements for the corrosion behavior of the fasteners have not yet been developed for inclusion in this document, but are being considered.

A working document, provided by a West German representative to the UEAtc working group ${ }^{2}$, outlined some of the possible steps under consideration as requirements for the UEAtc document. The document suggests that two tests for corrosion resistance are under discussion: (1) the sulfur dioxide/water vapor test (DIN 50 018) with 12 cycles of exposure using fasteners that have been drilled into and removed from a deck coupon, and (2) 20 days exposure in a salt spray test (DIN 50 021) using specimens consisting of fastener, insulation, and deck components. One interpretation of the salt spray suggestion is that the UEAtc working group believes that exposure to chlorides is important in considering corrosion resistance. The working group report also commented that zinc-coated carbon steel fasteners do not, in general, meet the requirements under discussion, while polymeric coated fasteners do.

2 The document was entitled, "Fastening Methods for Various Underground and Roof Constructions," K. Kayser, Gummersbach. 


\section{INFORMATION FROM QUESTIONNAIRES}

Questionnaires were sent to NRCA, RCI, ARMA, and SPRI members ${ }^{3}$ as sources of information on the fastener corrosion issue to assist in defining the factors that affect corrosion in service. The intent was to provide trends concernina firsthand observations of corrosion of fasteners, stress plates, and batten bars in service. This approach was taken because no data, based on systematic field studies, were available.

Table 1 indicates the number of questionnaires sent out and returned by members of each of the industry organizations. Although three of the organizations returned more than 50 percent of the questionnaires received, a limitation was that many individuals responding to the questionnaires had not had firsthand experience with fasteners in service.

Table 1. Summary of Number of Questionnaires Sent and Returned

\begin{tabular}{|c|c|c|c|}
\hline Association & $\frac{\text { Number of }}{\text { Sent out }}$ & $\frac{\text { Questionnaires }}{\text { Returned }}$ & $\begin{array}{l}\text { Percent } \\
\text { Return }\end{array}$ \\
\hline NRCA & 57 & 31 & 54 \\
\hline $\mathrm{RCI}$ & 32 & 20 & 63 \\
\hline ARMA & 40 & 7 & 18 \\
\hline SPRI & 12 & 8 & 67 \\
\hline
\end{tabular}

A summary of the key findings from the questionnaires is given in the sections tirac follow below. More complete analysis of the

${ }^{3}$ National Roofing Contractors Association (NRCA), Roof Consultants Institute (RCI), Asphalt Roofing Manufacturers Association (ARMA), and Single-Ply Roofing Institute (SPRI). 
responses to the questionnaire are given in Appendix D along with

all the questions and detailed bar graphs of the responses.

- Number of Responses. A total of 45 respondents from the four organizations provided, based on firsthand experience, information on corrosion of fasteners. It was estimated that these respondents had inspected about 1300 roofs of which 200, or 15 percent, were described as having some evidence of fastener corrosion.

- Age. The ages of the roofs for which corrosion of fasteners was observed ranged from 1 to more than 10 years.

- Fastener Materials. The respondents indicated that they observed corrosion on carbon-steel fasteners having all types of.coatings. In a predominant number of cases, the coating on these fasteners was zinc, perhaps because zinccoated fasteners are the oldest and most widely used. However, some respondents also reported observations of corrosion on the polymer-coated fasteners. Two respondents indicated that they observed corrosion with stainless steel fasteners.

- Type of Corrosion Reported. Whenever reported, uniform corrosion was the type most frequently indicated. This process can lead to thinning and eventual loss of fastener securement. Less frequently, localized corrosion was reported. This process can also lead to loss of fastener securement by crevice attack at the contacts at the deck and at the stress plate, and at isolated wet areas along the shank of the fastener.

Observations regarding corrosion of stress plates were less frequent than those given for fasteners.

- Roofing Projects. Corrosion of fasteners was reported for both new roofing and reroofing projects. The predominant project where corrosion was observed was re-roofing without tear-off. This observation was consistent with trade publication reports that a key factor affecting corrosion in service is mechanically attaching new roofing through existing systems that may contain wet insulation and be abrasive.

- Insulation, Membrane, and Deck Materials. Corroded fasteners were reported for all types of insulations, membranes, and deck materials mentioned in the questionnaires. In the case of insulations, the respondents noted a predominance of wood fiber and perlite boards. This observation may reflect the fact that these two board products are often used as leveling courses in reroofing projects without tear-off of the existing system (which is, as mentioned, a practice which may occur without proper 
consideration of moisture in the existing system, and result in applying the fasteners through wet insulation).

- The Role of Water. In all but one case where corrosion of fasteners was observed, water was indicated as being present and in contact with the fastener. Moreover, the roofs inspected by the respondents were, in general, leaking. 
5. MATERIALS AND CORROSION PROTECTION FOR FASTENERS, STRESS PIATES, AND BATTEN BARS

This section of the report presents a listing and discussion of the major screw-type fasteners, stress plates, and batten bars used for low-sloped roofing systems. Included is commentary concerning potential corrosion problems [30] that may arise with each type. The issues discussed in the commentary are factors that should be considered in selecting fastener systems. Moreover, for purposes of the present report, the commentaries provided assistance in preparing the research agenda given in Section 7 .

Table 2 gives a listing of the main types of fasteners and their corrosion protection that have been used or are currently available for low-sloped roofing systems. Table 3 lists stress plates and batten strips along with the protection used. The commentaries on factors to consider regarding potential corrosion of these fasteners, stress plates, and batten bars follow the tables. 
Table 2. Fastener Materials for Low-sloped Roofing systems

Material

1. Carbon steel - AISIa 1020

carburized \& hardened

2. Carbon steel - AISI 1020

carburized \& hardened

3. Carbon steel - AISI 1020

4. Stainless steel - AISI 410

$12 \%$ chromium, heat hardened

5. Stainless steel -

$14 \%$ chromium, 1\% nickel, \&

1\% molybdenum

6. Stainless steel - Bimetallic None AISI 304 stainless steel, cold hardened, (18\% chromium \& $8 \%$ nickel) shank with a hardened carbon steel tip

7. Aluminum-magnesium alloy; non threaded

\section{Coating}

None or oil; chromate coated (dipped)

Zinc coated

(electroplated)

Polymers (e.g., fluorocarbon \& epoxy); normally carburized \& hardened with a basecoat (inorganic or organic); applied in multi-layers

None

None

None

a. American Iron and steel Institute. 
Table 3. Stress Plate and Batten Strip Materials for Low-sloped Roofing Component

Material

Coating

1. Stress Plate

Carbon Steel - AISIa 1020

Zinc coated not hardened

(hot dipped coil stock)

2. Stress Plate

Carbon Steel - AISI 1020

Zinc/aluminum coated not hardened (hot dipped coil stock)

3. Stress Plate

Carbon Steel - AISI 1020

Paint or polymer not hardened (prepainted coil stock)

4. Stress Plate

stainless steel - AISI 304

None

5. Stress Plate

Zinc/Titanium Alloy

None not hardened

6. Stress Plate Plastic

(e.g., polypropylene)

None

7. Batten Strip Carbon Steel - AISI 1020 not hardened

Zinc coated

(hot dipped coil stock)

8. Batten strip

Aluminum

None

a. American Iron and steel Institute. 


\subsection{Commentary on corrosion concerns}

1. Fastener: Carbon Steel, Coating: None, Oil, Chromate

Commentary: These types of fasteners were the first generally used by the roofing industry. They are no longer used today. It would be anticipated that, among the carbon steel fasteners, they would have the highest risk of corrosion, because they have no, or at best minimal, protection.

Note that the carbon steel used for self-tapping fasteners is AISI 1020 (which has a relatively low carbon content of about $0.2 \%$ ) that has been provided with a carburized surface layer, which upon heat treatment gives it the hardness required for self-tapping capability.

2. Fastener: Carbon Steel, Coating: Electroplated Zinc

commentary: Zinc is a barrier and sacrificial coating. As a barrier, it separates the environment from the carbon steel. As a sacrificial anode, where steel is exposed to an aqueous environment at the pores in the coating, the zinc cathodically protects the steel. For roofing fasteners, the use of electroplated zinc coatings alone has essentially stopped. In the presence of moisture, the life of the zinc-coated fasteners now in service will be influenced by the thickness, porosity, and coverage of the coating.

\section{Fastener: Carbon Steel, Coating: Polymers}

Commentary: These coatings are organic polymers (e.g., fluorocarbon or epoxy) that are normally used with a base coat that may be either inorganic (e.g., zinc phosphate or ceramic) or organic. They are generally black or metallic silver in color, and applied in multi-layers. They have become the primary type of coating used in today's industry. They provide protection as barrier coatings only. Factors that need to be considered with regard to the effectiveness of the polymer-coating systems to provide adequate protection for roofing fasteners include:

- quality control of all steps in the coating process and its effect on porosity and the presence of pinholes.

- the effect of different base coats on coating adhesion and effectiveness; for example, organic coatings do not adhere well to zinc surfaces without a phosphate pre-coating.

o the ability of the coating system to resist aorasion during application and service.

o the long-term adhesion of the coating system to the substrate and its ability to resist blistering or peeling under the roof environment. 
Commentary: Type 410 stainless steel contains $12 \%$ chromium, and is hardened by heat treatments. Stainless steel is intended to provide corrosion resistance without need for a coating. The heat treatment of Type 410 is necessary to provide the hardness required to make the fastener self-tapping. However, the metallurgical changes produced by these heat treatments result in a significant reduction of the corrosion resistance of this alloy. Factors that need to be considered with regard to the corrosion resistance of fasteners made with this stainless steel include:

- its low resistance to pitting corrosion and chloride environments. Furthermore, if there is corrosion by chlorides (or perhaps acid corrosion), the hydrogen generated by the corrosion process may cause hydrogen embrittlement of the fastener that can lead to mechanical fracture under internal or external stress.

- the susceptibility of the 410 stainless steel to crevice corrosion. Crevices are formed between the fastener and the stress distribution plate, insulation, and the steel deck. crevices where water enters by capillary action become sites for accelerated corrosion. The changes in the aqueous chemical environment in crevices produced by initial corrosion accelerate subsequent corrosion processes in these locations. At the crevice formed between the 410 fastener and a steel deck, the galvanic metal couple may further accelerate crevice corrosion and with it, the production of hydrogen. As a result, hydrogen embrittlement of the 410 fastener may occur and make it susceptible to mechanical fracture. The contact point at the deck may be a location of maximum bending stress in the fastener and make this location most susceptible to fracture.

- the effectiveness of the sulfur dioxide/water vapor test to evaluate the corrosion resistance of the stainless steel alloy. The applicability of the test to this stainless steel alloy may be limited, considering that chloride corrosion could be a major factor affecting deterioration.

5. Fastener: $14 \% \mathrm{Cr}-1 \% \mathrm{Ni}-1 \% \mathrm{Mo}$ stainless steel, coating: None

Commentary: This stainless steel alloy contains $14 \%$ chromium, $1 \%$ nickel, and 1\% molybdenum. It has recently been used for roofing fasteners, and consequently, experience is limited. Unpublished data, brought to attention ${ }^{5}$ during the study, on salt spray test results indicated that this alloy showed a slightly superior performance over 410 stainless steel. In general, the question of using salt spray tests to evaluate long-term performance of

${ }^{5}$ Personal communication, Terry DeBold, carpenter Technology Corp., Reading, PA. 
the roof fasteners has not been addressed. Factors that need to be considered with regard to the corrosion resistance of fasteners made with this stainless steel alloy are chloride pitting, crevice corrosion, and hydrogen embrittlement, as discussed above for the 410 stainless steel alloy.

\section{Fastener: Bimetallic Stainless Steel, Coating: None}

Commentary: These fasteners have had only limited use in the United States. They are, with the exception of the tip, produced from type 304 stainless steel alloy. Type 304 is a non heattreatable alloy, and consequently, the fasteners require a hardenable carbon steel tip to allow self tapping into the deck during application. The 304 stainless steel alloy contains $18 \%$ chromium, and $8 \%$ nickel. Its corrosion resistance is superior to that of the 410 alloy with regard to chlorides and dilute acids. Unlike the 410 alloy, the 304 alloy is immune to hydrogen

embrittlement. Factors that need to be considered with regard to the corrosion resistance of this stainless steel include:

- the resistance of the fastener to crevice corrosion, as discussed for the 410 alloy above. Crevices formed by dissimilar metals, i.e., at the deck, or even in some cases at stress distribution plates, may be subjected to accelerated corrosion due to galvanic effects.

- the resistance of the fastener to chloride pitting and chloride stress corrosion cracking. Type 304 stainless steel may be vulnerable to chloride pitting and to chloride stress corrosion cracking. The latter is the result of combined action of chlorides and tensile stress. Cycles of alternate wetting and drying and stress conditions, either residual or external, accelerate chloride stress corrosion cracking. Fasteners, machined during production and drilled in place during installation may be assumed to have residual tensile stresses. Cracking due to chloride stress corrosion can lead to total fracture of the fastener with only a slight amount of corrosion.

- the resistance of the carbon steel self-tapping tip to galvanic corrosion. This tip may corrode by galvanic action with the type 304 stainless steel alloy. If it were to occur, in extreme cases, the tip could fall from the roof assembly.

\section{Fastener: Aluminum-Magnesium Alloy, Coating: None}

Commentary: This is a relatively recent product for roofing, and is not a screw-type conventional roofing fastener. It consists of a hollow tube composed of the aluminum-magnesium ( $3.5 \%$ alloy. A steel rod with a hardened tip is set in place in the tube. The fastener is intended for steel decks only. Using an impact tool designed for fastener installation, the inner steel rod along with the tube are driven through the steel deck. Using another tool, the inner steel rod is pulled back up and out of the 
fastener tube and is removed from the roof. This step is done such that the bottom of the tube is split and pulled tight against the underside of the deck. During this rod-removal step, when a given level of tension is reached while pulling on the rod, the hardened tip on the rod breaks away, freeing the remainder so that it can be freely extracted. The hardened tip remains in the tube section which protrudes below the steel deck. Factors that need to be considered with regard to the corrosion resistance of fasteners made with this alloy include:

- galvanic corrosion at the crevice where the fastener is in contact with the steel deck.

- possibility of stress corrosion of the aluminum-magnesium alloy.

- galvanic action of the steel tip that remains in the tube after extraction of the rod.

- galvanic action between the fastener and the steel stress plate. This may be of particular concern in cases where the coating on the plate is either damaged or insufficient, exposing the steel substrate of the plate in contact with the aluminum-magnesium alloy fastener.

- galvanic action between the fastener and coating (normally a zinc-aluminum alloy) of the stress plate.

8. Stress Plate: Carbon Steel, Coating: Zinc

Commentary: This stress plate has, until recently, been the major type of metallic stress plate used for roofing. It is being replaced with other types, as described below. As with zinc-coated fasteners, the zinc provides both a barrier and sacrificial protection. Note that the steel used for stress plates is the AISI 1020, and is precoated coil stock from which plates are cut by stamping. As a result, cross-sections at the center hole and outerside edges are bare steel. Factors that need to be considered with regard to the corrosion resistance of these stress plates include:

- crevice corrosion at the contact point between fastener and stress plate. The zinc coating on the stress plate may be expected to delay attack on exposed (areas without coating) carbon steel by galvanic protection.

- hydrogen embrittlement of type 410 stainless steel fasteners, if used with these stress plates. If hardened carbon stainless steel (type 410 of 12 percent chromium content) is in contact with the zinc coating on the stress plate, the result could be the promotion of hydrogen generation, and thus hydrogen embrittlement of the type 410 stainless steel. (Note again: type 304 stainless steel is relatively immune to hydrogen embrittlement.) 
- the crevice-corrosion resistance of types 304 and 410 stainless steel fasteners in contact with the zinc-coated stress plates. At contact points between these fasteners and the stress plates, crevice corrosion could be accelerated by the dissimilar metal couple.

\section{Stress Plate: Carbon Steel, Coating: Zinc-Aluminum}

Commentary: This type of metallic strass plate has recently increased in use in response to efforts to provide fastener systems having improved corrosion resistance. The factors that need to be considered with regard to the corrosion resistance of these stress plates are the same as those discussed above for zinc-coated carbon steel stress plates.

\section{Stress Plate: Carbon Steel, Coating: Paint or Polymer}

Commentary: This type of metallic stress plate has also been used in response to efforts to provide fastener systems having improved corrosion resistance. The factors that need to be considered with regard to the corrosion resistance of these stress plates include the porosity and adhesion of the coating.

11. Stress Plate: Type 304 Stainless Steel, Coating: None

Commentary: As mentioned above, this 18\% chromium and $8 \%$ nickel alloy has some resistance to chlorides and acids. However, it is still susceptible to stress corrosion and crevice attack. These plates should preferably be used with type 304 stainless steel fasteners. The factors that need to be considered with regard to the corrosion resistance of these stress plates include:

- stress corrosion as discussed above for 304 fasteners.

- crevice corrosion as discussed above for 304 fasteners. Crevice corrosion at crevices between these stainless steel stress plates with carbon steel or 410 stainless steel may be accelerated due to galvanic effects.

12. Stress Plate: Zinc-Titanium Alloy, coating: None

Commentary: This type of metallic stress plate, manufactured from solid zinc-titanium alloy, has recently been introduced by at least one manufacturer. The alloy has been available for some time, and contains about 2-3 percent titanium. The factors that need to be considered with regard to the corrosion resistance of these stress plates are the same as those discussed above for zinc-coated carbon steel stress plates.

13. Stress Plate: Plastic, Coating: None

Commentary: Plastic stress plates, (e.g., polypropylene) have been introduced to eliminate corrosion problems. An advantage to the use of these types of stress plates is that they may be molded such that the head of fastener is locked in the plate to 
minimize back-out. Although these plates are non-metallic, they may still contribute to crevice corrosion at the contact with the fastener in the presence of water. However, with the plastics, there is no dissimilar-metal galvanic corrosion. Factors that need to be considered with regard to the corrosion resistance of fasteners used in contact with plastic stress plates include:

- crevice corrosion at the fastener head. The plastic stress plate can offer an efficient crevice at the head of the fastener where crevice corrosion might possibly occur.

- the quality of the polymeric stress plate to perform satisfactorily over the long-term. Evaluation techniques for assessing long-term performance (aging) of polymeric stress plates are lacking. The effects of creep, stress in the plates, and heat during service are of particular importance. Field experience has shown that some plastic stress plates have cracked in service.

\section{Batten Strip: Carbon Steel, Coating: None}

Commentary: Batten strips have been primarily used for securement of mechanically attached single-ply roofing membranes. The batten strips generally run parallel to the direction of the membrane sheet. Metallic fasteners are applied periodically through the batten at pre-punched holes, and through the membrane (and insulation) and deck below. Often, batten strips are installed at the edges of the membrane sheets, and consequently, are placed in the seams. Zinc-coated batten strips are the most common type used for this application. Factors that need to be considered with regard to the corrosion resistance of these batten strip-fastener assemblies include those already described for $z$ inc-coated stress plates.

\section{Batten Strip: Aluminum, Coating: None}

Commentary: Like zinc-coated steel batten strips, aluminum batten strips are used primarily for mechanically attached single-ply roofing systems. Factors that need to be considered with regard to the corrosion resistance of these batten stripfastener assemblies include:

- a combination of galvanic and crevice corrosion between the batten strips and the fasteners. Steel fasteners are used with aluminum batten strips. If the coating, either polymeric or zinc, on the carbon-steel fasteners is ruptured by abrasion during application or in service, galvanic corrosion may occur between the steel and aluminum. A similar effect may occur with 304 and 410 stainless steel fasteners, which are uncoated. In the galvanic process, aluminum would be consumed and the hole in the batten strip may enlarge to the point of loss of contact with the head of the fastener. 
6. DISCUSSION OF THE SULFUR DIOXIDE/WATER VAPOR TEST

As indicated in the introduction to the present report, a sulfur dioxide/water vapor test (Kesternich test ${ }^{5}$ ) was adapted "in response to a need for a standardized evaluation method" [19] for assessing the corrosion resistance of fasteners, stress plates, and batten strips. The method is now the major means by which the U.S. roofing industry is assessing corrosion resistance $[18,21]$. The following sections provide a summary of the sulfur dioxide/water vapor test and give the authors' analysis of the advantages and limitations associated with its use.

\subsection{Summary of the Test Method}

The sulfur dioxide/water vapor test method for fasteners was an application of the German DIN 50018 procedure [20]. In the modified method, the test specimens are cycled in and out of a highly acidic environment and the percent corrosion forming on their surface is estimated. A task group was recently formed by ASTM Committee D 08 on Roofing and Waterproofing to develop a voluntary consensus standard test based on the roofing industry's modified sulfur dioxide/water vapor test. The parameters of this industry test [19] are as follows:

- test specimens -- Fasteners, stress plates, and batten bars are all tested according to the procedure. Fasteners for steel decks are driven through specified deck coupons such that $1 / 2$ to $3 / 4$ in. (13 to $19 \mathrm{~mm}$ ) of the shank protrudes below the underside of the deck coupon. Fasteners for iuncrete and wood decks are first drilled into the deck material, then removed and mounted in plastic blocks for placement in the exposure chamber.

${ }^{5}$ The name of the test has been adopted by the roofing industry from the cabinet (i.e., Kesternich chamber) in which the specimens are placed for testing. 
Stress plates and batten bars are suspended in the test chamber using glass rods. These plates and bars are not tested in contact with fasteners.

- the environment -- The environment consists of adding two liters of sulfur dioxide $\left(\mathrm{SO}_{2}\right)$ gas into the cabinet which already contains two liters of water. The temperature of the trough of the cabinet is set at $104^{\circ} \mathrm{F}\left(40^{\circ} \mathrm{C}\right)$.

- the exposure cycle - The exposure cycle consists of 8 hours in the sulfur dioxide/water vapor environment, and 16 hours in a drying environment created by turning off the heater and venting the cabinet. The specimens are rinsed with distilled water after the drying stages of the cycle. Fifteen cycles are conducted, with the sulfur dioxide/water vapor test atmosphere being freshly-prepared before beginning a new cycle.

- the evaluation criterion - The evaluation criterion is based on examination of the test specimen surface and estimation of the amount of surface corrosion or rust produced during the cycling. The acceptance criterion is that the specimens shall not show more than $15 \%$ of the surface area corroded or rusted. This percent is visually estimated.

For estimating the amount of surface corrosion, some areas of the test specimens are excluded. Specifically, in the case of fasteners in steel deck coupons, the portion of the fastener protruding below the coupon is not included. For stress plates and batten bars, small areas of the surface around the fastener hole $(1 / 32$ in.) or at the specimen perimeter (1/16 in.) are excluded.

\subsection{Significance of the Method}

The significance of the test as given is that it "provides a standardized laboratory method to evaluate the ability of fasteners to resist corrosion in a controlled highly corrosive environment" [19]. No mention of the relationship of the test results to the performance of metallic fasteners in roofing systems, nor of the types of fastener materials suitable for testing by the procedure is made. 


\subsection{Advantages of the Method}

The desire to provide metallic fasteners and related components having improved corrosion resistance is a major step forward in assuring the construction of low-sloped roofing systems which provide satisfactory long-term performance.

- The sulfur dioxide/water vapor test appears to be a useful tool for assessing the integrity and adhesion of protective coatings. In this regard, fastener manufacturers and roofing system producers have a relative basis for the development and selection of fasteners, stress plates, and batten bars. The availability of a standard procedure has given impetus to the development of coated fasteners having improved protection, and to the elimination of fasteners that were marginally coated. The method provides potential for detecting the presence of pin holes in barrier coatings.

\subsection{Iimitations of the Method}

The sulfur dioxide/water vapor test procedure is Iimited in that it applies primarily to the effectiveness of barrier coatings to provide protection under the test conditions. A general limitation is that the relationship of the performance of fasteners in the test to performance in service has not been established. The period of time over which the procedure has been in use has been too short to establish such a relationship. Moreover, no systematic means exists in the industry to establish the data base relating in-service performance to test results. Another general limitation is that the test is now being applied to materials (uncoated) for which rust or surface corrosion products are not the appropriate criterion for evaluation of performance in the method.

Specific limitations of the test method, as it may be applied to both coated and uncoated materials are listed below as related to 
the test specimen, environment, exposure cycle, and evaluation criterion. Two benefits of listing these limitations are that it provides suggestions for the enhancement of the present procedure, and it also identifies gaps in the present technique, thus directing future research efforts to develop an improved procedure.

- test specimens -- The configuration of the test specimens leads to a number of limitations:

- The resistance of the coating to abrasion is not assessed: a) abrasion due to drilling through roofing components including existing gravel, aged (or embrittled) membranes, insulations, stress plates, and decks; and b) abrasion due to movement of the roof during service.

In this regard, it was learned ${ }^{6}$ during this study that FMRC plans to initiate an abrasion step in the sulfur dioxide/water vapor test procedure during 1989. As planned, in the case of new constructions, the fasteners will be pre-driven through an abrasive insulation. For reroofing without tear-off, the fasteners will be predriven through a broomed, gravel-surfaced built-up membrane.

- The stress plate is not tested with the fastener. Adverse interactions between the two such as galvanic or crevice corrosion are not evaluated for the situation where the coating has been removed by abrasion.

- The insulation is absent. The effect of possible corrosion accelerating agents in insulations is not evaluated.

- Bending stress is absent. Fasteners in service may be bent, and the resulting stress can contribute to hydrogen embrittlement corrosion processes.

- the environment -- $\left(\mathrm{SO}_{2} ; 104^{\circ} \mathrm{F}\right.$ or $\left.40^{\circ} \mathrm{C}\right)$

- The relationship between $\mathrm{SO}_{2}$ and roof environments is not generally known. It is known that some industrial pollutants contain $\mathrm{SO}_{2}$ that contributes to acid rain.

${ }^{6}$ Personal communication, George A. Smith, Factory Mutual Research Corp., Norwood, MA. 
- Other aggressive environments such as chloride and nitrogen oxides are not addressed. It is known that chlorides are major contributors to many corrosion processes. In the cases of hardened 410 stainless steel and 304 stainless steel (with a hardened carbon steel tip), some important potential problems such as chloride, crevice and pitting corrosion, and chloride stress corrosion cracking are chloride-induced phenomena. In addition, hydrogen stress corrosion cracking of hardened type 410 stainless steel is chloride induced.

- The temperature is limited as compared with roof top temperatures which, in the case of black surfaces, can reach as high as $176^{\circ} \mathrm{F}\left(80^{\circ} \mathrm{C}\right)$ or more.

- the exposure cycle -- (15 cycles; $8 \mathrm{~h}$ in $\mathrm{SO}_{2}$ and $16 \mathrm{~h}$ out)

- Only one specific cycle has been suggested. Some corrosion processes are dependent upon wetting and drying. A question to be asked is whether other cycles might be more appropriate.

- The total test time is limited. For coated carbon steels where cycling may peel away the coating, the question arises whether 15 cycles are adequate. In addition for coated carbon steels, longer periods of test may be needed for some processes such as galvanic and stress corrosion. Also, crevice corrosion based on concentration of acid in the crevice may require longer times to be manifest.

- the evaluation criterion - ( -15 percent surface corrosion or rust)

- The criterion using visual examination of the specimens is subjective. In cases where the surface corrosion is in the vicinity of 15 percent, it may be difficult to distinguish between acceptance and rejection.

- The criterion is not adequate for evaluating localized crevice, galvanic, pitting, or stress corrosion. This is of importance with some stainless steels, zinc/aluminum alloys, and zinc/titanium alloys.

- The evaluation of the crevice created by contact of the fastener with the steel deck coupon is not addressed. Crevice corrosion can lead to separation of the fastener from the deck. Only surface corrosion of the fastener system components is estimated in the evaluation process.

- The portion of the fastener protruding below the metal deck coupon is not included. Admittedly, corrosion of the section of the fastener below the deck may not necessarily adversely affect roof performance. However, if some portion of the corroded section fastener below 
the deck falls away, in the absence of a ceiling, it could be disruptive to operations in the space below. A case for consideration is the use of type 304 stainless steel fasteners with hardened carbon tips. Because of galvanic effects, the tip may be prone to separation depending on the environment of the building. 


\section{RECOMMENDATIONS FOR RESEARCH}

A primary objective of the study was to provide recommendations for research needed to fill in the gaps in knowledge about the corrosion of fasteners. This section of the report provides the recommendations. The results of the study indicated that there are at least three major gaps in the knowledge:

1) Evaluation test procedures for the corrosion resistance of fasteners are limited and need to improved.

2) A data base on field performance of fasteners is lacking.

3) Non-destructive diagnostic procedures for assessing the condition of in-place fasteners are not available.

Thus, consistent with these findings, three major areas for research are recommended to provide data and tests in these areas. The approach taken below to outline research in these three areas is to state a title and objective. These are followed by a background statement which summarizes the significance of each study. Then a brief recommended approach for reaching the objective is given.

1. Title: Improved Laboratory Methods for Assessing Corrosion Resistance of Fastener Systems

Objective: To enhance the reliability of the sulfur dioxide/water vapor test and to provide additional, improved methods for evaluating corrosion resistance of fastener systems as a tool for quality assurance and durability analysis.

Background: Until recently, no standardized method was used by the U.S. roofing industry to evaluate the corrosion resistance of fasteners. In recognition of the potential magnitude of the corrosion issue, the 15-day sulfur dioxlae/water vapor test was recently introduced and is now widely used. Our analysis (Section 6) indicated that the test has many limitations. The test is primarily suited for assessing the integrity of barrier coatings. It does not consider chloride effects. Moreover, it does not include effects of major roofing system components, particularly insulations. If the magnitude of the potential corrosion problem is recognized by having a test, then the 
limitations of the current test need to be overcome and new methods should be considered. In this regard, there is a need for improved, and perhaps more rapid, methods for evaluating the integrity of protective coatings. Such methods should include the effects of chlorides and other aggressive environments such as nitrogen oxides in assessing the performance of fasteners. Finally, the development of an accelerated simulated service test that takes into account the roof environment, and system components should be undertaken.

\section{Recommended Approach:}

- Provide and validate improvements in the current sulfur dioxide/water vapor test. Such actions would include:

(1) develop a standardized abrasion technique to be applied to the coated fasteners before testing,

(2) use a specimen that has the stress plate in contact with the fastener,

(3) investigate the use of temperatures above $104^{\circ} \mathrm{F}\left(40^{\circ} \mathrm{C}\right)$ to approach more closely elevated temperatures that may be encountered in roofing systems; also investigate the addition of more cycles to determine whether any corrosion process is progressive,

(4) the precision and bias of the sulfur dioxide/water vapor test should be determined and used to provide an improved pass/fail criterion.

- Develop a method that considers the effects of chlorides on fastener corrosion. Such a method is needed because chlorides can be aggressive towards all metallic materials used for fastener systems. As has been previously mentioned, the sulfur dioxide/water vapor test does not include the effects of chloride. As a suggestion, the use of the salt fog test (ASTM B117) could be explored for adaptation to some aspects of this problem such as underfilm corrosion on polymeric coated carbon steel, and the tendency for galvanic crevice corrosion on 304 and 410 stainless steels drilled into carbon steel decks.

- Investigate the use of alternative methods for assessing the integrity of coatings on carbon steel fasteners. Such methods are intended to provide quality assurance data on coating integrity that can be obtained in a shorter time period than that of the 15-day sulfur dioxide/water vapor test. Methods suggested for investigation are: (1) spark testing, (2) the ferroxyl test which consists of spraying the surface with a solution of acetic acid and potassium ferriferrocyanide (if bare iron is present, a readily observable blue color is developed) [32], (3) a test in an acidified solution of copper sulfate. If bare iron is present, a readily detectable copper deposit is formed.

- Develop a test methodology for determining the permanence of coatings (e.g., polymeric, and zinc) that may be on carbon steel fasteners, stress plates, and batten bars. It is 
considered that carbon steel fasteners that are well-coated when new may provide acceptable performance over the long term provided the coating can survive the rigors of abrasion connected with installation and potential for delamination due to elevated temperature and moisture in the roof environment. Thus, the intent is to have a methodology that assesses the initial integrity of the coating, its resistance to abrasion during installation, and its resistance to delamination due to environment -1 effects. Thus, it is suggested that the fasteners be initially subjected to a barrier integrity test (e.g., ferroxyl or copper sulfate), then in turn to abrasion and adhesion tests, and again the barrier test. The abrasion and adhesion tests need to be developed through the laboratory research program.

- Characterize fasteners before and after exposure. To provide an improved understanding of the performance of fasteners in service, methods of metallography and surface analysis for characterizing fasteners before and after exposure in service or to simulated environments should be investigated. Such methods can play an important role in determining whether fasteners are corroding by comparable mechanisms in service and in simulated service tests.

- Develop, based on reliability techniques, an accelerated simulated service methodology. Such a methodology would be applicable to all types of fastener systems (e.g., coated carbon steel, various stainless steels, aluminum alloys, zinc-aluminum alloys zinc titanium alloys, and plastics). The intent here is to provide a test that will consider the known possible effects on the corrosion of fasteners. These factors include abrasion of coatings during installation, chemical contaminants in the insulation, environmental contaminants in water such as chlorides, sulfur dioxide, nitrous acid, and hydrogen sulfide, internal and applied stresses, temperature (cycling and gradient), cycles of wetting and drying, galvanic effects between dissimilar metals, and the availability of oxygen (particularly in the case of stainless steels). The work of the ASTM C16 task group on corrosiveness of residential building thermal insulation may assist in initiating this task.

\section{Title: Data Base on Field Performance}

objective: To improve the $m$ ns for obtaining field data and conducting failure analyses on the fastener corrosion problem including the factors affecting corrosion in service, the current magnitude of the problem, and trends in the incidence of fastener system failures. A related activity is to characterize roof environments with regard to their effect on fastener corrosion.

Background: The current study substantiated that corrosion of fasteners has been observed in practice on a scale significant 
enough for the industry to initiate several countermeasures such as corrosion testing and introduction of new materials. Our analyses of the corrosion issue indicates a potential for continued corrosion problems in the future. In addition, our analysis has found that there is no systematic method for obtaining data on the incidence and causes of failures in service. Some of the new materials, particularly stainless steels, may experience different forms of corrosion in service than those that were encountered with the earlier generation of carbon steel fasteners. To ascertain whether the countermeasures are effective, and to better identify the magnitude and trends in the incidence of fasteners system failures, a mechanism for obtaining field data is needed.

\section{Recommended Approach:}

- On a periodic basis, provide questionnaires to representatives of industry organizations that are in position to have extensive field experience. Such organizations include consultant groups (e.g., RCI), and contractor groups (e.g., NRCA, MRCA). Analyze the results for trends in failures and their causes. Each succeeding questionnaires should be designed to elicit the most relevant data as derived from the experience with previous questionnaires.

- Develop a mechanism to provide for systematic analysis of in-service performance, failures, and reporting of performance information. The concept is to have available a structured procedure for monitoring performance. A major challenge is to determine whether or not the various forms of corrosion discussed in section 5 for the newer fastener materials and coatings are occurring in practice. One subtask would be to develop a form for reporting on observations on fasteners based on inspections of individual roofs. The task is envisioned as an industry-wide effort to collect, collate, and disseminate performance data that can be use to direct future improvements in fastener systems and identify needed research. It would require the participation of consultant and contractor groups. The field data obtained should address both acceptable and unacceptable performance and should be non-proprietary. A focal point to direct this activity would be needed, for example, the Architectural and Engineering Performance Information center (AEPIC).

- Characterize the performance and properties of fasteners, stress ilutes, and batten bars obtained from the field. This should include fastener systems that have performed both acceptably and unacceptably. Information on the history of the roofs (e.g., age, types of materials, moisture in roof, leaks,...) from which these components are taken would be needed to assist in the identification of the cause of failure and corrosion mechanisms. 
- Characterize roof environments for potential corrosiveness. (1) Studies would be conducted to analyze the chemical constituents (e.g., moisture, $\mathrm{pH}$, salts) of roofing components that could affect corrosion. These components should be obtained from roofing systems being inspected, and the results correlated with the condition of embedded fasteners. (2) To monitor the environment continuously, electrochemical probes might be embedded in the various layers of insulation to obtain data on the moisture content and corrosiveness of the system as a function of the thickness of the insulation, and diurnal and annual cycles. Data from these probes can be recorded using automatic collection techniques. It is envisioned that this technique would require some laboratory investigation before installation in the field. (3) Another factor to be addressed would be the role of the local exterior environment (e.g., seaside, acid rain, and air pollution).

\section{Title: Diagnostic Procedures for Corrosion Assessment}

Objective: To investigate the development of diagnostic tests for assessing the corrosion condition of in-place fasteners.

Background: A key barrier to the identification of the extent of the problem in service is that the fasteners are hidden within the roofing system and their condition cannot be observed without cutting into the roof. Consequently, routine maintenance inspections of roofs provides no information on fastener condition. Non-destructive diagnostic procedures for assessing the corrosion of in-place fasteners are not available. The availability of such procedures would facilitate obtaining field data and conducting failure analyses of fastener corrosion.

Recommended Approach:

- Explore using non-destructive evaluation (NDE) techniques for assessing the condition of fasteners in place. The review of NDE methods by Mathey and Clifton [31] may provide a starting point for such an investigation. The intent of the study would be to provide a method that could be used in the field without cutting into the membrane system. At present, some of the well-known NDE techniques that are used for assessing the integrity of metals, such as ultrasonic, eddy current, and electrical resistance measurements do not appear to be applicable. For a limited number of cases, a novel approach for investigation involves tapping the membrane-covered head of the fastener (where accessible, e.g., just below a membrane without gravel) with a mallet. In cases of complete separation along the fastener shank or at the deck contact point, the soft response of the tap (e.g., perhaps the extent of rebound) with the mallet may indicate fastener failure. If the technique is applicable, equipment for standardizing the impact and measuring the response might be developed. 


\section{CONCLUSIONS AND RECOMMENDATIONS}

The use of metallic mechanical fasteners for securing membranes or both insulation and membranes to the structural deck of lowsloped roofing systems is a common practice in the United states. In some cases, the fasteners have been observed to corrode in service in the presence of moisture. Depending upon the extent of corrosion, loss of securement may result, making the roofing vulnerable to damage during high winds. This study was conducted: 1) to summarize available information related to the corrosion of fasteners in low-sloped roofing systems, 2) to estimate, if possible, the nature and magnitude of current and future problems, and 3) to determine the need for research to correct the problems identified, and if appropriate, to recommend a research program.

Included in the study were a review of the literature, a survey of fastener materials and their performance, discussions with individuals knowledgeable in roofing and related industries, and questionnaires sent to manufacturers, contractors, and consultants. These activities were complemented by the assistance of a five-member industry review panel. An analysis was made of the forms and mechanisms of corrosion which might affect the variety of fastener materials in roofing systems containing moisture with and without salts and acids. In addition, an analysis of the advantages and limitations of the sulfur dioxide/water vapor test currently used by the U.S. industry to assess corrosion resistance was conducted. 


\subsection{Conclusions}

From the review of the available information and analyses made in

this study, the following conclusions are made:

1. Fasteners have been observed to corrode in service in the presence of water, and in some cases, with the loss of fastener securement. All sources of information on this point are in agreement, and numerous examples are given in our sources.

2. On the basis of the available information, it was not possible to estimate the extent of the fastener corrosion problem. In particular, the incidence of loss of fastener securement due to corrosion could not be established because of the inaccessibility of installed fasteners within roofs.

3. However, in almost all cases, the corrosion of fasteners was reported to occur in wet insulation, and in roofs that had often leaked. In some cases, severe corrosion and loss of securement was reported to have occurred in less than two years of service.

4. In the future, unless corrosion resistant fastener systems are used, corrosion of fasteners in wet roofs is likely to continue. The incidence can be expected to be related to the number of wet roofs. Two factors are important in reducing the extent of future problems with metallic fasteners: 1) for new construction, installation of wet materials should be avoided and the spread of water due to unexpected leaks during service should be minimized, and 2) for reroofing without tear-off, application of fasteners through wet insulation and abrasive membranes in the existing system should be avoided.

5. New coating systems, such as polymeric coatings and base coats to adhere them to carbon steel, have been introduced in response to efforts by industry to provide fastener systems with improved corrosion resistance. The introduction of such coatings has produced a need for new or improved evaluation methods for important properties affecting fastener corrosion resistance. Such properties include adhesion, porosity, and abrasion resistance required to maintain the coating during installation.

6. New materials, such as stainless steels also introduced in response to efforts by industry to provide fastener systems with improved corrosion resistance, have brought with them additional corrosion mechanisms different from those encountered with carbon steel. For example, various stainless steels may be subject to pitting, crevice corrosion, and stress corrosion cracking in the presence of dissolved chloride salts. 
7. Improvements to the sulfur dioxide/water vapor (Kesternich) test and new approaches for evaluating corrosion resistance of fasteners are needed.

8. A method is needed to evaluate the abrasion resistance of coated fasteners. Current evaluation procedures for corrosion resistance do not consider abrasion resistance of coated fasteners. Loss of protective coating by abrasion, particularly during installation, would expose the steel substrate of the fastener to the roof environment.

\subsection{Recommendations}

The study identified three major aspects about the performance of fasteners where the knowledge base is limited and should be improved: (1) improved evaluation test procedures for the corrosion resistance of fasteners, (2) a data base on field performance, and (3) non-destructive diagnostic procedures for assessing in-place condition of fasteners.

Consistent with a major objective of the study, it is recommended that the research needed to overcome these limitations be conducted. Completion of the recommended research will help facilitate the assessment and use of fastener systems which will perform satisfactorily in wet roofing environments. 


\section{REFERENCES}

1. Frohnsdorff, G., Masters, Larry W., and Martin, Jonathan W., "An Approach to Improved Durability Tests for Building Materials and Components," Technical Note 1120, National Bureau of Standards (U.S.), Washington DC (July 1983), 35 pages.

2. Dupuis, Rene, "Test Results and Trends for EPDMs and Modified Bitumens," 1986 Handbook of Commercial Roofing Systems, HBJ Publications, Cleveland, $O H$ (1986), pp. 8-12.

3. Rossiter, Walter J., Jr., "Single-ply Roofing - A Decade of Change," Standardization News, ASTM, Philadelphia, PA (September 1985), pp. 32-35.

4. Rossiter, Walter J., Jr. and Mathey, Robert G., "A Methodology for Developing Tests to Aid Service-Life Prediction of Single-ply Roofing Membranes," 7th Conference on Roofing Technology, National Roofing Contractors Association, Rosemont, IL (April 1983), pp. 8-11.

5. Gish, Brian D. and Jablonowski, Thomas I., "Weathering Tests for EPDM Rubber Sheets for Use in Roofing Membranes, "8th Conference on Roofing Technology, National Roofing Contractors Association, Rosemont, II (April 1987), pp. 5468 .

6. Cash, C.G., "Durability of Bituminous Built-up Roofing Membranes," ASTM STP 691, P.J. Sereda and G.G. Litvan, Eds., ASTM, Philadelphia, PA (1980), pp. 741-754.

7. "Insulated Steel Deck," Data Sheet 1-28, Factory Mutual Engineering Corp., Norwood, MA (May 1983), 26 pages.

8. Corrosion, Shreir, L.L., Ed., Vol. 1 \& 2, NewnesButterworths, London (1976).

9. S. Riaz Hasan, "Fastener Coatings: Which Ones Are Best?" RSI (July 1986), pp. 17-19.

10. Bradford, John, "Corrosion is Major Danger for Fasteners," RSI (January 1986), pp. 62-64.

11. Baxter, Richard P., "Roof Insulation Mechanical Fasteners," Contractors Guide (September 1986), p. 44.

12. Baxter, Richard P., "Corrosion and Mechanical Fastener Systems," Contractors Guide (November 1986), p. 62 .

13. Smith, George A., Jr., "Fastener Corrosion to be Judged by New Standard," RSI (January 1987), pp. 21-22. 
14. Russo, Michael, "Roof Fasteners: Corrosion and Back-Out Threats," RSI (January 1987), pp. 49-52.

15. Casaccio, Ellen K., "Mutually Assured Construction," Roofer Magazine, Volume 7, Issue 3 (March 1987), pp. 28-30.

16. Choiniere, Stan, "Nailing It Down;" Roofer Magazine, Volume 7, Issue 3 (March 1987), pp. 31-33.

17. S. Riaz Hasan and Hodder, Albert, "Performance of Fasteners," Proceedings, NBS/NRCA 8th Conference on Roofing Technology, National Roofing Contractors Association, Rosemont, IL (April 1987), pp. 1-11.

18. "ARMA, NRCA, RIC/TIMA, and SPRI Position on Rusting and Corrosion of Fasteners in Roofing Assemblies," Bulletin \#14, National Roofing Contractors Association, Rosemont, IL (February 1986), 1 page.

19. "Recommended Procedure for Evaluation of Corrosion Resistance of Steel Fasteners," Single-Ply Roofing Institute, Deerfield, IL.

20. "Corrosion Testing: Exposure in Cyclic Environment Producing Condensation in a Sulfur Dioxide Atmosphere," Deutsche Normen, DIN 50018 (May 1978), 4 pages.

21 "Approval Standard: Class I Roof Covers," Class Number 4470, Factory Mutual Research, Norwood, MA (April 1986), 37 pages.

22. Chang, Te-Chuan and Busching, Herbert W., "Energy Savings Potential of Roofing Research," ORNL/Sub/82-22293/1, Oak Ridge National Laboratory (December 1983), 204 pages.

23. Busching, Herbert $w$. and Porcher Joel P., Jr., "Roofing Industry Perspective and Research Capability," ORNL/Sub/8222293/2, Oak Ridge National Laboratory (March 1985), 85 pages.

24. "Good Roofs Save Energy," National Roofing Contractors Association, Rosemont, II.

25. Kanz, George F. and Held, Daniel R., "Field Performance of Mechanically Fastened Elastomeric and Plastomeric Membranes," Proceedings, NBS/NRCA 8th Conference on Roofing Technology, National Roofing Contractors Association, Rosemont, IL (April 1987), pp. 32-39.

26. Paulsen, Einar M., "Roofing Fasteners," Project Report 21, Norwegian Building Research Institute (NBRI), Trondheim/Oslo $(1987), 35$ pages. 
27. Mechanical Fastening of Bituminous and Polymeric Membranes," Design Sheet Building Details A 554.206, Norwegian Building Research Institute, Oslo, Norway 1988), 6 pages.

28. Baxter, Richard, "Moisture Accumulation in Single-ply Assemblies," Roofing Spec (June 1984), pp. 35,36,38, 39 .

29. "Elastomeric, Thermoplastic, and Modified Bitumen Roofing," Technical Report of CIB W.83 \& RILEM 75- SLR Joint Committee, Materials and Structures, Vol. 19, No. 112 (July/August.1986), pp. 323-330.

30. Fontana, Mars G., Corrosion Engineering, 3rd edition, McGraw-Hill Book Co., New York (1986).

31. Mathey, Robert G. and Clifton, James R., "Review of Nondestructive Evaluation Methods Applicable to Construction Materials and Structures," Technical Note 1247, National Bureau of Standards (U.S.), Washington DC (June 1988), 203 pages.

32. Lackey, J.Q. and streicher, M.A., "Detection and Removal of Iron Contamination from Stainless steel Surfaces," Journal of Materials, JMLSA, Vol. 3, No. 2 (Dec 1968), pp. 983-995.

33. "Standard Definitions of Terms Relating to Corrosion and corrosion Testing," ASTM Book of Standards, American Society for Testing and Materials, Philadelphia, PA (1988). 


\section{ACKNOWLEDGMENTS}

This study was sponsored by the Department of Energy, Office of Energy Utilization Research, Energy Conservation Utilization and Technologies (ECUT) Program. The authors appreciate the assistance and encouragement of Ted Lundy and George courville, Oak Ridge National Laboratory, during the conduct of the study.

Special thanks are extended to the members of the industry review panel who provided invaluable assistance throughout the course of the study. Their assistance included commenting on the initial work plan, suggesting sources of information on the corrosion issue, and commenting on the study findings. The members of the panel were:

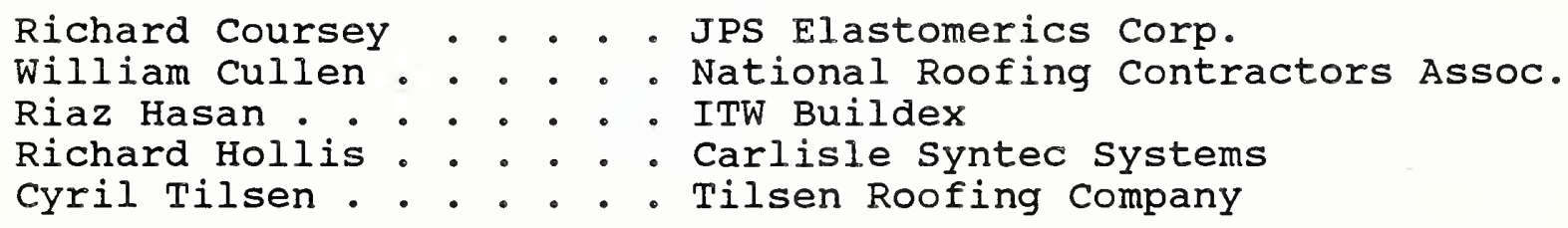

The authors also appreciate the cooperation of the NRCA, RCI, $A R M A$, and SPRI in sending the questionnaires on fastener corrosion to selected members of these organizations. The time spent by the individual members in responding to the questionnaires, as well as that spent in follow-up discussions with the authors, is also appreciated. Thanks are also expressed to those leaders of these organizations who made arrangements for distribution of the questionnaires:

John Brennan . . . . Asphalt Roofing Manufacturers Assoc. Riaz Hasan . . . . . . Single-ply Roofing Institute

Robert LaCosse . . . . National Roofing Contractors Assoc. Robert Phillips . . . Roof Consultants Institute 
Thanks are also extended to George Smith, Factory Mutual Research Corp., for his discussions during the study and noteworthy comments on a draft of this report. In addition, the authors acknowledge the assistance of their NIST colleagues, James Clifton, E. Escalante, Geoffrey Frohnsdorff, and Larry Masters, who provided valuable comments during a review of this report. 


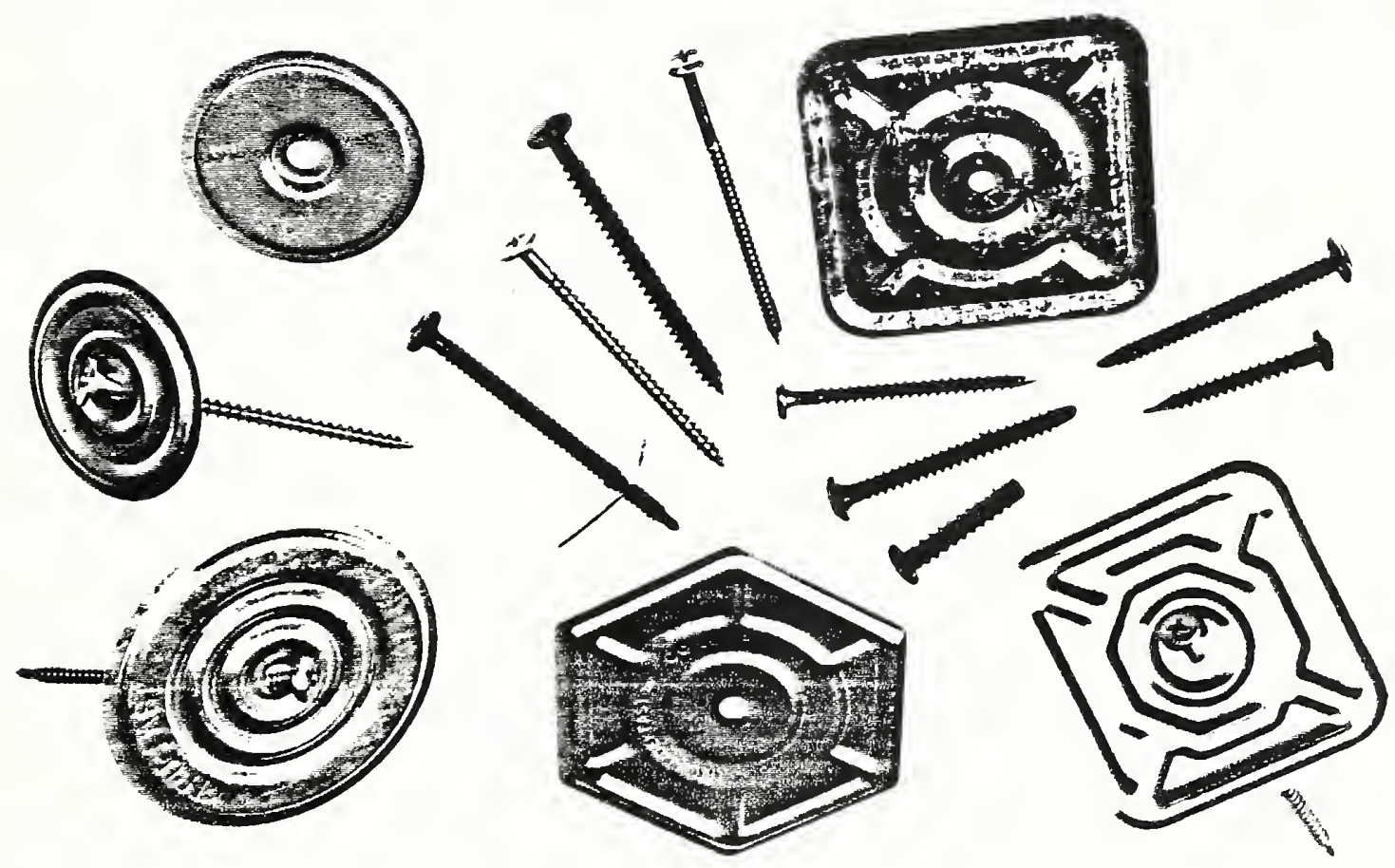

Figure 1. Typical Fasteners and Stress Plates Currently Used in Low-Sloped Roofing 


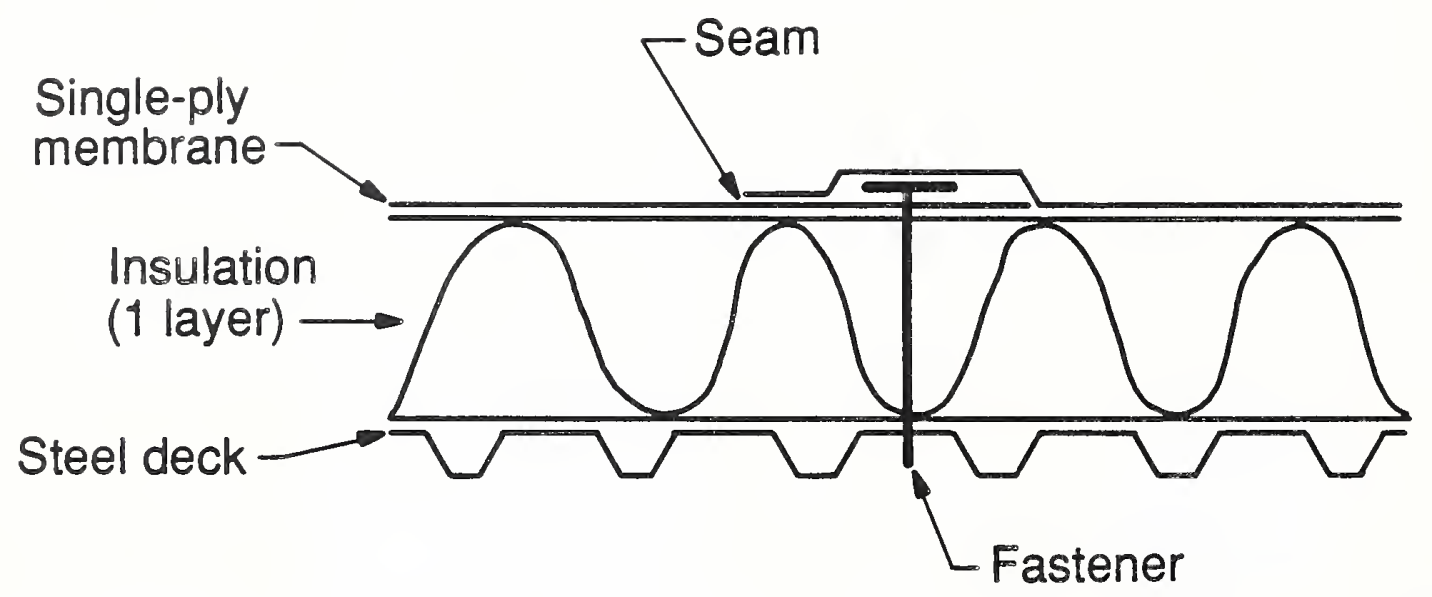

B) Fastening Membrane and Insulation

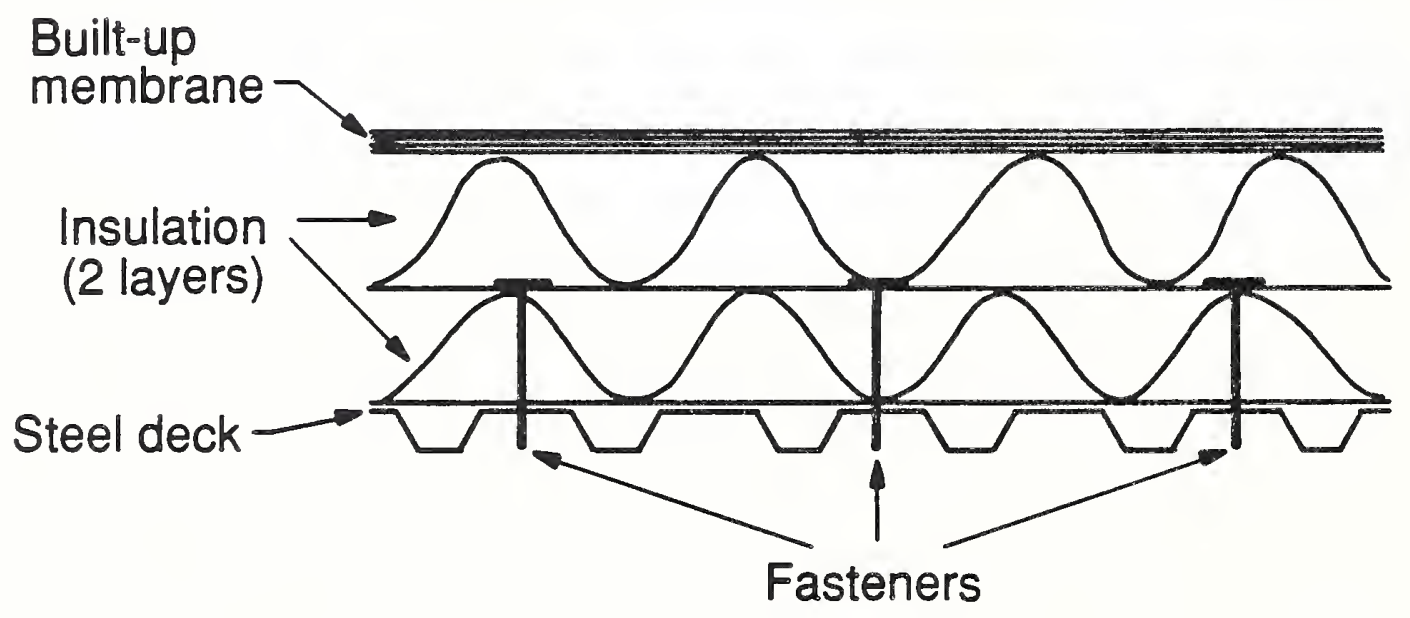

A) Fastening First Layer of Insulation

Figure 2. The Use of Fasteners to Secure Roof Components to Decks: A) First Layer of Insulation, and B) Insulation and Membrane (Not to Scale) 
Surface corrosion removed by cleaning; note no apparent thinning of the shank.

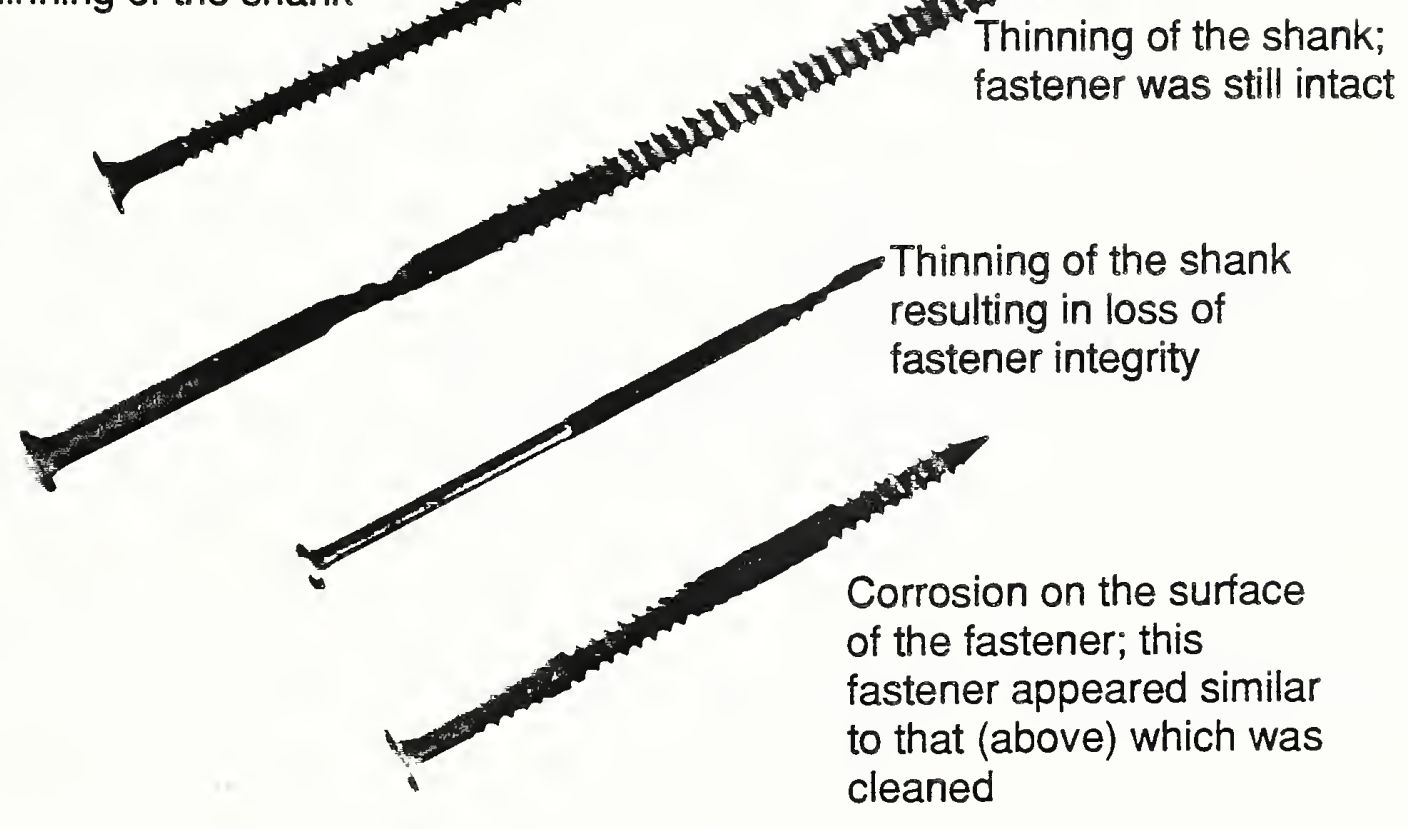

Figure 3. Fastents's That Experienced Corrosion In Service 


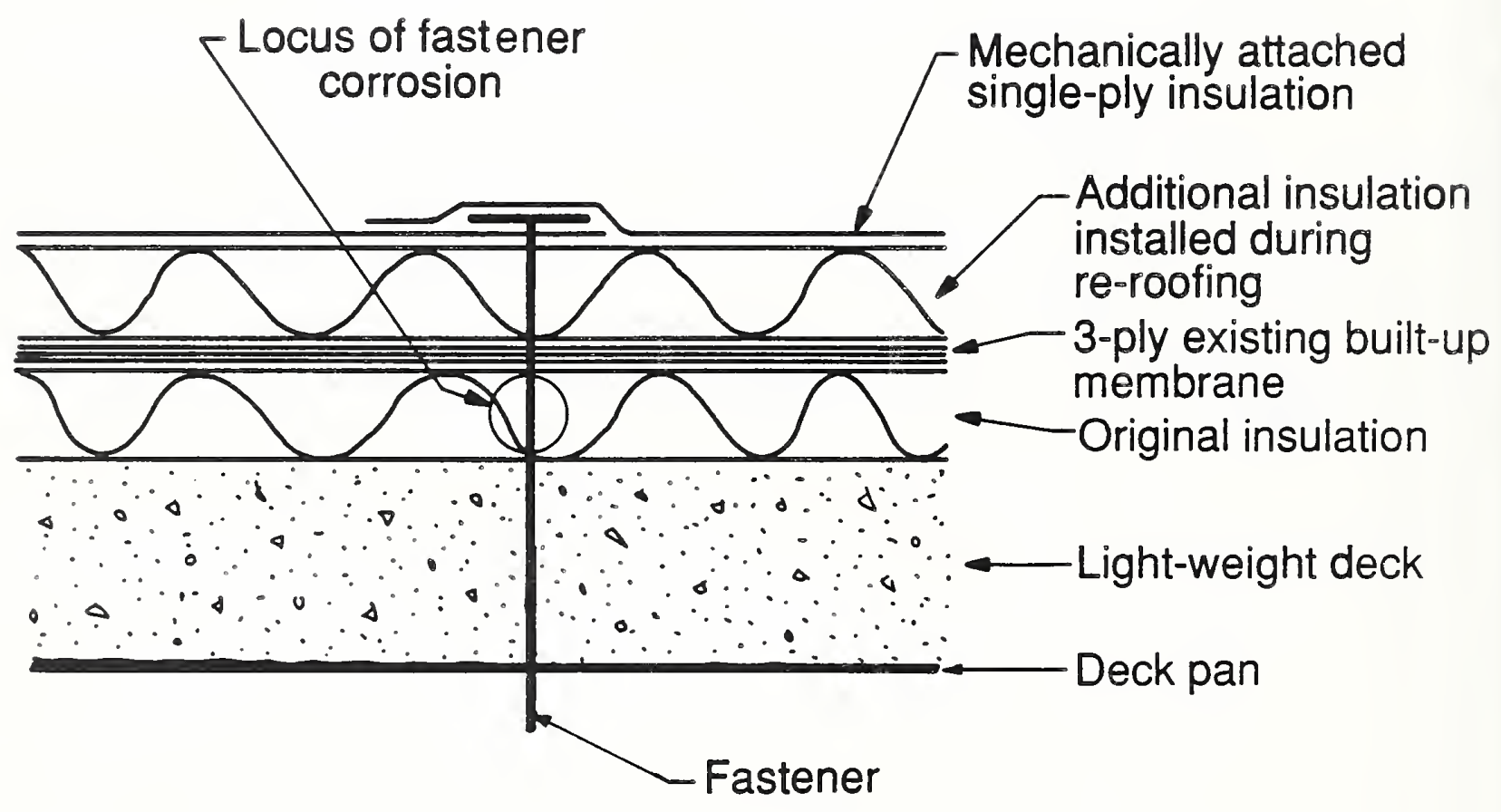

Figure 4. Cross-Section of a Mechanically-Attached Single-Ply Membrane System Installed Over An Existing Built-Up Membrane system (not to Scale). The Fastener Experienced Marked Thinning of the Shank in the Area Within the Insulation 
APPENDIX A. DEFINITIONS OF CORROSION TERMS USED IN THIS REPORT

This Appendix gives definitions of corrosion terms used in this report. They were taken from ASTM G 15, "Definition of Terms Relating to Corrosion and Corrosion Testing" [33] and shreir's text [1].

Term

Definition

Corrosion

The undesirable deterioration of a metal or alloy, i.e., an interaction of the metal with its environment that adversely affects those properties of the metal that are to be preserved [1].

Crevice Corrosion

Embrittlement

Galvanic

corrosion

Hydrogen

Embrittlement

Localized

Corrosion

Pitting

Rust

Stress-

Corrosion

cracking

Uniform

Corrosion
Localized corrosion at a metal surface at, or immediately adjacent to, an area that is shielded from full exposure to the environment because of close proximity between the metal and the surface of another material [33].

Localized corrosion resulting from a crevice formed between two surfaces - one of which is a metal [1].

The severe loss of ductility or toughness or both, of a material, usually a metal or alloy [33].

Accelerated corrosion of a metal because of electrical contact with a more noble metal or non-metallic conductor in a corrosive electrolyte [33].

Hydrogen-induced cracking or severe loss of ductility caused by the presence of hydrogen in the metal [33].

Corrosion at discrete sites, for example, pitting, crevice corrosion, and stress corrosion cracking [33].

Corrosion of a metal surface, confined to a point or small area, that takes the form of cavities [33].

A corrosion product consisting primarily of hydrated iron oxide [33]. (A term properly applied only to ferrous alloys.)

Cracking produced by the combined action of corrosion and static tensile stress (internal or applied) [1].

Corrosion that proceeds at about the same rate over a metal surface [33]. 
APPENDIX B. NORWEGIAN RECOMMENDATIONS ON FASTENER CORROSION This Appendix reproduces the Norwegian recommendations for testing the ability of protective coatings on fasteners to provide corrosion resistance, and for a system of categorizing corrosion risk based on the test results. The information is provided by way of example as the approach taken by Norway in response to observations made regarding the corrosion of fasteners in service. The recommendations were made by Paulsen in the NBRI Project Report 21, "Roofing Fasteners" [26]. The table in the present Appendix was also taken from Paulsen's report.

Testing of protective coatings (from NBRI Project Report 21, [26])

Corrosion protection is tested by a DIN 50018 Kesternich apparatus using 2.0 liter $\mathrm{SO}_{2}$ according to procedure described in Factory Mutual standard 4470 where maximum $15 \%$ of the surface may be attacked by red rust when the sample is subjected to the stated number of cycles.

The temperature stability of organic coatings is tested for 300 hours at $90^{\circ} \mathrm{C}$ and $100 \% \mathrm{RH}$ and the coatings should not peel off or show any blistering. 
Categorizing corrosion risk according to NBRI Project Report 21 [26]

The risk of corrosion on metallic fasteners may be grouped into three categories:

Category $K$. Moisture caused by condensation may occur on the underside of the membrane only for short periods. Good opportunities for drying out to room climate.

Examples: steel deck roof without vapor barrier; stress plate on fastener covered, or embedded in bitumen

Category KL A great risk for moisture coming to lie on the fastener for long periods, the moisture being caused by high relative humidity in the air between the roof membrane and an impermeable substratum. Poor opportunities for drying out.

Examples: steel deck roof with vapor barrier concrete deck roof re-roofing stress plate on fastener exposed at edge of membrane

Category KLA Like KL, but with aggressive substances in insulation or on existing membrane when re-roofing takes place.

Examples: phenol in insulation re-roofing in an industrial area where corrosion-promoting pollution is present 
Table Bl. Corrosion Resistance for Metallic Fasteners as Given in the Norwegian Recommendations

Required corrosion resistance

\begin{tabular}{|c|c|c|c|c|c|}
\hline \multirow[t]{3}{*}{$\begin{array}{l}\text { Cate- } \\
\text { gory }\end{array}$} & \multirow[t]{3}{*}{$\begin{array}{l}\text { Roof } \\
\text { constructions }\end{array}$} & \multirow{3}{*}{$\begin{array}{l}\text { Required } \\
\text { minimum } \\
\text { corrosion } \\
\text { protection } \\
\text { stated in } \\
\text { Kesternich } \\
\text { cycles }\end{array}$} & \multicolumn{3}{|c|}{$\begin{array}{l}\text { Types of coating and } \\
\text { materials of interest } \\
\text { for mechanical fasteners }\end{array}$} \\
\hline & & & \multirow[b]{2}{*}{ Stem } & \multicolumn{2}{|l|}{ Stress plate } \\
\hline & & & & $\begin{array}{l}\text { Covered } \\
\text { or embedded }\end{array}$ & Exposed \\
\hline$K$ & $\begin{array}{l}\text { Steel } \\
\text { deck roof } \\
\text { without } \\
\text { vapour barrier }\end{array}$ & 2 & $\begin{array}{l}10-15 \mu \mathrm{m} \\
\text { EIZn }\end{array}$ & $20 \mu \mathrm{mZn}$ & $\begin{array}{l}\text { As for } \\
\mathrm{KL}\end{array}$ \\
\hline$K L$ & $\begin{array}{l}\text { Roofs with } \\
\text { vapour barrier } \\
\text { Concrete } \\
\text { deck roofs } \\
\text { Re-roofing }\end{array}$ & 8 & $\begin{array}{l}\text { Special } \\
\text { coating } \\
\text { * Stainless } \\
\text { steel } \\
\text { *Al } \\
\text { Plastic }\end{array}$ & As for $K$ & $\begin{array}{l}20 \text { mAlZn } \\
\text { * Stainless } \\
\text { steel } \\
\text { *Al } \\
\text { Plastic }\end{array}$ \\
\hline$K L A$ & $\begin{array}{l}\text { As for } \mathrm{Kl} \text {, } \\
\text { but stem of } \\
\text { fastener } \\
\text { exposed to } \\
\text { aggressive } \\
\text { substances }\end{array}$ & $>15$ & As for $K L$ & As for $K$ & As for $K L$ \\
\hline
\end{tabular}

* Galvanic corrosion may occur in combination with certain other materials. 
APPENDIX C. SUMMARY OF RESPONSES FROM ABROAD ON QUESTIONS REGARDING FASTENER CORROSION

This Appendix presents a summary of the responses received from foreign building research institutes and related organizations that were asked for information regarding the corrosion issue. The responses were in the form of personal communications, either by letter, phone, or in person. The summary is as follows:

Belgium

Research Lab of a Material supplier

Canada

National Research Council (NRC)

Denmark

Danish

Building

Research

Institute

England

Building

Research

Establishment (BRE)

\section{France}

Centre

Scientifique et Technique du

Batiment (CSTB)
Corrosion of fasteners in service is not a often discussed subject, and generally not an issue. Standards are not available.

There is no information available. They are aware of the concerns in the United States from the trade publications.

The use of fasteners is limited in Denmark. They have heard of the concerns, primarily from Norway, and have seen a few examples. The respondent also mentioned the UEAtc draft document under development.

Little information is available in England on the corrosion issue. In general, the issue has not raised any current concerns. One reason may be that the single-ply market represents only about 5\% of the market, so few mechanically fastened systems are installed. A study has recently been initiated on steel siding and roofing which should include fasteners; the results are not expected until late 1989.

There are no examples of pronounced problems when the building environment is normal. The fasteners sold in France are primarily from U.S. companies selling through European subsidiaries. They are aware of the U.S. situation, and have heard of reports of corrosion from Germany. The respondent also mentioned the UEAtc draft document under development.

Fastener use is not very common, particularly because the roof decks are concrete. The respondent indicated that he had no information to forward.
Israel

Building

Research

station 
Japan

Tokyo Institute of Technology

South Africa

Council for

Scientific and

Industrial

Research (CSIR)

Switzerland

Eidgenossische

Materialprufungsund Versuchsanstalt (EMPA)

West Germany

Bundesanstalt fur Materialforschung und -prufung (BAM)
No information is available. Mechanically fastened roofing systems have had little use in Japan.

Mechanical fasteners are not used. The respondent included a copy of a 1967 report that addressed whether fasteners were coated with zinc according to the requirements of a South African specification.

Corrosion is of concern and should be respected. There are no standards for mechanical fasteners. They will soon be assessing a large mechanically fastened roof, but nothing is presently available.

The respondent sent copies of the DIN sulfur dioxide/water vapor test and a salt spray test. He also mentioned the UEAtc draft under development. He included a document from available to the UEAtc working group for its discussions concerning requirements for fastener corrosion. The document was entitled, "Fastening Methods for Various Underground and Roof Constructions," $\mathrm{K}$. Kayser, Gummersbach. 


\section{APPENDIX D. QUESTIONNAIRE RESULTS}

During the course of the present study, questionnaires on corrosion of fasteners in service were sent to selected members of NRCA, RCI, ARMA, and SPRI. The questionnaire approach was taken as a first step in compiling a broad base of information addressing factors affecting corrosion of fasteners in service, in recognition of the fact that no systematic studies of the subject had been conducted. Individuals receiving a questionnaire were asked to respond based on their firsthand experience. If they had no such experience, they were asked to return the uncompleted questionnaire for purposes of record keeping.

All questions required multiple choice answers. This was to eliminate subjective interpretation of written answers (if they had been asked for) and to allow for graphic summary of the questionnaire returns. This Appendix presents the authors' analysis of the results of the questionnaire surveys. The analysis is followed by bar graphs in which the percent response versus the multiple choice answer are given. Each plot is also accompanied by the question. Not all respondents answered each question. The number above each bar in the plots indicates how many answers were received for that choice of answer.

For some questions, more than one answer was allowable, and in these cases, the response may total more than 100 percent. In general, most questions were sent to the four industry associations, and a single plot gives all results. In a few 
cases, specific questions were only sent to the NRCA. In these cases, the plots note that the question was only sent to NRCA. The narrative summary of the results is given in the paragraphs which follow. In general, the discussions address the results of a group of related questions. Each group has been given a title. The numbers in parenthesis after the title refer to the specific questions discussed in that group and plots of results which follow the discussions. For some questions, follow-up phone calls to respondents were made to clarify or complement the questionnaire results. Information obtained by follow-up phone calls is noted, where appropriate, in the summaries.

\section{Experience of Individuals who Received Questionnaires $(1-6)$}

The individuals receiving the questionnaires were considered to have considerable experience. Contractors who responded stated that 25 to $75 \%$ of their installations were mechanically attached, and a rough estimate was that they had installed about 3000 mechanically fastened roofs. The consultants and suppliers (ARMA and SPRI) had generally been involved with mechanically fastened systems for 5 to 6 years or more. The consultants and fastener suppliers have dealt with all type of roofs (single-ply and bituminous). However, as perhaps expected, the ARMA respondents were only involved with bituminous roofing. The RCI respondents stated that most of their inspections were of modified bitumen roofing.

\section{Materials Used for Fasteners (7\&8)}

The results indicated that both carbon steel and stainless steel have been used to produce roofing fasteners. Follow-up phone calls clarified that most are carbon steel, with the use stainless steel being rather recent. The specification numbers of the steels were requested, but most respondents did not provide this information. From the few responses, it was found that varbon steel is AISI 1020, and both AISI 304 and 410 stainless steels are being used.

The respondents indicated that $z$ inc and polymeric coatings were the predominant types for which they had observations. 
Generally, carbon steel and plastics are used for stress plates. The type of plastic was generally not identified, although a few respondents indicated that polypropylene has been used.

As indicated in the responses, zinc coating is the primary method of protecting carbon-steel stress plates. However, follow-up phone calls to some respondents indicated that zincaluminum alloy is also being used now and may increase in use in the future to the extent of replacing zinc-coated plates.

\section{Inspections of Mechanically Fastened Roofs (11-15)}

Not all individuals who received the questionnaires had experience in inspecting mechanically fastened roofing systems. A significant number of respondents from all groups had not inspected such systems and, therefore, did not answer the questionnaires. The percent of respondents (including those not answering questions) was as follows: $63 \%$ of RCI, $67 \%$ of SPRI, $54 \%$ of NRCA \& $18 \%$ of ARMA.

The largest number of inspections was made by NRCA and RCI. Most NRCA respondents have inspected less than ten mechanically fastened roofs; nevertheless, based on the returns, it was estimated that 300 roofs were inspected by the NRCA group. (This corresponded to about $10 \%$ of the estimated roofs that the NRCA respondents had installed.)

of the four groups, RCI respondents inspected the greatest number of roofs. Estimates of the number of mechanically fastened roofs inspected by the groups other than NRCA were: 670 by RCI, 160 by ARMA, and 170 by SPRI. The total estimate of mechanically fastened roofs inspected by the respondents was 1300 .

In many cases where mechanically fastened roofs were inspected, the fasteners were not observed. Fastener manufacturers, as a group, most often observed fasteners; whereas the RCI group provided the greatest frequency of inspections. A total of 45 individuals provided the information on corrosion observations by completing the questionnaires.

All groups reported observing some corrosion of fasteners during inspections. On the basis of the responses, the total number of roofs inspected where fasteners were seen to have some corrosion was estimated to be about 200 or 15 percent of the estimated number of roofs inspected. The break-down by groups was: 80 by RCI, 60 by NRCA, 30 each by ARMA \& SPRI. 
The NRCA respondents indicated that corrosion was primarily on the fastener, and to a lesser extent on both the fastener and stress plate; it was never reported to be on the stress plate alone. The implication of this finding was that the weak link is generally the fastener, although sometimes the stress plate is involved.

The predominant defects reported by the NRCA respondents were:

- rust on some or all of the surface

- thinning of the fastener shank by corrosion.

Observations reported less often were:

- separation of the fastener from the deck, or along the shank into two or more pieces

- preferential corrosion of the fastener at the stress plate, or at the deck.

Although only a few of the latter observations were reported by the respondents, they provide evidence of the seriousness of corrosion and the need to characterize in-service performance. In the extreme, fastener separation and corrosion at the deck can result in damage by high winds. Moreover, the lesser observations reported indicate that corrosion processes such as crevice corrosion are occurring.

\section{RCI, ARMA, and SPRI Observations of Carbon-steel Systems (19\&20)}

The responses to these questions were similar to those provided by the NRCA respondents. The predominant observations were:

- rust on some or all of the fastener surface

o thinning of the fastener shank.

Observations reported less frequently were:

- separation of the fastener from the deck, or into two or more pieces

- preferential corrosion of the fastener at the stress plate, or at the deck.

The observations on separation and corrosion at the deck indicate potentially serious problems and a need to monitor inservice performance. 
Surface Treatment of Carbon-Steel Fasteners Where Corrosion Was observed $(21-23)$

Corrosion was observed on carbon-steel fasteners having all types of coatings. The predominant coating was zinc.

A key observation is that individuals inspecting roofs do not always know or recognize the type of coating on the fasteners. Some education may be necessary, if detailed data on fastener performance in service is to be recorded.

The respondents also indicated that the carbon steel fasteners on which they have observed corrosion are still in use. These are still the predominant type today.

observations of Corrosion on Stainless Steel Fasteners (24\&25)

Every defect listed in these two questions was observed, including cracking and preferential corrosion at the deck (which may be indicative of stress corrosion cracking and crevice corrosion).

NRCA Observations of Corrosion on Stress Plates (26\&27)

When corrosion conditions were severe enough to cause corrosion of the stress plates, all defects listed in these two questions were noted. The most susceptible location was the point of contact with the fastener (crevice corrosion).

RCI, ARMA \& SPRI Observations of Corrosion on Stress Plates $(28-30)$

Only a few observations of corrosion on stress plates were reported. This indicated that stress plates were attacked less frequently than fasteners.

The predominant observations were rusting on either the top, or both top and bottom surfaces. Some crevice corrosion was reported at the stress-plate/fastener contact point.

Use of Fasteners Where corrosion was observed (31)

Corrosion was observed on fasteners used for attachment of insulation alone, and for attachment of both insulation and membrane to the deck. This response is in line with reports given in industry trade publications.

Water in Contact with corroded Fasteners (32)

In most cases, water was observed in contact with the corroded fasteners and stress plates. Only one respondent indicated a case where no water observed. 
Fasteners Tested by FMRC 4470 Procedure (33)

The majority of the responding contractors did not know if corroded fasteners that they observed had been subjected to the FMRC 4470 procedure. This was not surprising, because the test requirements are relatively recent.

\section{Age of Roofs with Corroded Fasteners (34\&35)}

Roofs of all ages (up to 10 years or more) were reported to contain some corroded fasteners. Some were only one to two years old. OnIY NRCA respondents indicated a predominant age range which was within the three to eight year period.

\section{Types of Roofing Projects where Corrosion was observed (36\&37)}

All groups of respondents indicated that corroded fasteners were observed in both new and re-roofing (including tearoff) applications. The predominant project for observing corrosion was re-roofing without tear-off. This observation was consistent with trade publication reports that a key factor affecting corrosion in service is mechanically attaching new roofing through existing systems that may contain wet insulation.

Membrane Types in systems where Corrosion was observed (38\&39)

All groups of respondents found corroded fasteners in all types of membrane systems. A higher number of observations was indicated for built-up roofing and EPDM membranes, which may reflect the fact that these two types predominate in today's industry. The respondents also indicated a slightly higher frequency of corrosion for single-ply systems. This perhaps reflects their use in re-roofing projects without tear-off.

Leaking Membranes (40)

The roof was generally, but not always, reported to be leaking, when corrosion of fasteners was observed. This observation may reflect the fact that the roof was inspected because a problem was occurring.

Vapor Retarders in Systems where Corrosion Was Observed (42\&43)

Both systems with and without vapor retarders were reported as having corroded fasteners, although the majority of respondents indicated no vapor retarder in the system. This observation probably reflects the fact that the majority of low-sloped roofing systems do not include vapor retarders. 
Insulations in Systems Where corrosion Was Observed (42\&43)

All types of insulations have been involved. Some predominance of mineral fiber (perlite) and wood fiber boards was noted. This observation may reflect the frequent use of mechanically fastened systems for re-roofing projects without tear-off. These two board products are often used as leveling courses in such projects.

Wet Insulation $(44 \& 45)$

The majority of the respondents reported that the insulation was either always or frequently wet in cases where corrosion was observed. A few indicated that it was rarely wet. No respondent replied that it was never wet. (Note: In preparing the questionnaires, a definition of "wet" insulation was not given, so that some ambiguity was probably present in the question)

Because the attachment of the first layer of insulation in steel deck systems was historically a main reason for using fasteners, the questionnaires asked whether the respondent felt that the insulation contributed to corrosion. In general, most respondents believed that the insulation played a role in the corrosion process.

\section{Decks of Systems Where Corrosion Was Observed $(46-49)$}

Corrosion was reported for all types of decks with metal predominating. The predominance of metal decks could reflect: (1) more corrosion problems with these decks, (2) more use of these decks with fasteners, or (3) more inspections of systems having these decks. Information was not available to support or refute reasons why metal decks predominated.

In most cases, the individual inspecting the roof with corroded fasteners could not observe the deck. Only the RCI group generally reported seeing the deck at the location of fastener penetration. In situations where the metal deck was observed at the locations of fastener penetration, often the deck, as well as the fastener, were found to be corroded. (Note: this question may have been ambiguous and implied seeing the deck from the top side of the roof only.)

Humidity within the Buildings (50)

The humidity in the buildings (having corroded roofing fasteners) was generally described as nomal. tie relationship of this response to observed corrosion was not known. The importance of the question was whether a majority of respondents would have indicated a predominance of high interior humidity conditions (which was not found). 
Experience with the FMRC 4470 Test Procedure (51-53)

Most respondents believe that the FMRC procedure has been beneficial. Most do not know whether fasteners that have corroded in service have passed the FMRC 4470 test procedure. Correlations between performance in the test procedure and in service are not known, according to the respondents. 
1. Has your company installed low-sloped roofing using mechanical fasteners: (circle one)
a. yes
b. no

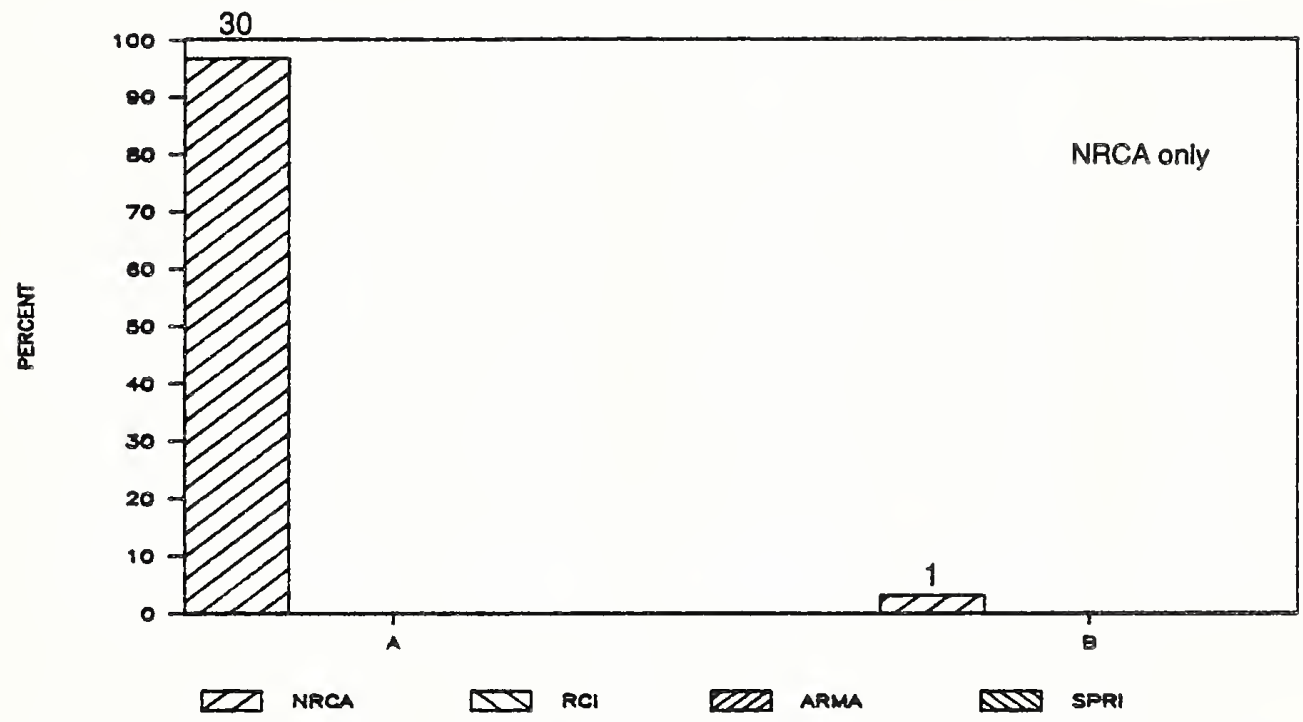

2. How would you describe the frequency of use of mechanically fastened systems in relation to the total low-sloped roofing installed by your finm: (circle one)
a. Erequent (more than 75\%)
b. considerable (about 50\%)
c. moderate ( about 25\%)
d. slight (less than 108)

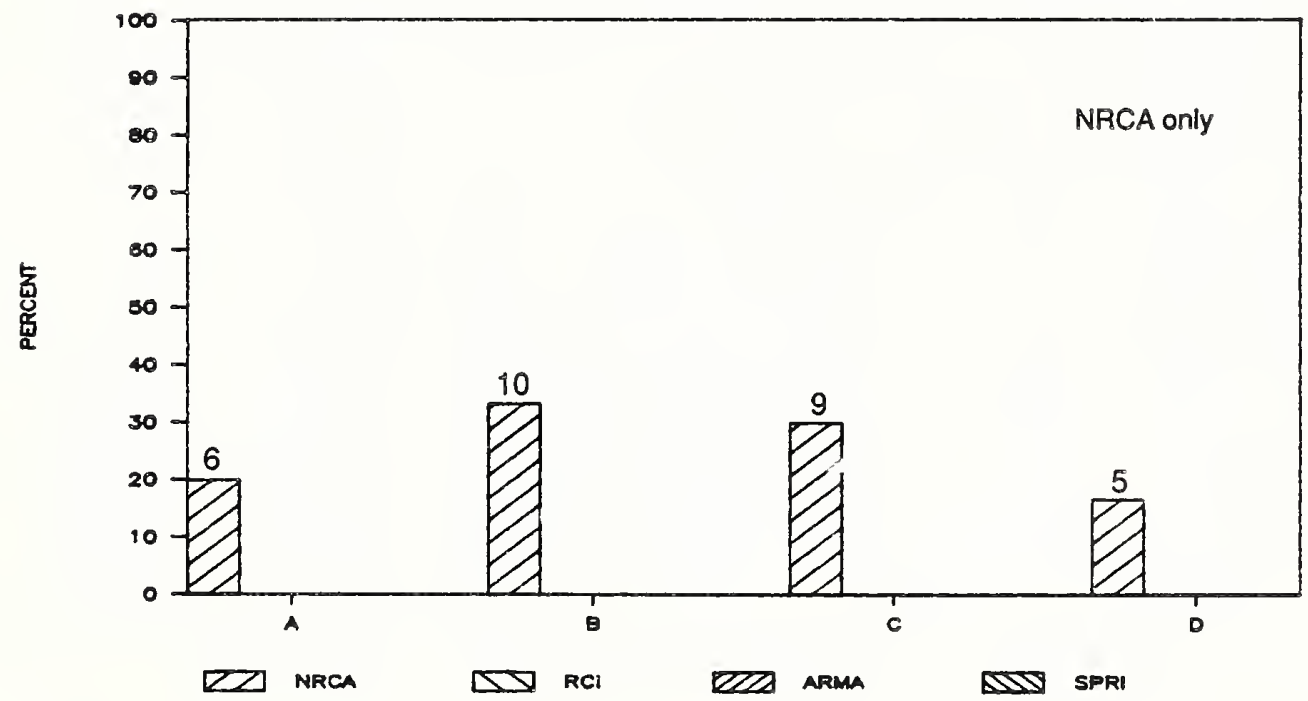


3. Please indicate the approximate number of mechanically fastened roofing systems that you have installed: (circle one)
a. less than 25
b. $25-50$
d. $75-100$
c. $51-75$
e. $101-150$
f. $151-200$
g. more than 200

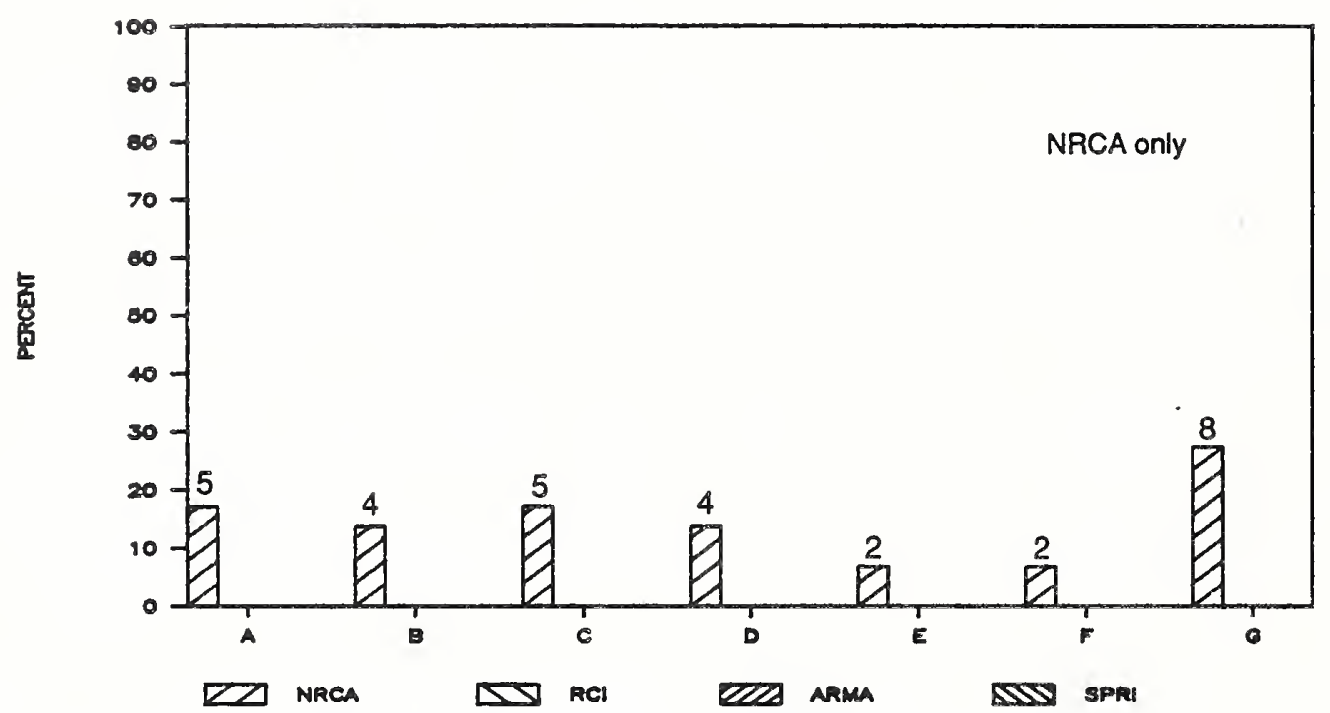

4. For how long has your fim been providing fasteners or conducting inspections of low-sloped roofing: (circle one)
a. 1 - 2 years
b. 3 - 4 years
d. 7 - 8 years
c. 5- 6 years
e. 9- 10 years
f. more than 10 years

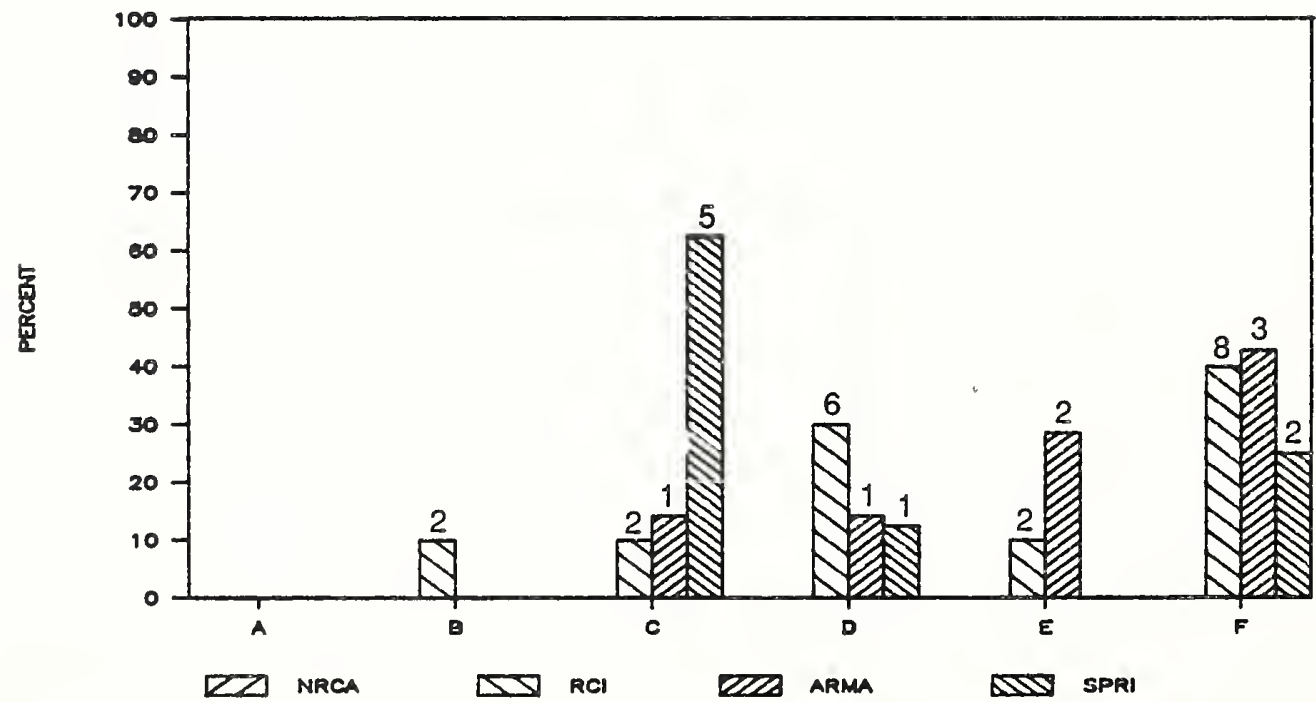


5. For what type of membrane systems does your firm provide fasteners or conduct inspections: (circle as many as appropriate)

Bituminous

a. built-up

b. modified bituminous $\frac{\text { Single-Ply }}{\text { c. EPDM }}$

e. other

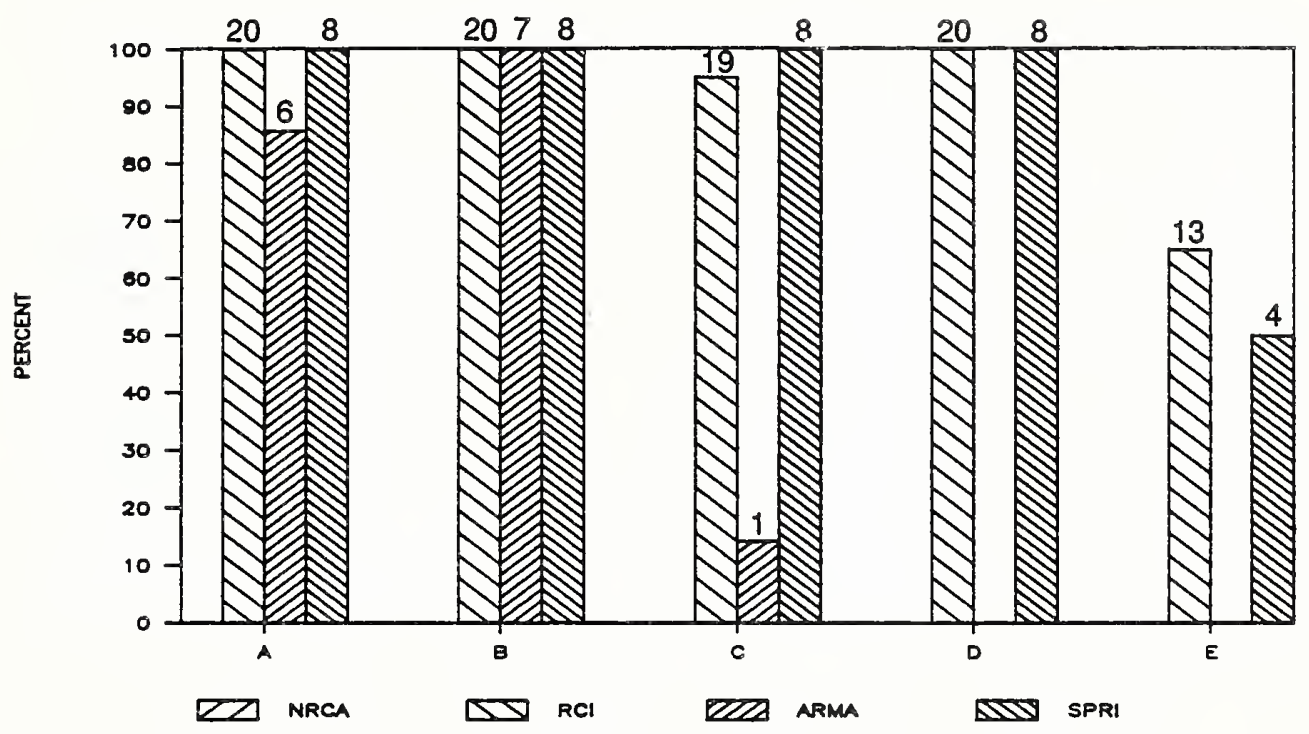

6. If, in the previous question, you answered more than one system, please indicate the relative extent to which one type of membrane system may have predominated: (circle one)

a. almost all bituminous

b. primarily bituminous with some single-ply

c. about the same for both types

d. primarily single-ply with some bituminous

e. almost all single-ply

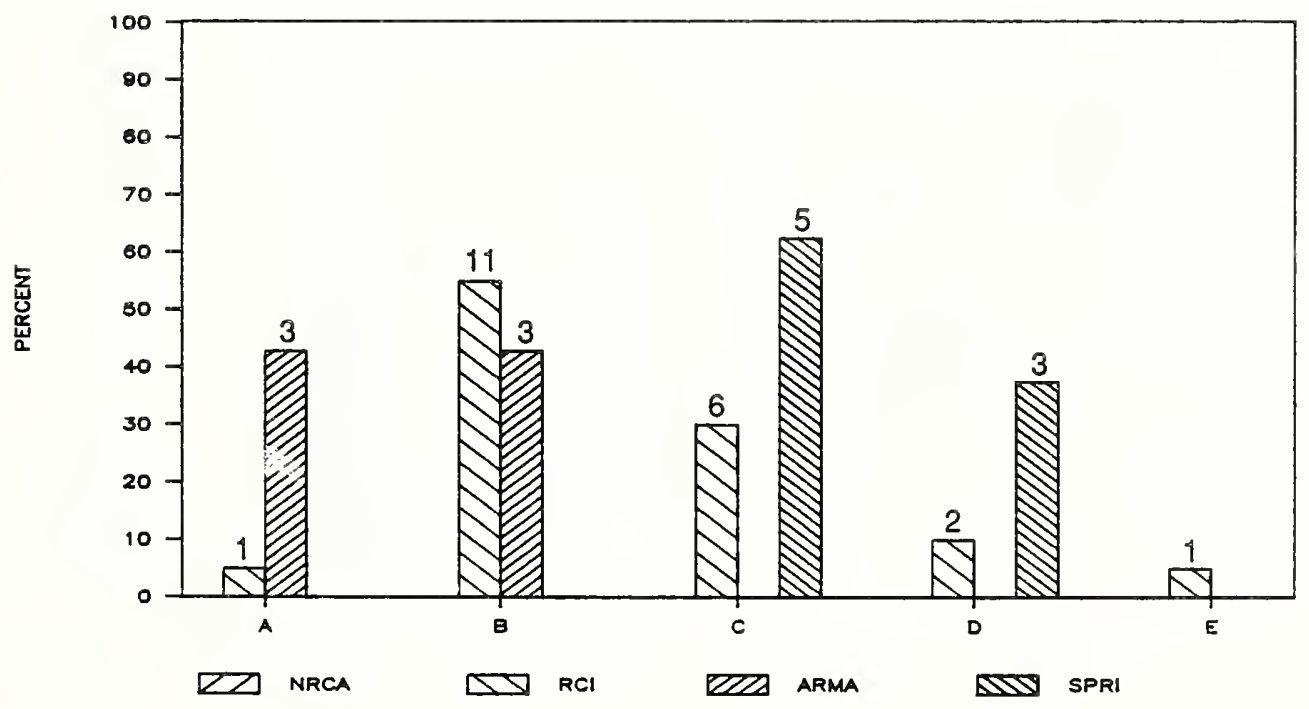


7. What metals or alloys are used to make fasteners incorporated in your roofing systems: (circle as many as appropriate)

a. carbon steel (what is ASTM specification no.

b. stainless steels (What are AISI nos.

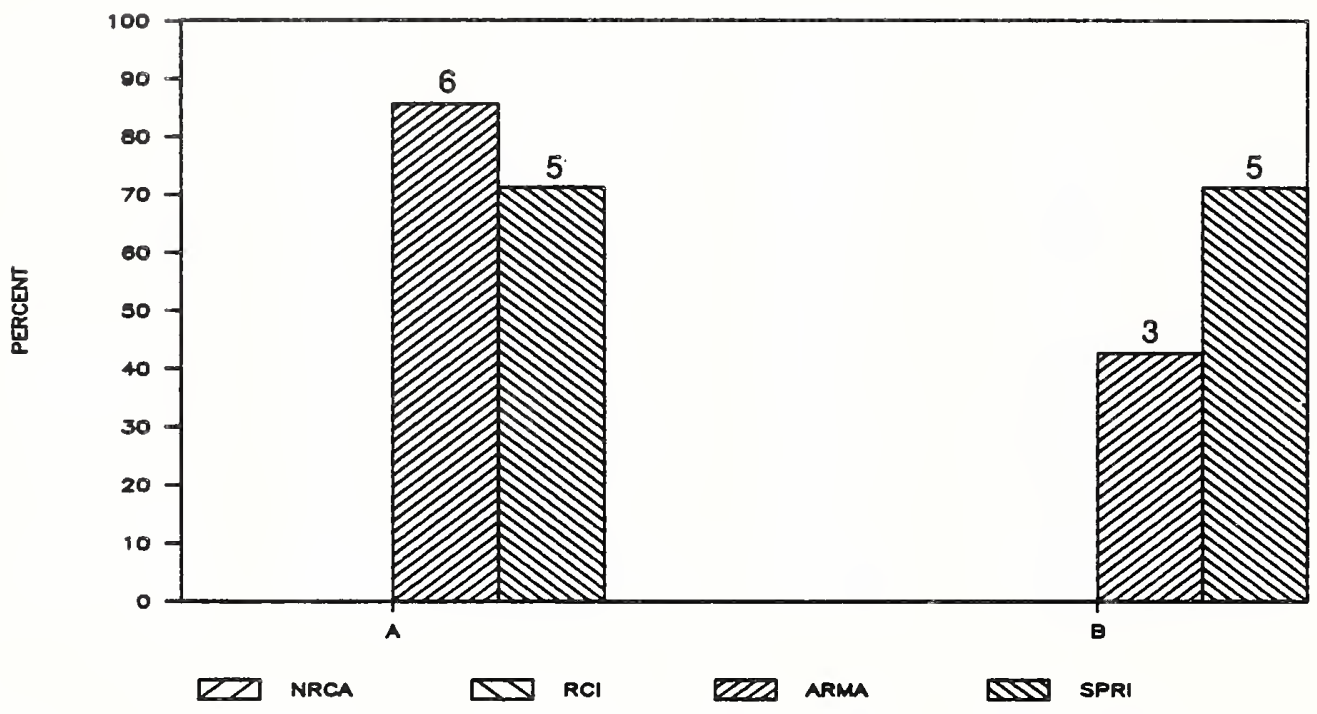

8. What is the surface treatment on carbon steel fasteners: (circle as many as appropriate)
a. oil
d. polymeric
b. black oxide
e. other
c. zinc coatings

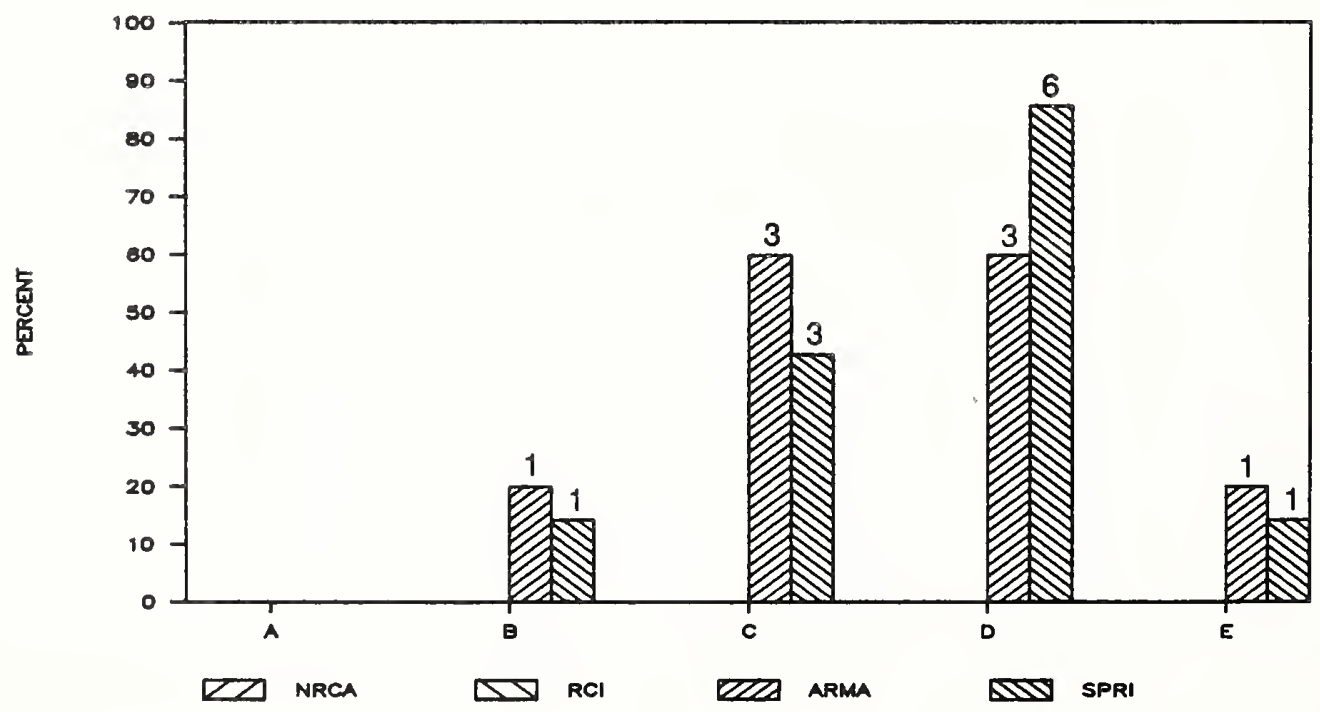


9. What metals, alloys or other materials are used to make stress plates incorporated in your systems: (circle as many as appropriate)

a. carbon steel (what is ASTM specification no.

b. stainless steels (What are AISI nos.

c. plastic (which ones<smiles>c1ccccc1</smiles>

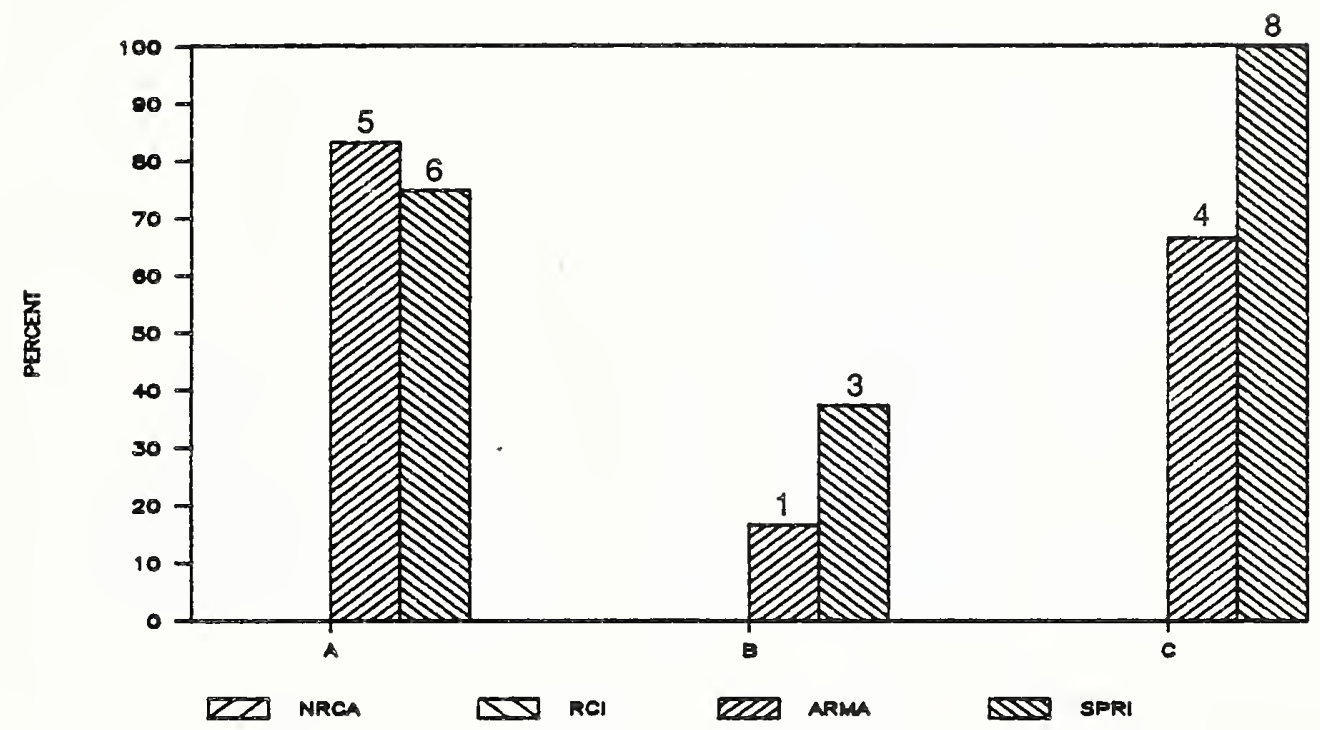

10. What is the surface treatment on carbon steel stress plates (circle as many as appropriate)
a. oil
b. black oxide
c. zinc coatings

d. polymeric

e. other

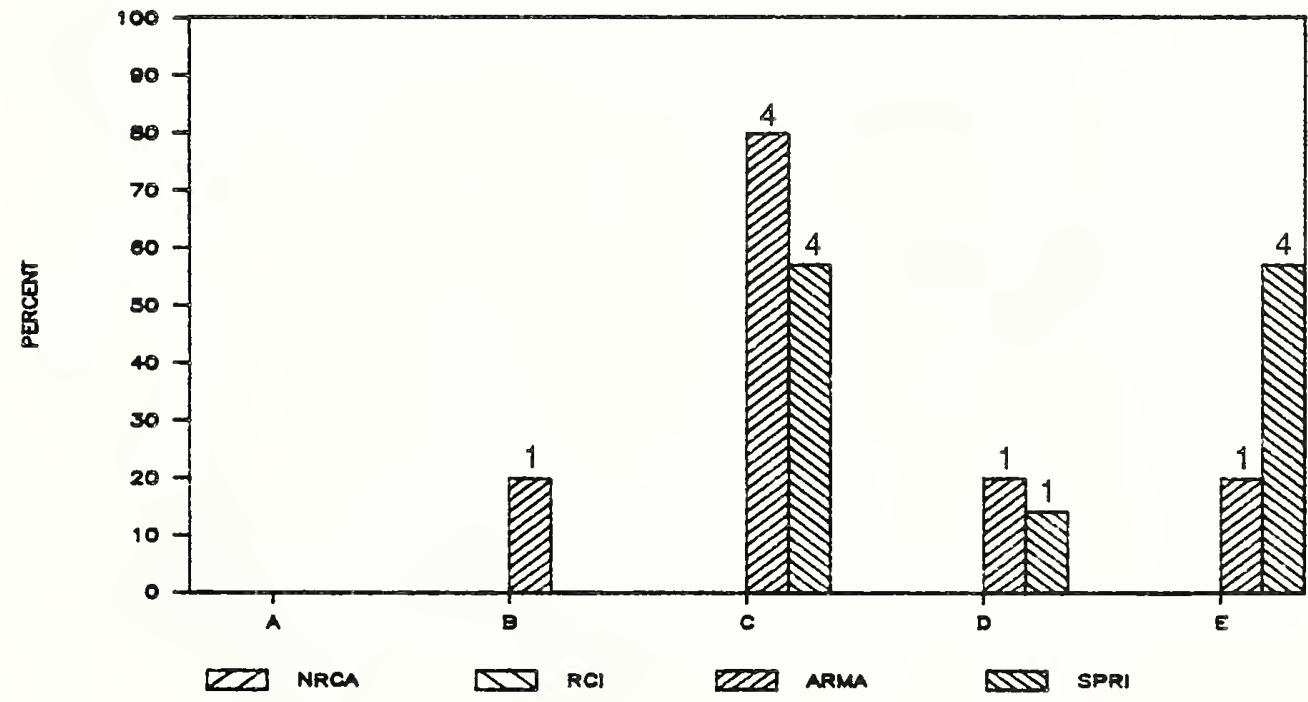


11. Have you had the opportumity to inspect aged roof installations in which screw type fasteners were used to secure the insulation and/or membrane in place: (circle one)
a. yes
b. no

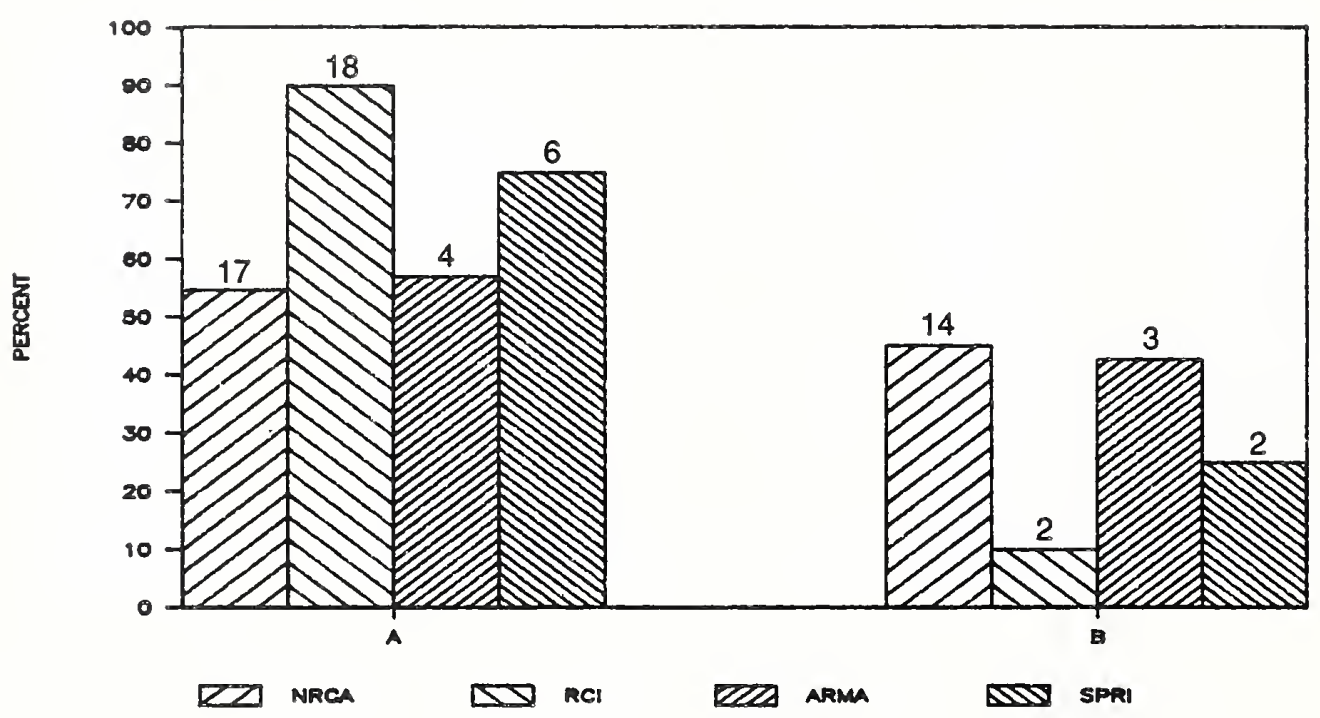

12. About how many of these roofs with fasteners have you inspected firsthand: (circle one)
a. less than 10
b. $10-20$
d. $31-40$
c. $21-30$
e. $41-50$
f. more than 50

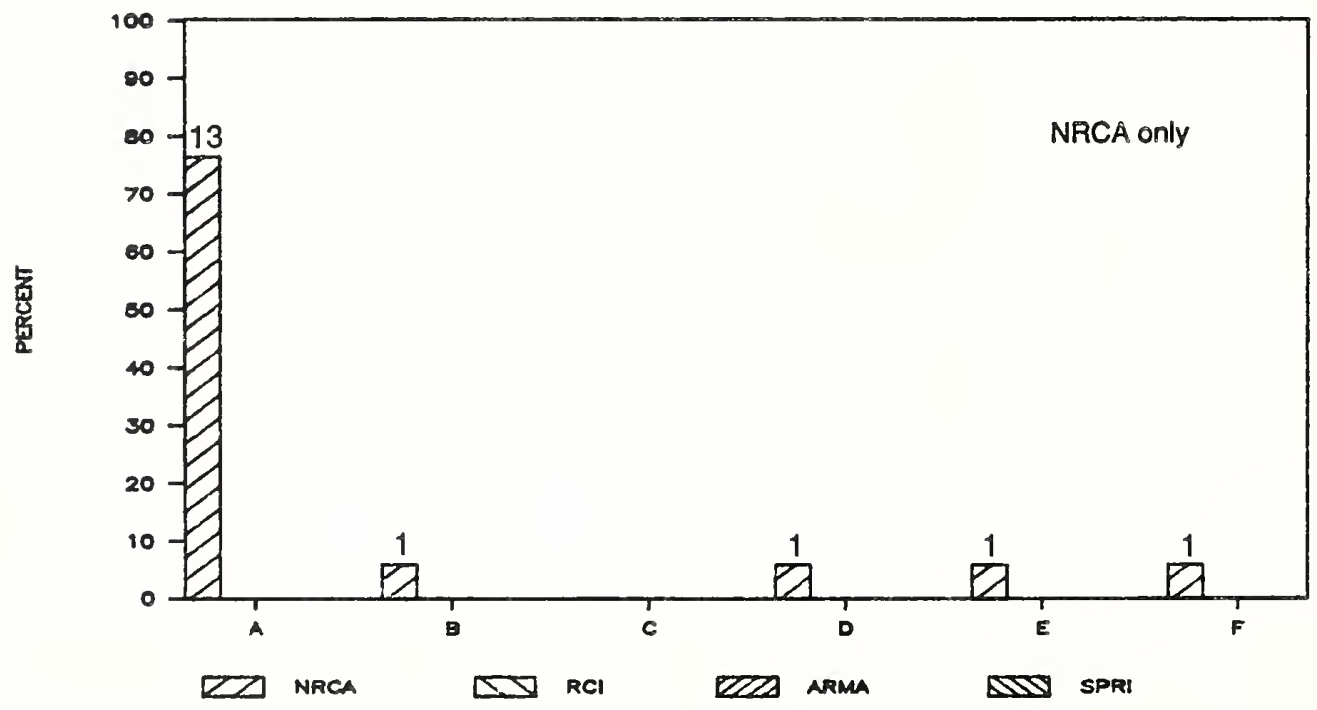


13. About how many of these roofs with fasteners have you inspected: (circle one)
a. less than 20
d. $61-80$
b. $20-40$
$81-100$
c. $41-60$
f. more than 100

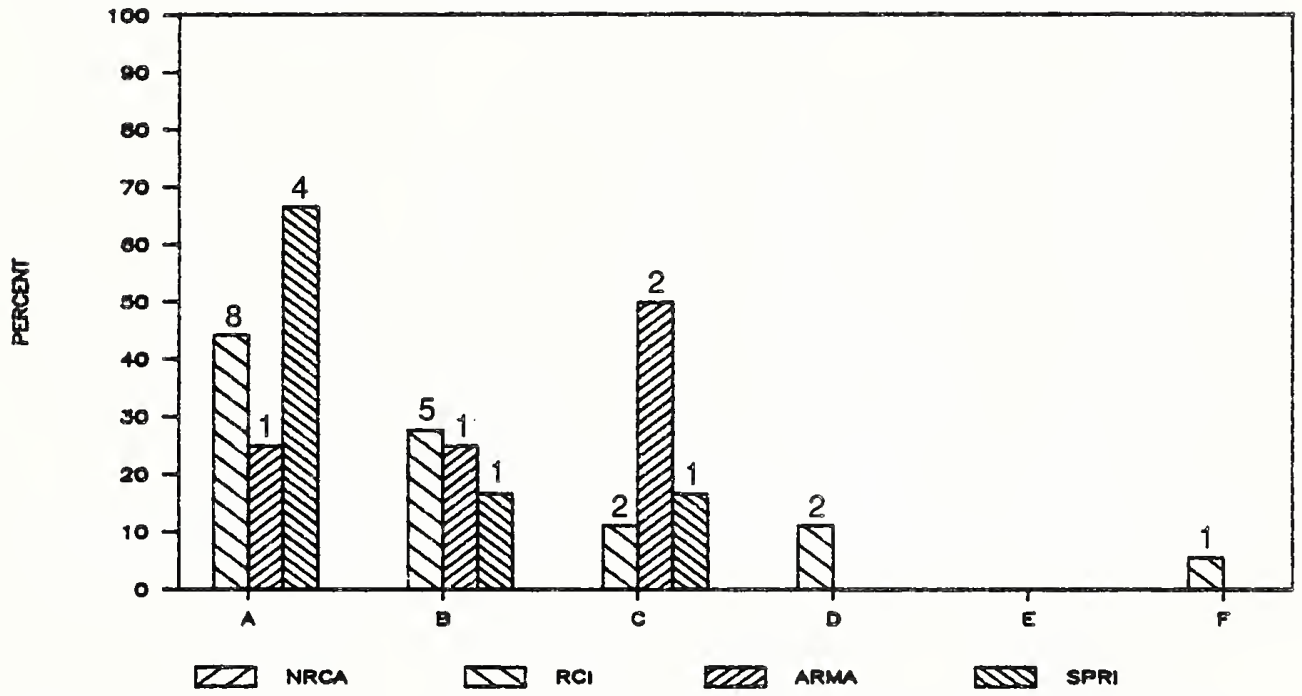

14. Were you able to observe the condition of the mechanical fasteners and stress plates (or batten bars) in these roofs: (circle one)

a. not at all

b. about $10 \%$ of the roofs

c. about 258 of the roofs

d. about $50 \%$ of the roofs

e. about $75 \%$ of the roofs

f. about all cases

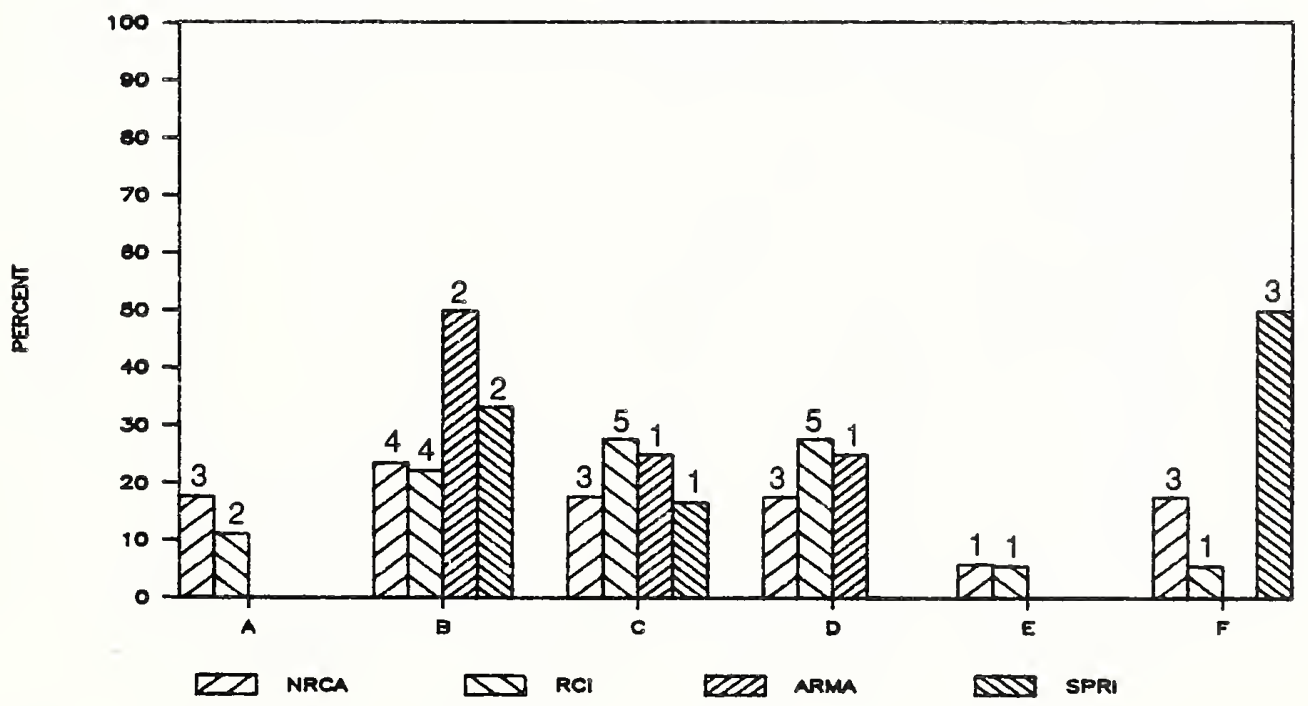


15. When you were able to observe the condition of the mechanical fasteners and stress plates, in about what percentage did the fasteners show some corrosion: (circle one)

a. not at all

b. about $10 \%$ of the roofs

c. about $25 \%$ of the roofs d. about $50 \%$ of the roofs

e. about $75 \%$ of the roofs

f. about all cases

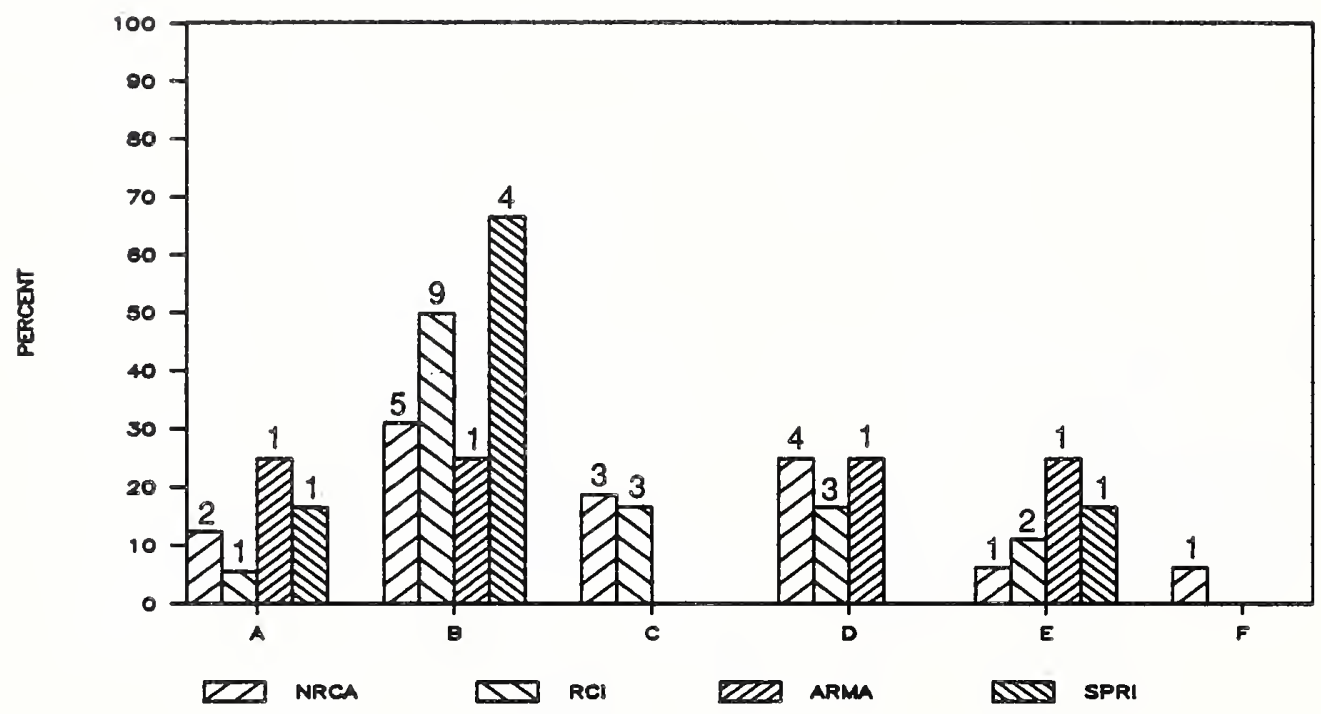

16. Was the corrosion you observed: (circle one)

a. primarily on the fastener

b. primarily on the stress plate (or batten bar)

c. generally on both the fastener and the stress plate (or batten bar)

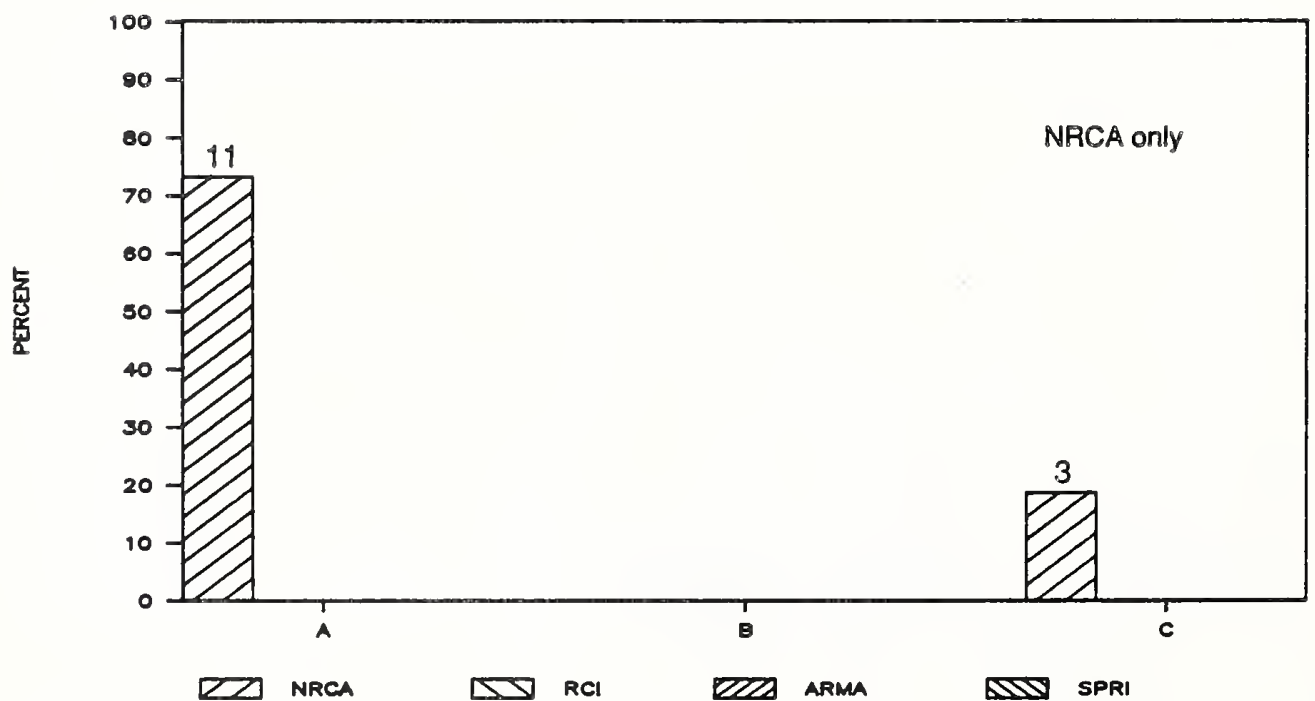


17. From your experience (when corrosion was found), what was your general impression of the corrosion observed on the fasteners: (circle as many as appropriate)

a. evidence of rust over some of the surface

b. evidence of rust over essentially the entire surface

c. thinning of the fastener shank

d. separation of the fastener from the deck

e. separation of the fastener into two (or more) pieces

f. preferential corrosion of the fastener at the stress plate

g. preferential corrosion of the fastener at the deck

h. other

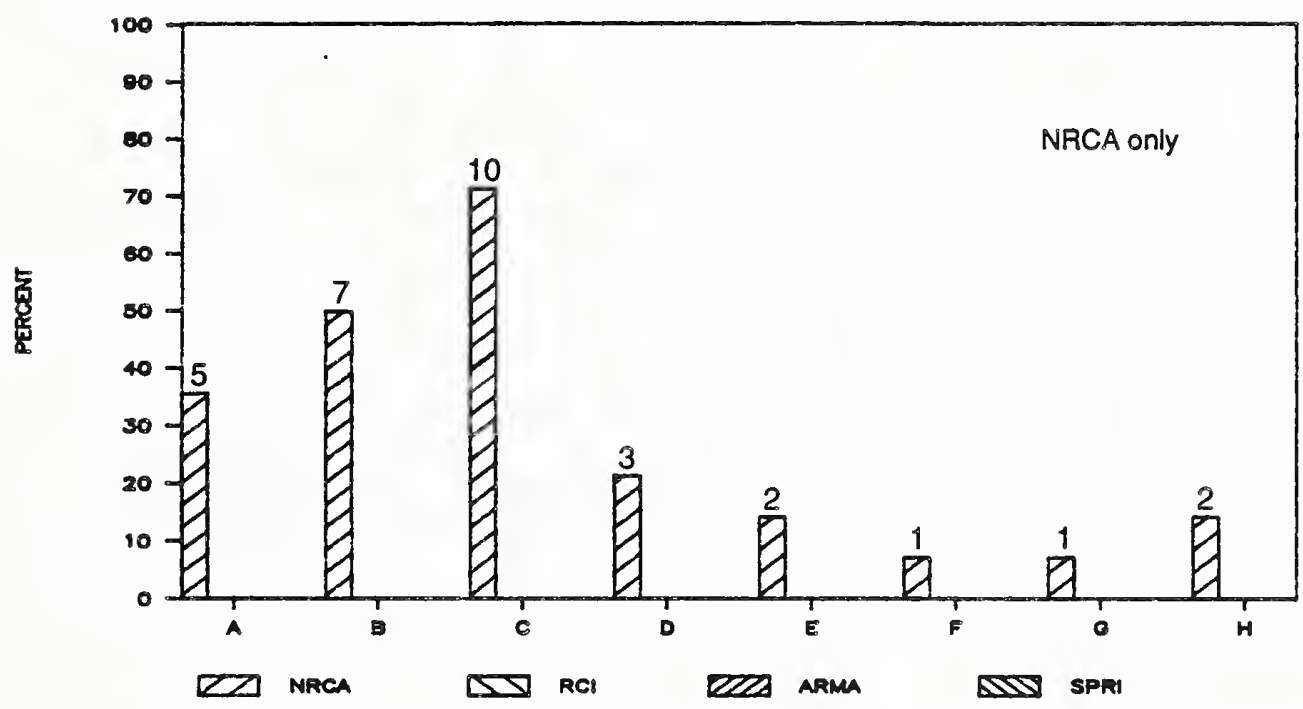

18. If, in the previous question, you circled more than one answer, please

indicate the type of corrosion observation that predominated: (circle one)

a. evidence of rust over some of the surface

b. evidence of rust over essentially the entire surface

c. thiming of the fastener shank

d. separation of the fastener from the deck

e. separation of the fastener into two (or more) pieces

$\mathrm{f}$. preferential corrosion of the fastener at the stress plate

g. preferential corrosion of the fastener at the deck

h. other

i. none predominated

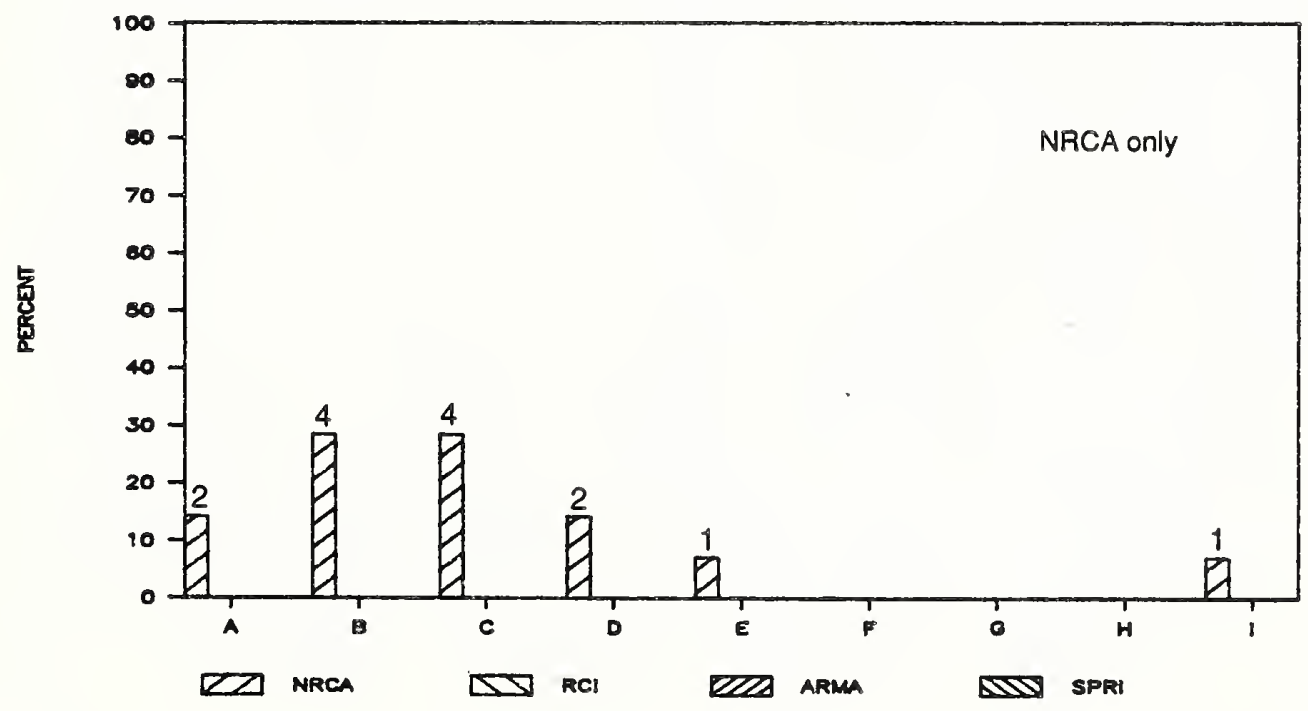


19. When observed, what was the type of corrosion of carbon-steel fasteners: (circle as appropriate)
a. evidence of rust over some of the surface
b. evidence of rust over essentially the entire surface
c. thiming of the fastener shank
d. separation of the fastener from the deck
e. separation of the fastener into two (or more) pieces
f. preferential corrosion of the fastener at the stress plate
g. preferential corrosion of the fastener at the deck
h. other

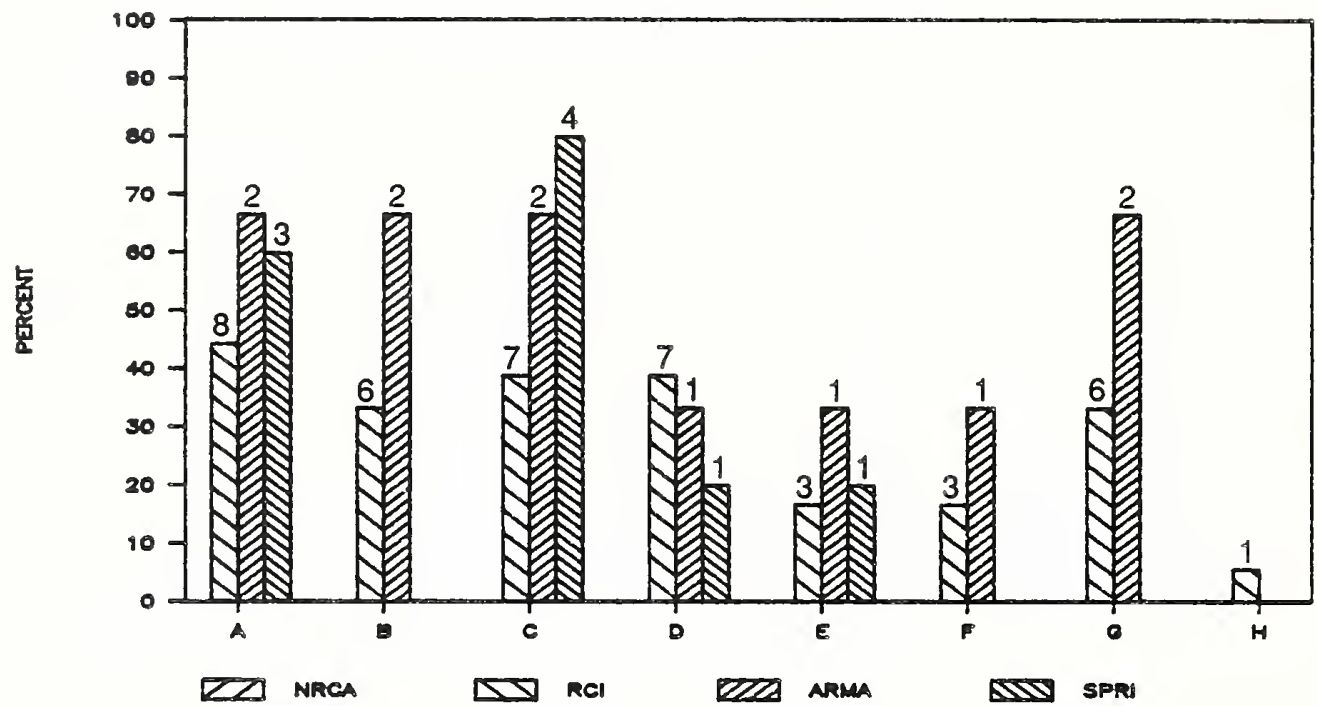

20. If, in the previous question, you circled more than one answer, please indicate the type of corrosion observation that predominated: (circle one)
a. evidence of nust over some of the surface
$\mathrm{b}$. evidence of rust over essentially the entire surface
c. thinning of the fastener shank
d. separation of the fastener from the deck
e. separation of the fastener into two (or more) pieces
f. preferential corrosion of the fastener at the stress plate
g. preferential corrosion of the fastener at the deck
h. other
i. none predominated

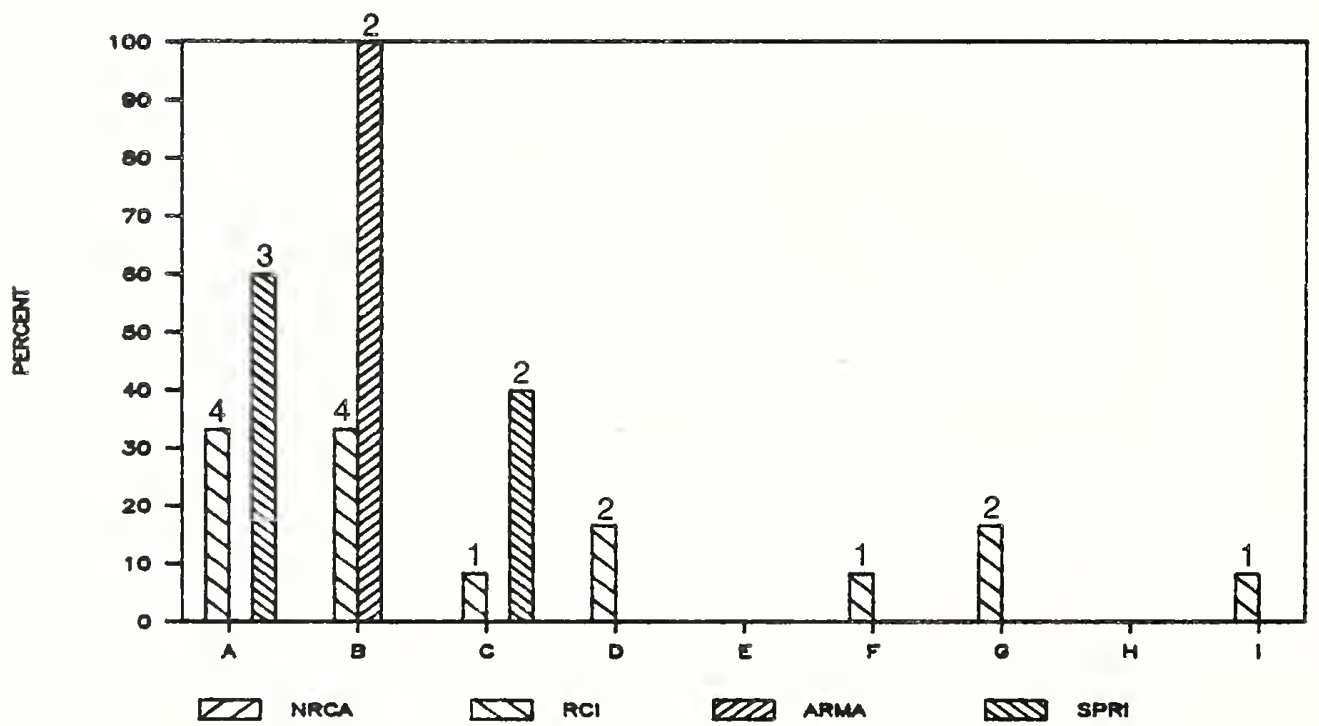


21. When corrosion of fasteners was observed, what was the surface treatment on carbon steel fasteners: (circle as many as appropriate)
a. oil
b. black oxide
c. zinc coatings

d. polymeric

e. other

f. do not know

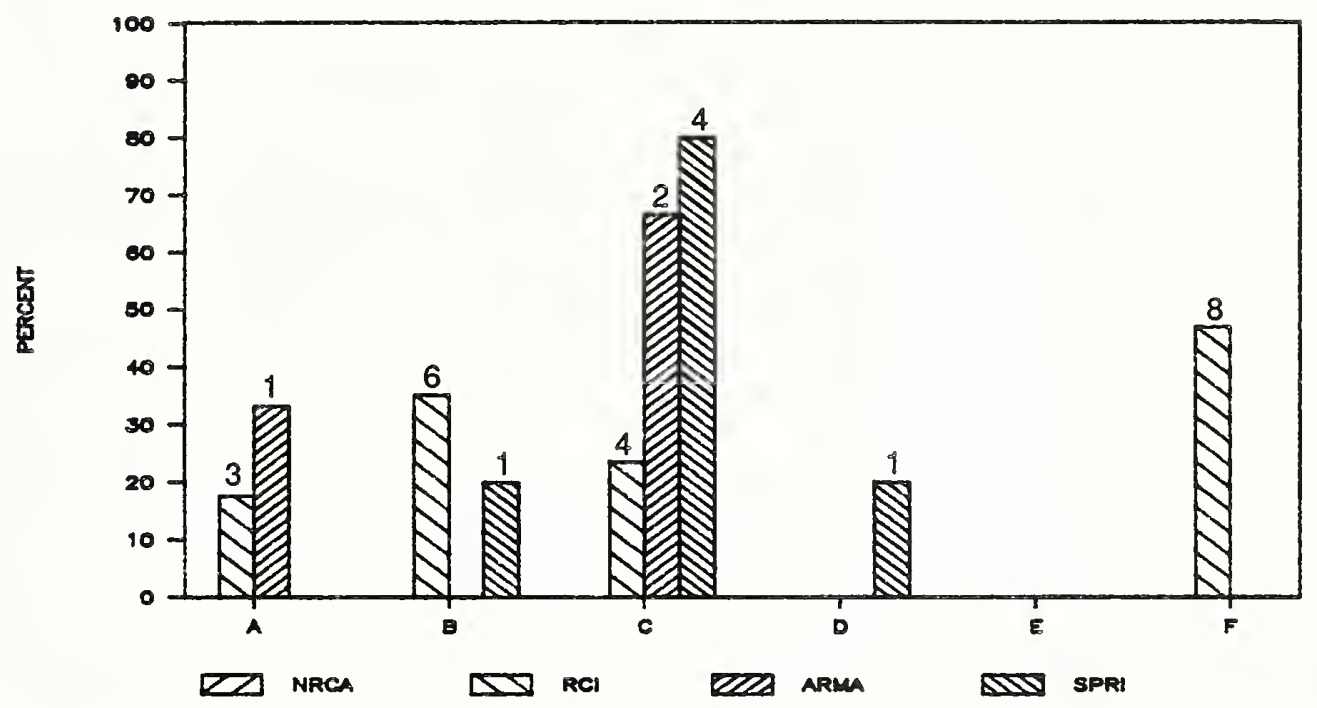

22. If, in the previous question, you circled more than one answer, please indicate the type of treatment that predominated: (circle one)
a. oil
b. black oxide
d. polymeric
c. zinc coatings
e. other
f. none predominated

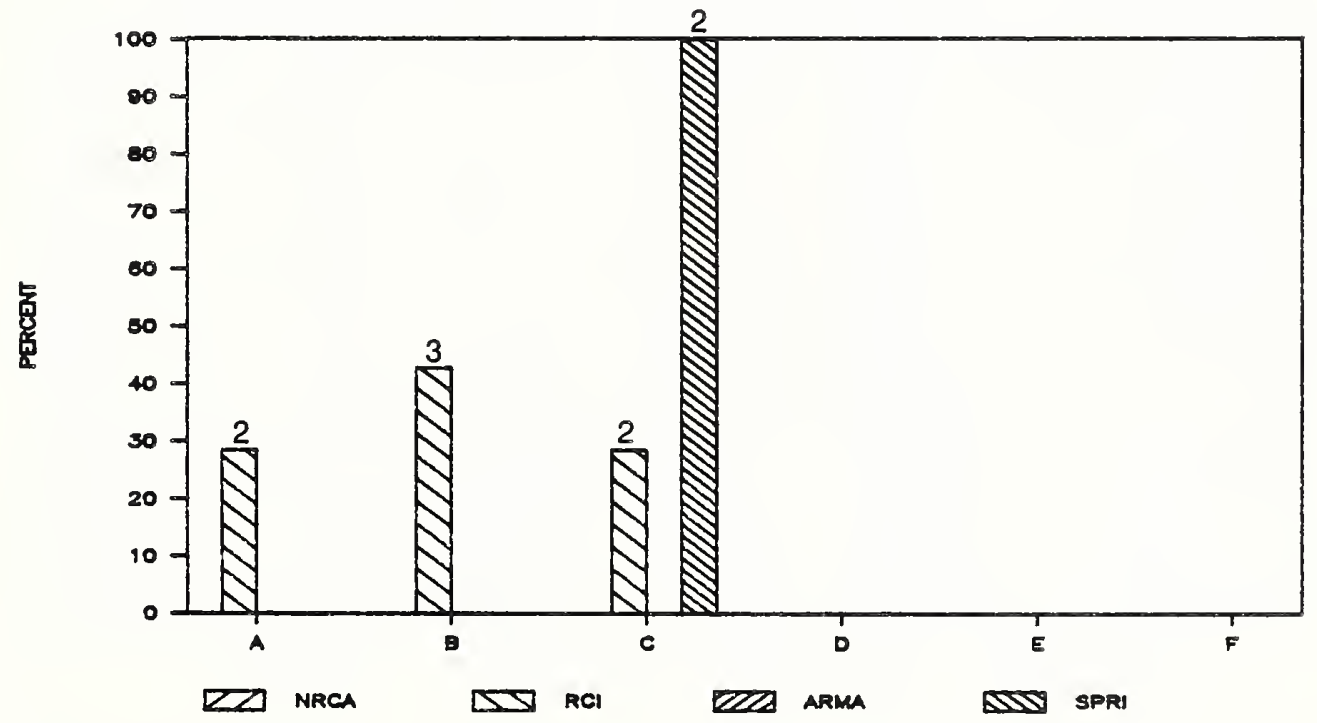


23. Is the type of fastener, indicated in question \# 22, available on today's market: (circle one)
a. yes
c. do not know

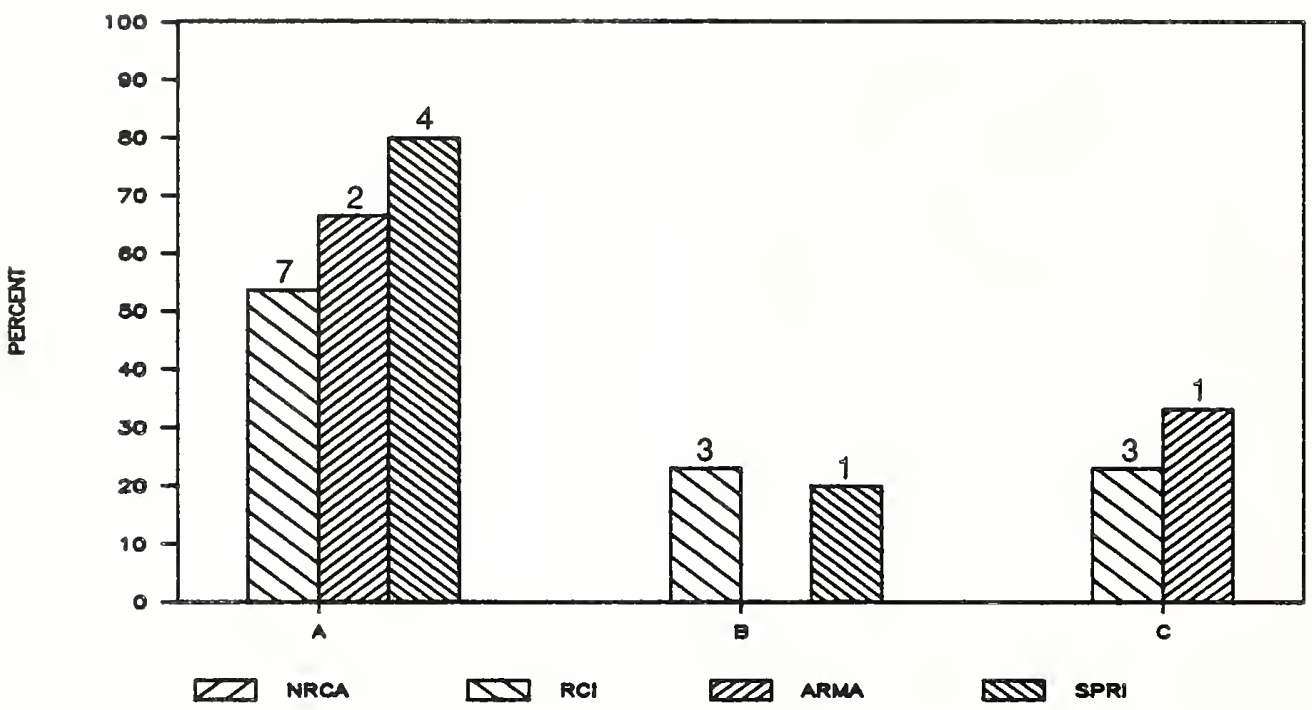

24. When observed, what was the type of corrosion of stainless steel fasteners: (circle as many as appropriate)

a. rusting

b. pitting

c. cracking (cracks or fracture)

d. preferential corrosion of the surface in contact with the stress plate

e. preferential corrosion of the surface in contact with the

deck

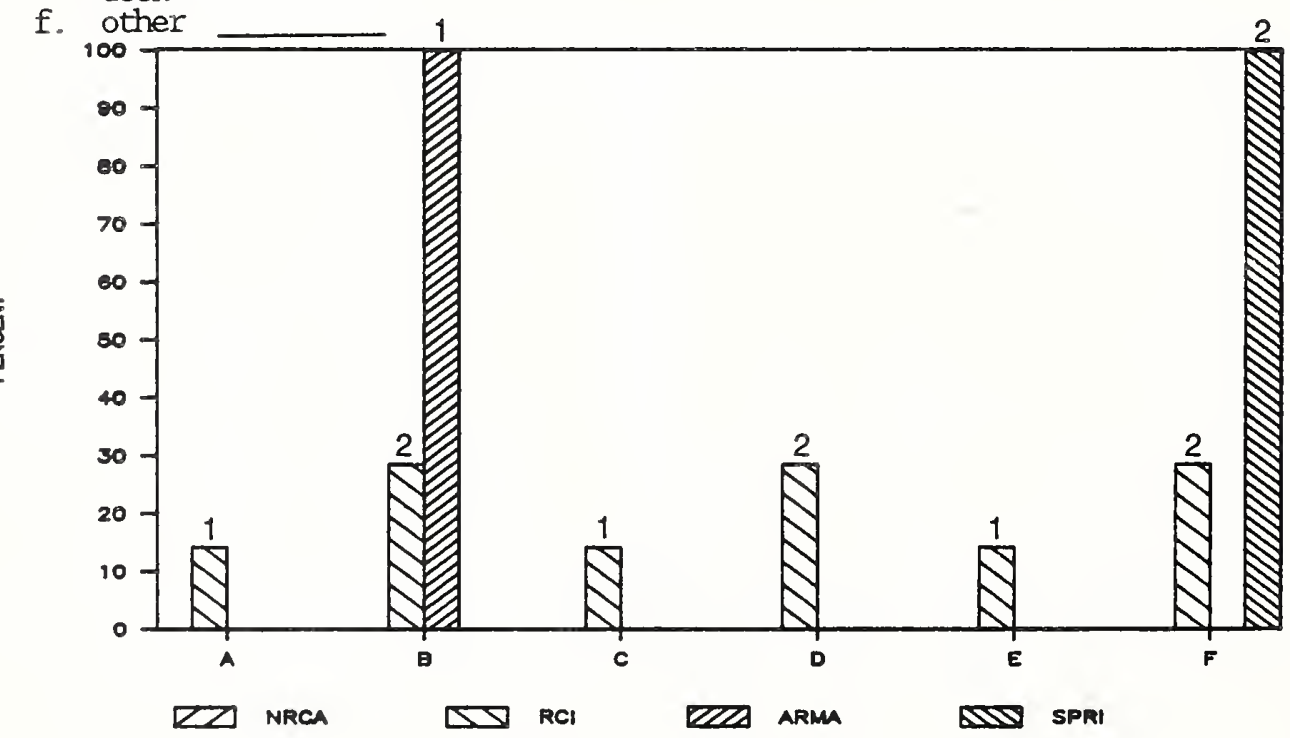


25. If, in the previous question, you circled more than one answer, please indicate the one type of corrosion observation that predominated: (circle one)
a. rusting
b. pitting
c. cracking (cracks or fracture)
d. preferential corrosion of the surface in contact with the stress plate
e. preferential corrosion of the surface in contact with the deck
f. other
g. none predominated

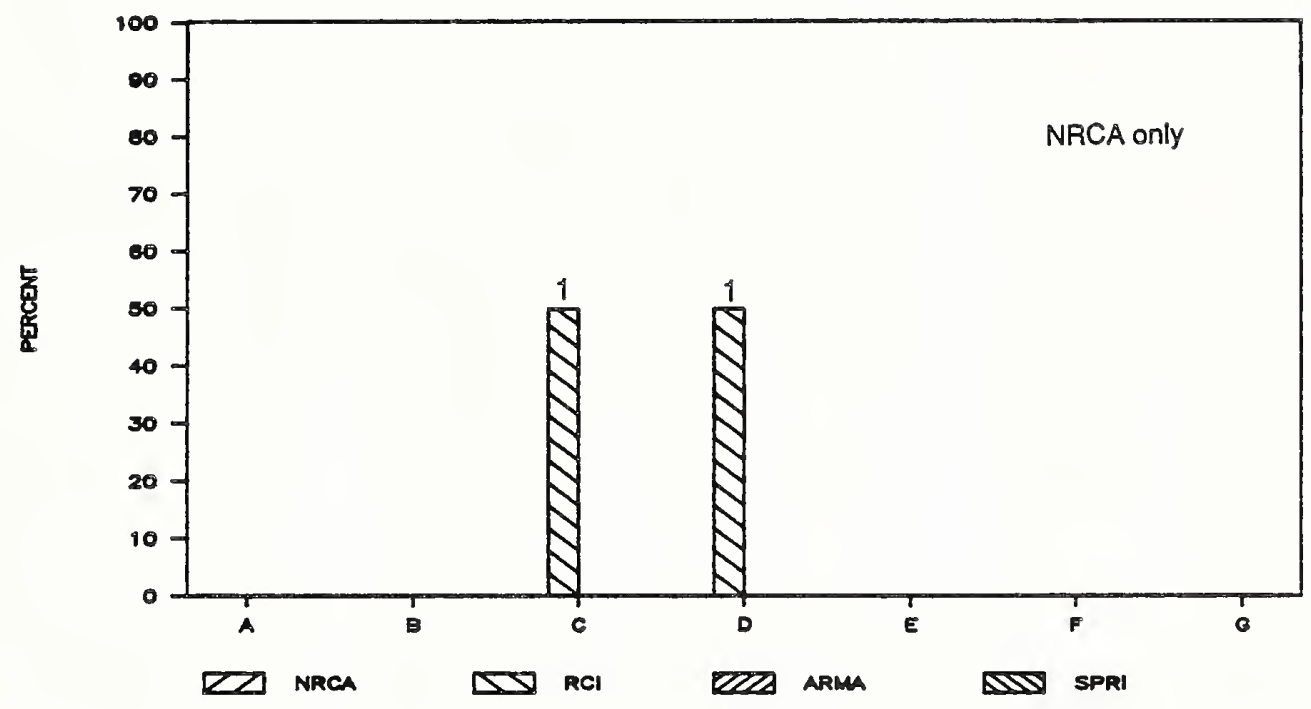

26. From your experience (when corrosion was found), what was your general impression of the corrosion observed on the stress plates (or batten bars): (circle as mary as appropriate)

a. evidence of rusting on the top

$\mathrm{b}$. evidence of rusting on the bottom

c. preferential corrosion at the surface area in contact with the fastener

d. impairment of the structural integrity (e.g., crmbling) of the plate, or loss of contact with the fastener

e. other

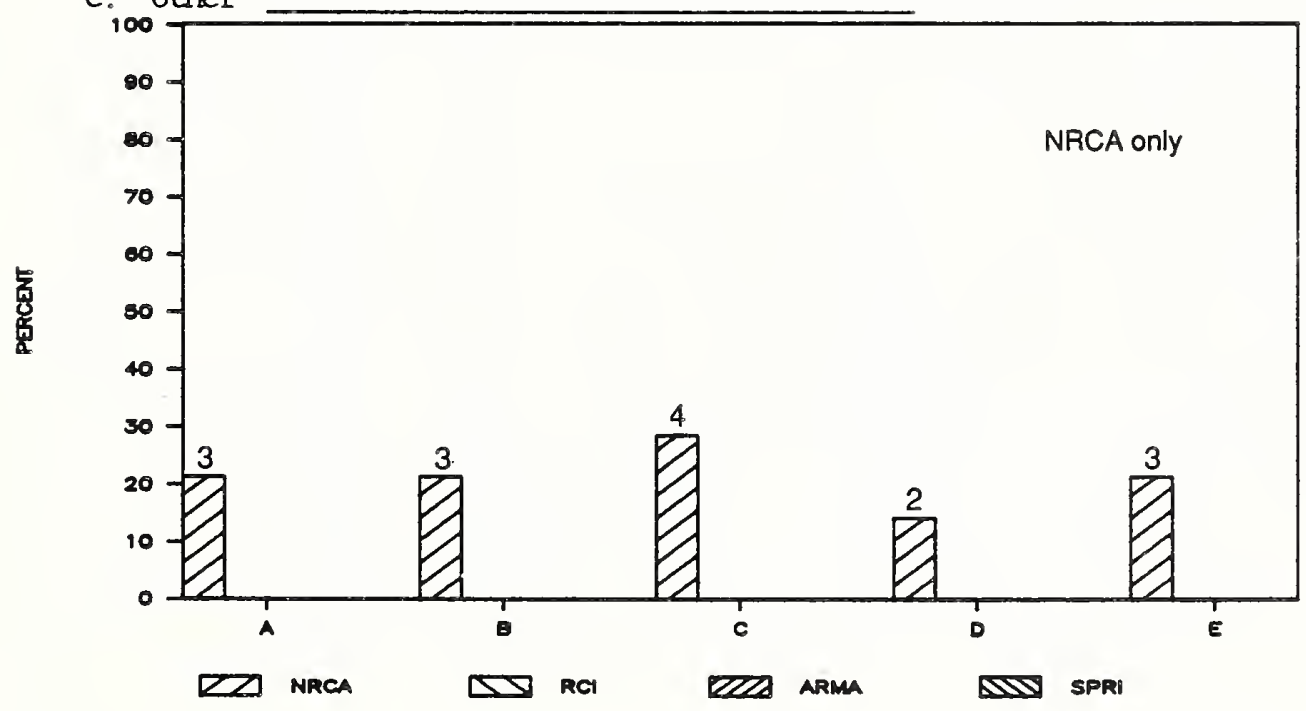


27. If, in the previous question, you circled more than one answer, please indicate the one type of corrosion observation that predominated: (circle one)

a. evidence of rusting on the top

b. evidence of rusting on the bottom

c. preferential corrosion at the surface area in contact with the fastener

d. impairment of the structural integrity (e.g., crumbling) of the plate, or loss of contact with the fastener

e. other

f. none predominated

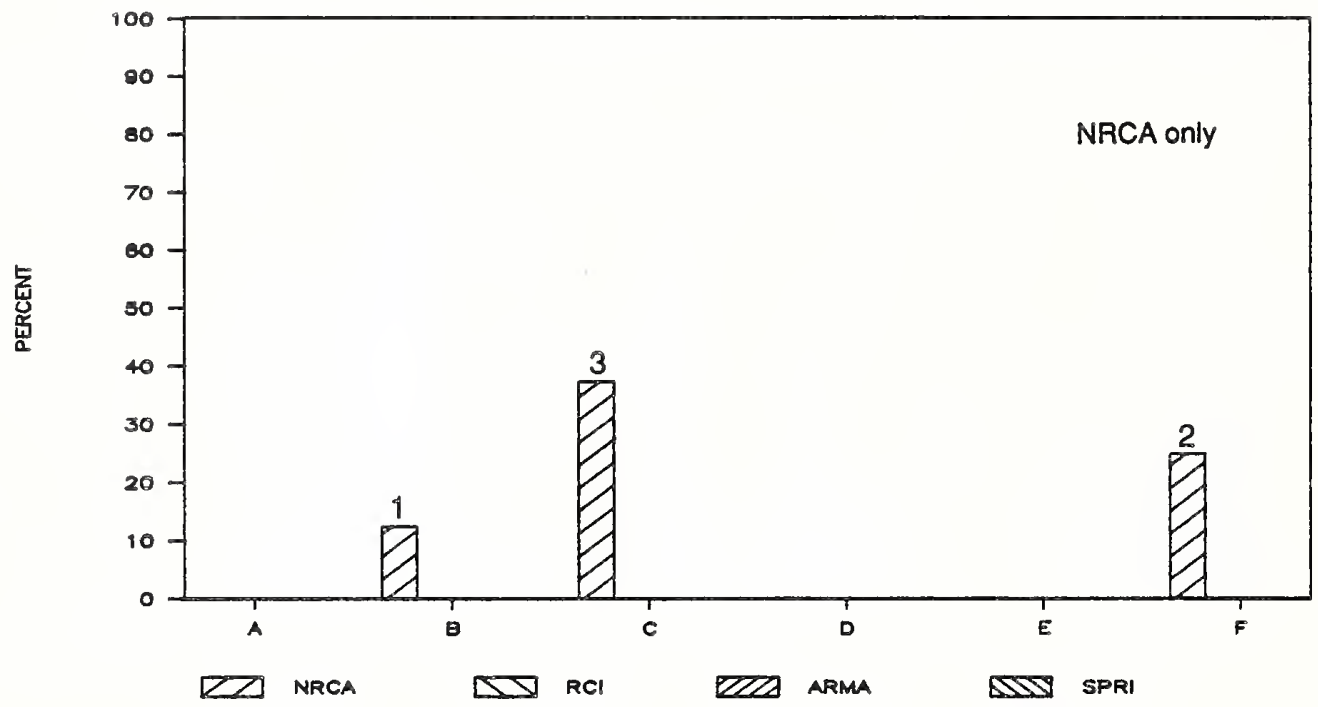

28. When you were able to observe the condition of the mechanical fasteners and stress plates, in about what percentage did the stress plates show some corrosion: (circle one)

a. not at all

b. about $10 \%$ of the roofs

c. about $25 \%$ of the roofs d. about $50 \%$ of the roofs

e. about $75 \%$ of the roofs

f. about all cases

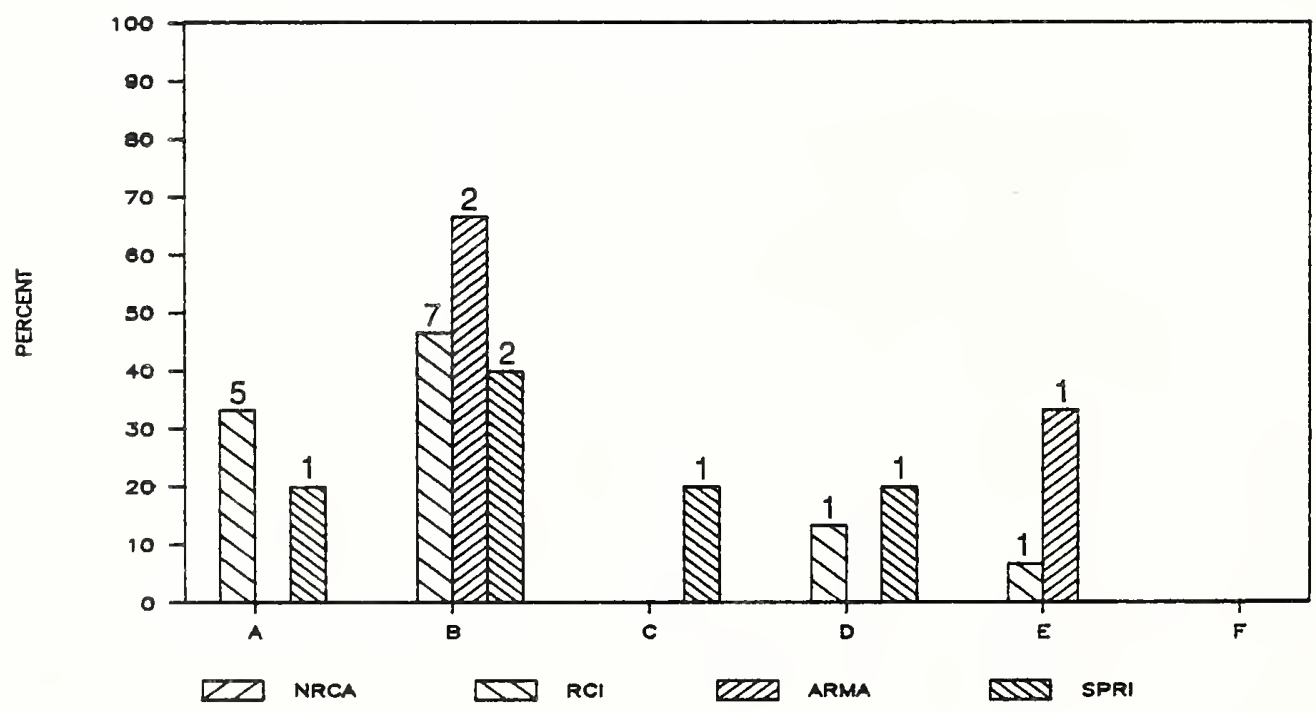


29. When observed, what was the type of corrosion of carbon-steel stress plates: (circle as appropriate)

a. nusting on top surface

b. nusting on bottom surface

c. rusting on both top and bottom surfaces

d. preferential corrosion at the contact with the fastener

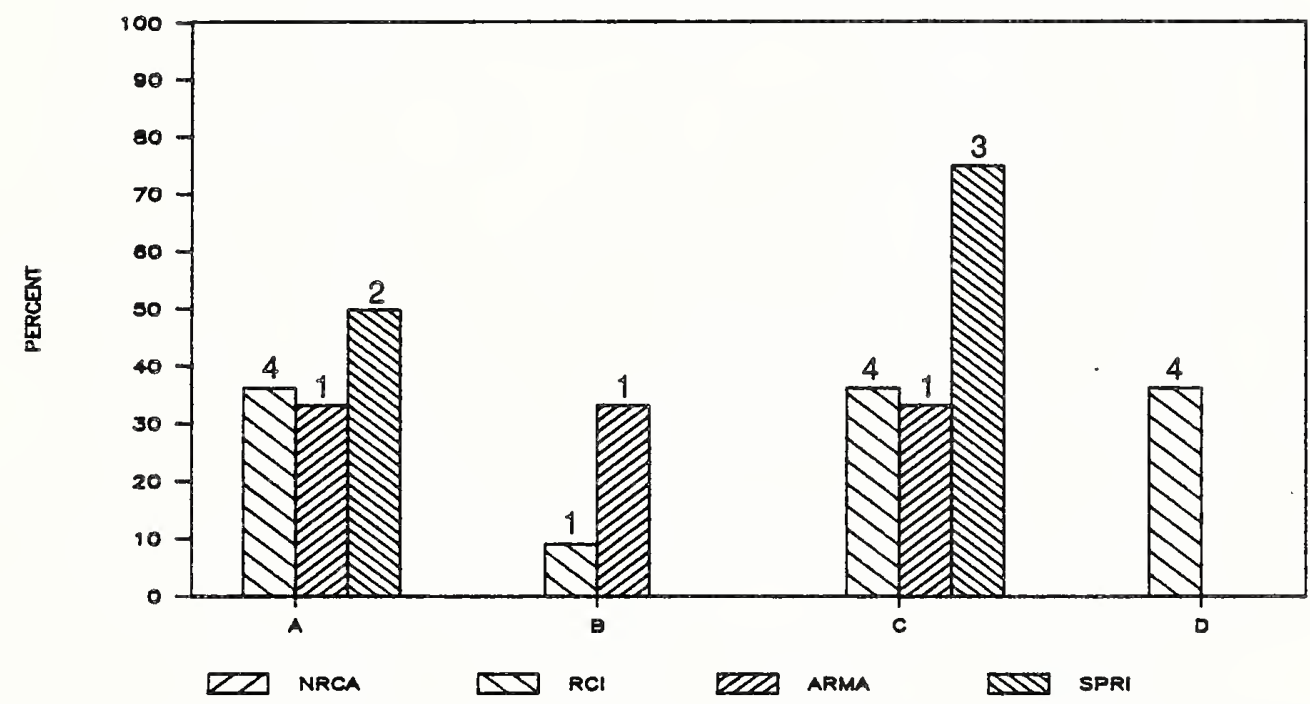

30. If, in the previous question, you circled more than one answer, please indicate the type of corrosion observation that predominated: (circle one)

a. rusting on top surface

b. nusting on bottom surface

c. rusting on both top and bottom surfaces

d. preferential corrosion at the contact with the fastener

e. none predominated

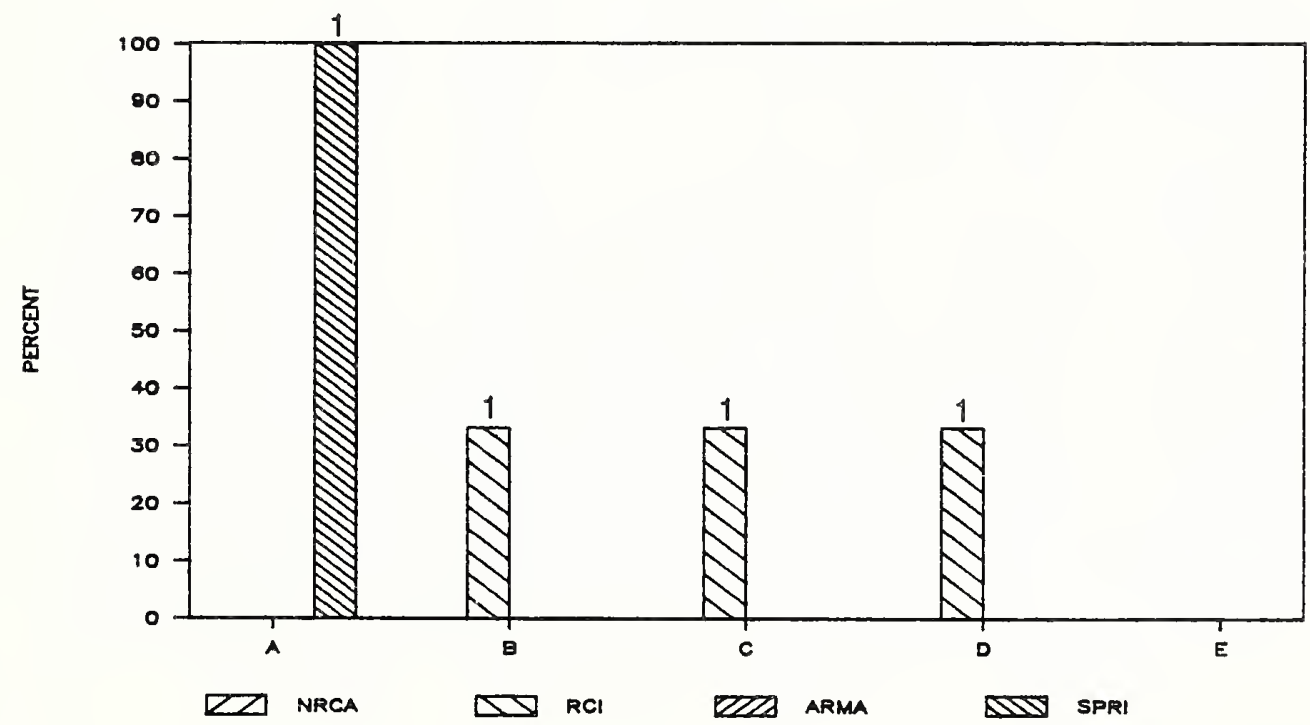


31. In cases where you observed corrosion, were the fasteners and stress plates (or batten bars) used: (circle one)
a. primarily for attaching the insulation
b. primarily for attaching both the insulation and membrame
c. about equally for both types of applications

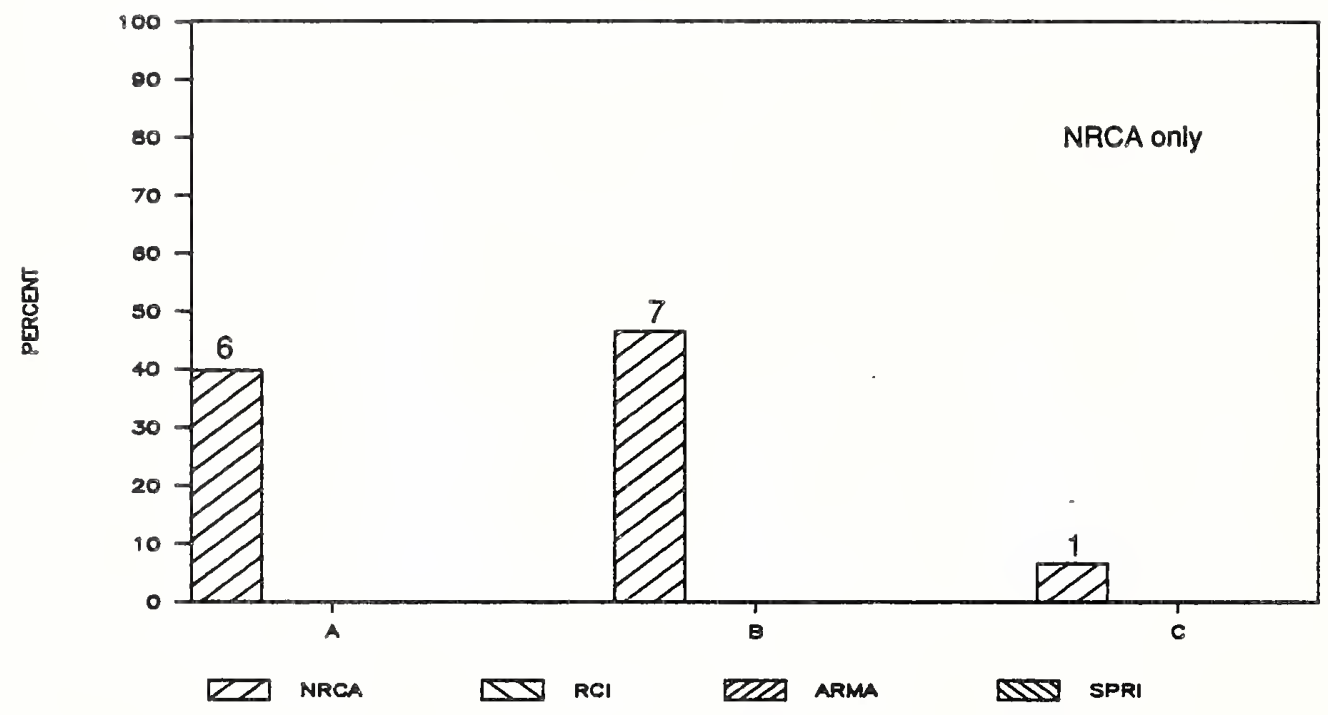

32. In cases where you observed corrosion of the fasteners or stress plates, how frequently was water found in contact with them: (circle one)
a. always
d. seldom
b. frequently
e. never
c. some times
f. do not know

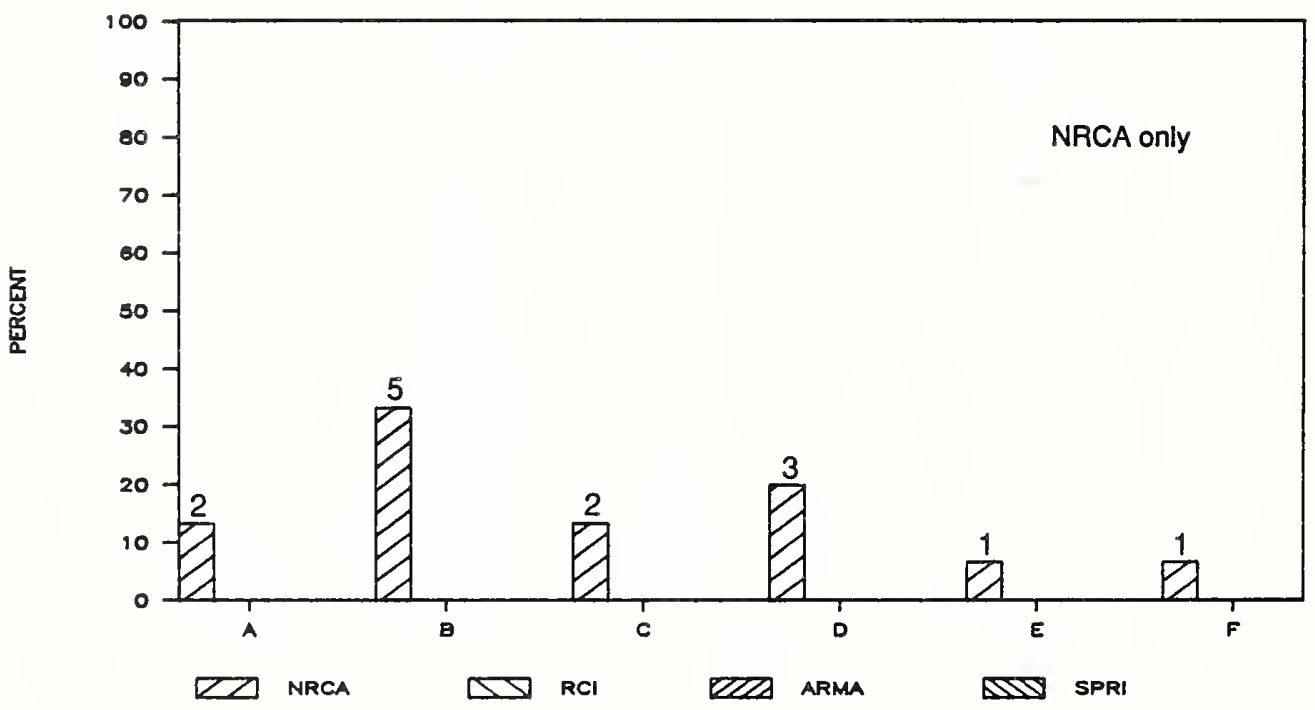


33. Do you know whether any of the corroded fasteners, installed since 1986, had been subjected to the Factory Mutual test procedure for corrosion resistance: (circle one)
a. yes
b. no

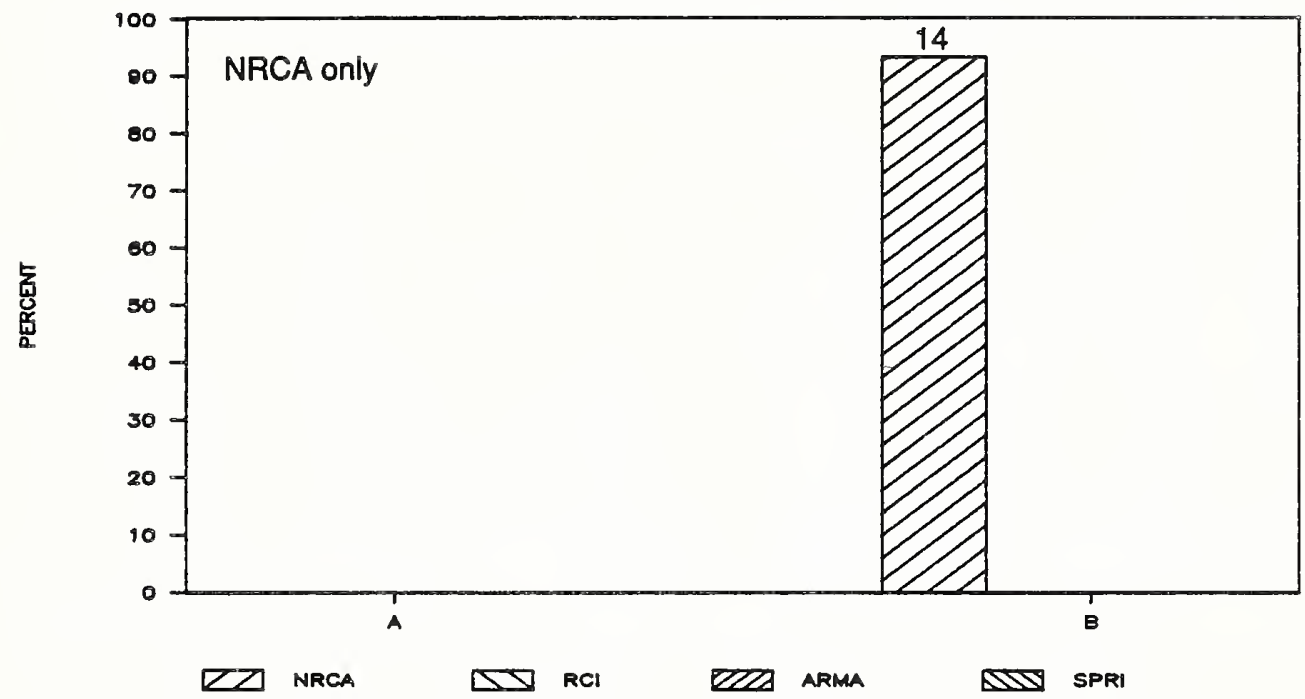

34. What were the ages of the roofs where corrosion was observed: (circle as many as appropriate)
a. 1 - 2 years
b. 3 - 4 years
d. 7 - 8 years
c. 5 - 6 years
e. 9 - 10 years
f. more than 10 years

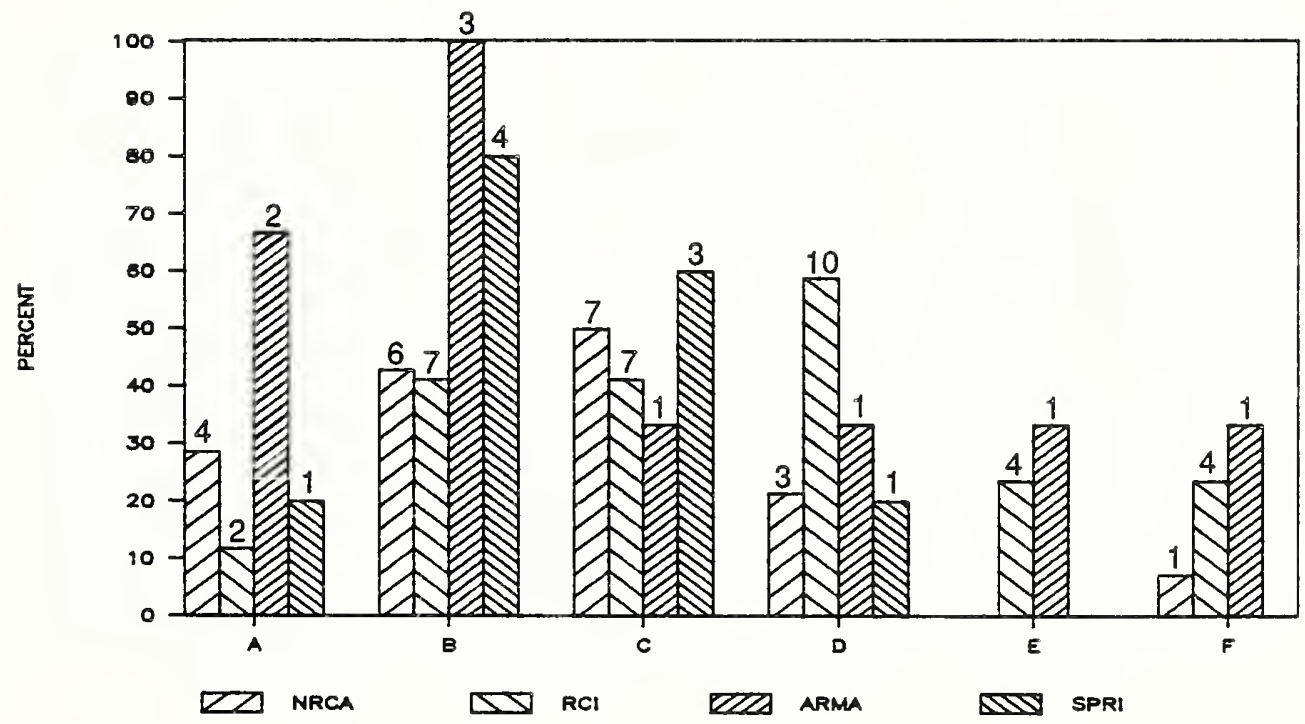


35. If, in the previous question, you circled more than one answer, please indicate the one age grouping that predominated: (circle one)
a. 1 - 2 years
b. 3 - 4 years
d. 7 - 8 years
c. 5 - 6 years
e. 9 - 10 years
f. more than 10 years
g. none predominated

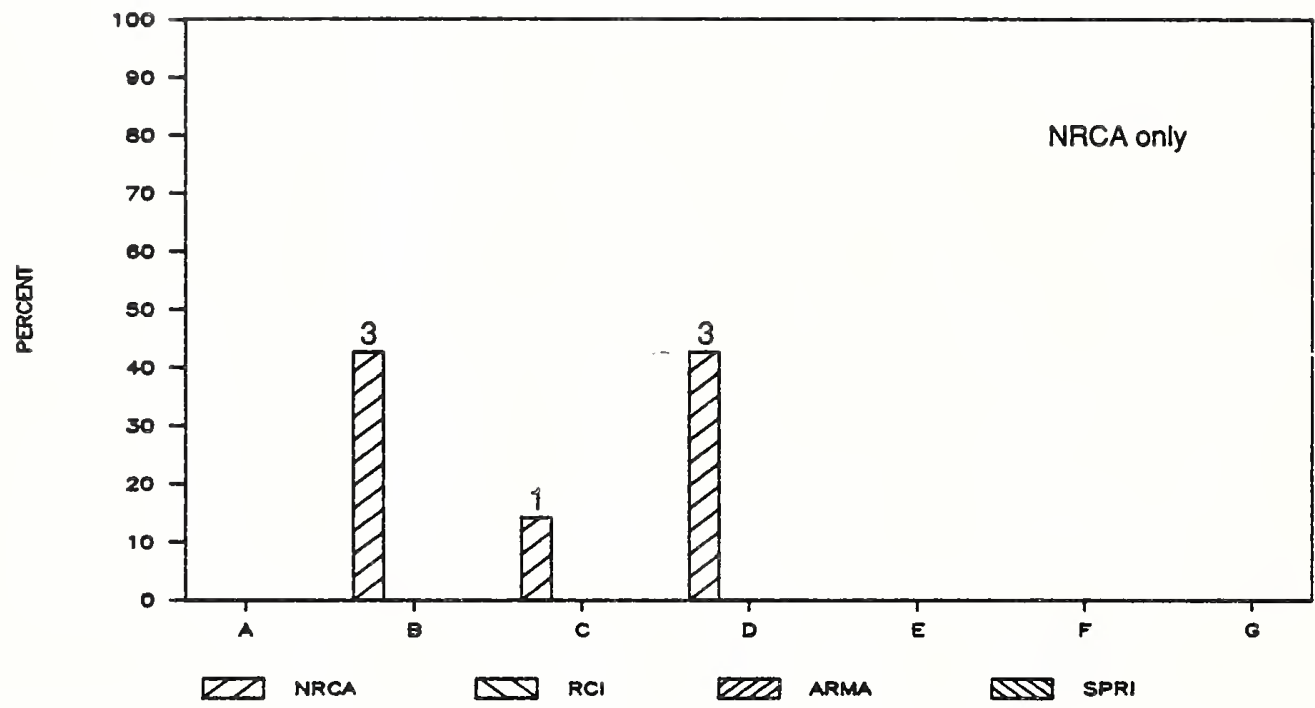

36. What were the types of roofing projects where you observed corrosion of fasteners: (circle as many as appropriate)

a. new construction

c. recover without tearoff

b. reroofing with tearoff

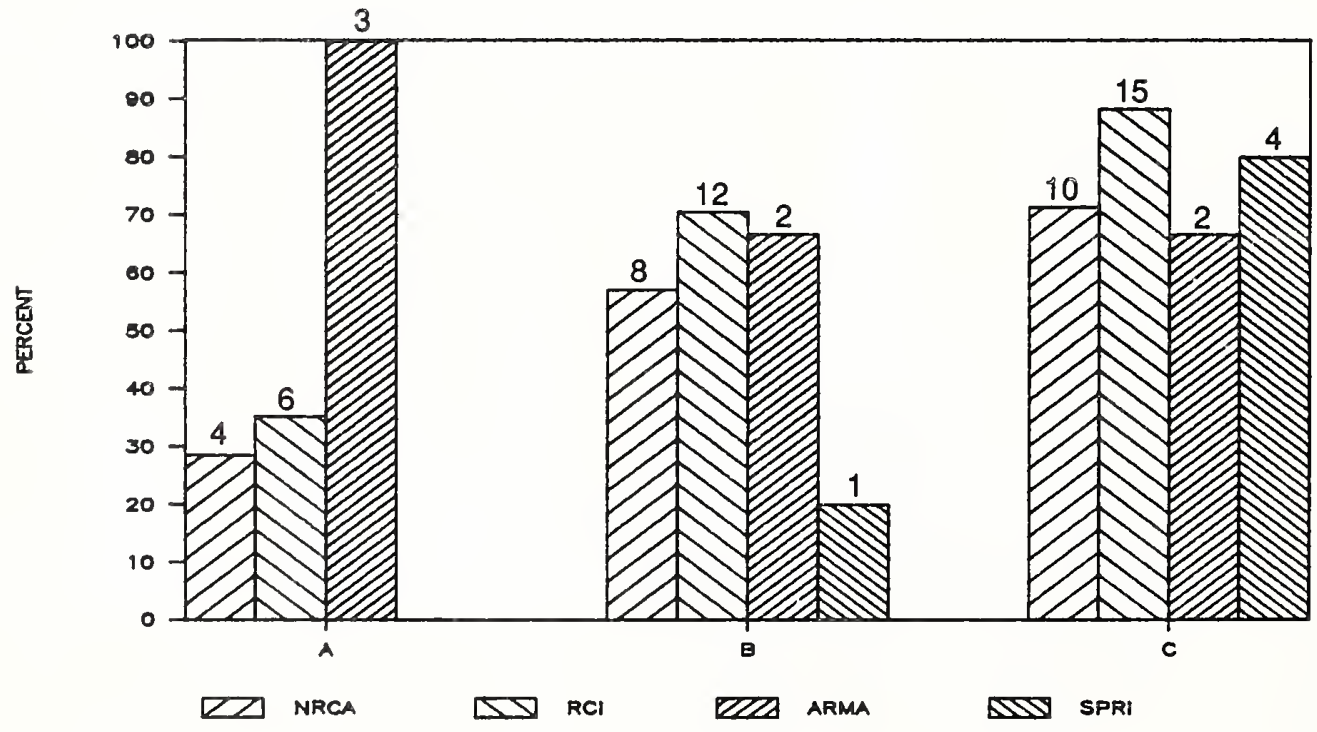


37. If, in the previous question, you circled more than one answer, please indicate the one type of project which predominated: (circle one)

a. new construction

b. reroofing with tearoff c. recover without tearoff

d. none predominated

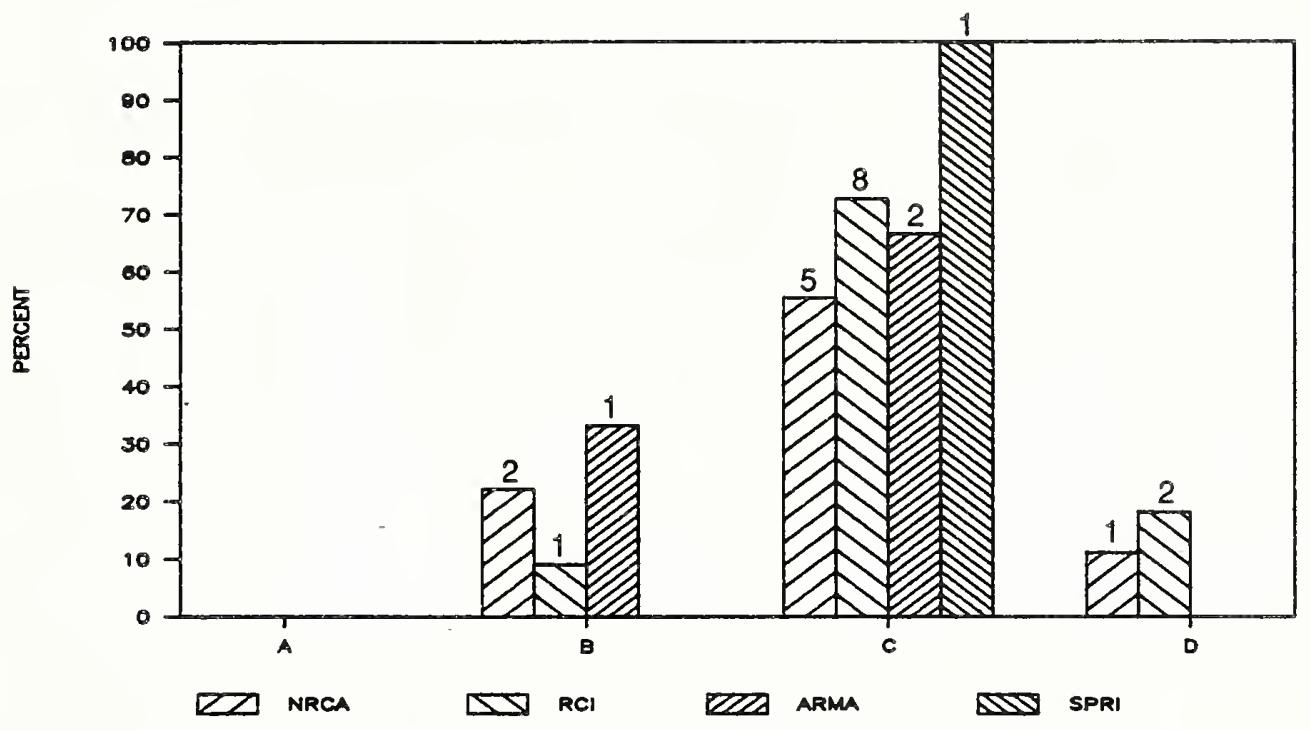

38. What were the membrane systems where corrosion of fasteners and stress plates (or batten bars) was observed: (circle as many as appropriate)

Bituminous

a. built-up

b. modified bituminous
Single-Ply

c. EPDM

d. PVC

e. other

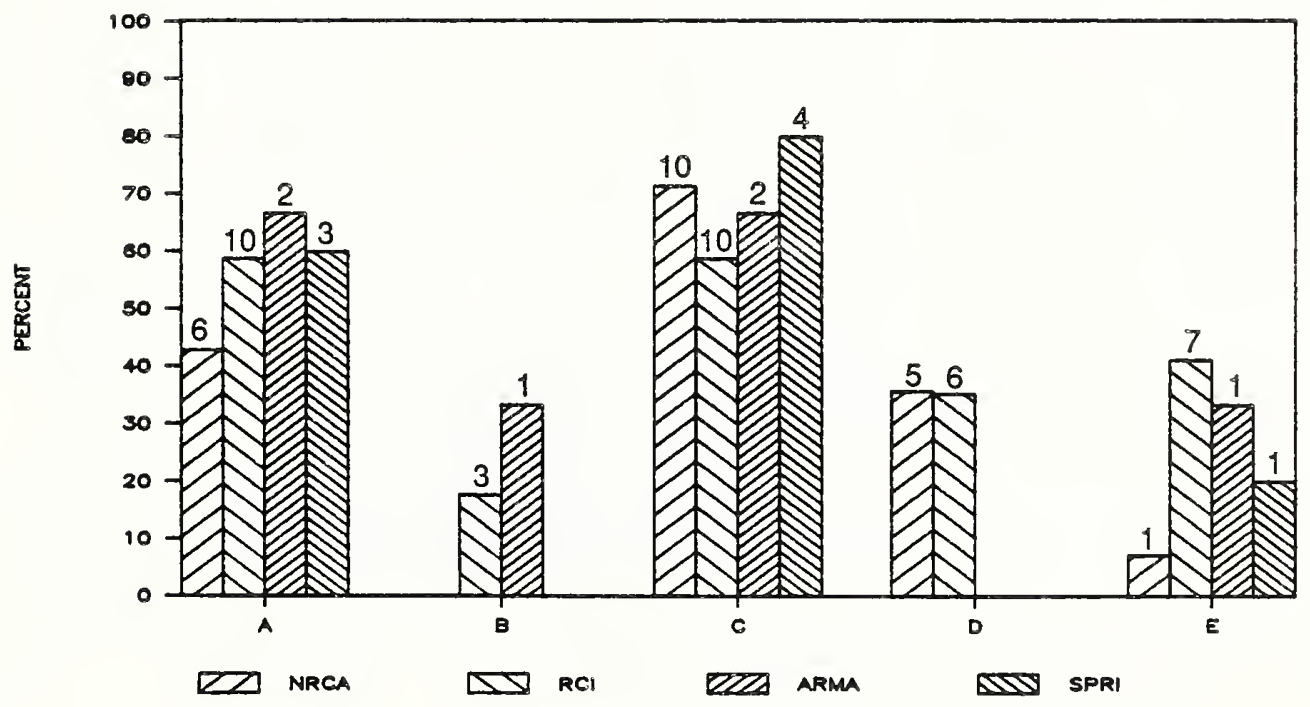


39. If, in the previous question, you answered more than one system, please indicate the relative extent to which one type of membrane system predominated: (circle one)
a. almost all bituminous
b. primarily bituminous with some single-ply
c. about the same for both types
d. primarily single-ply with some bituminous
e. almost all single-ply

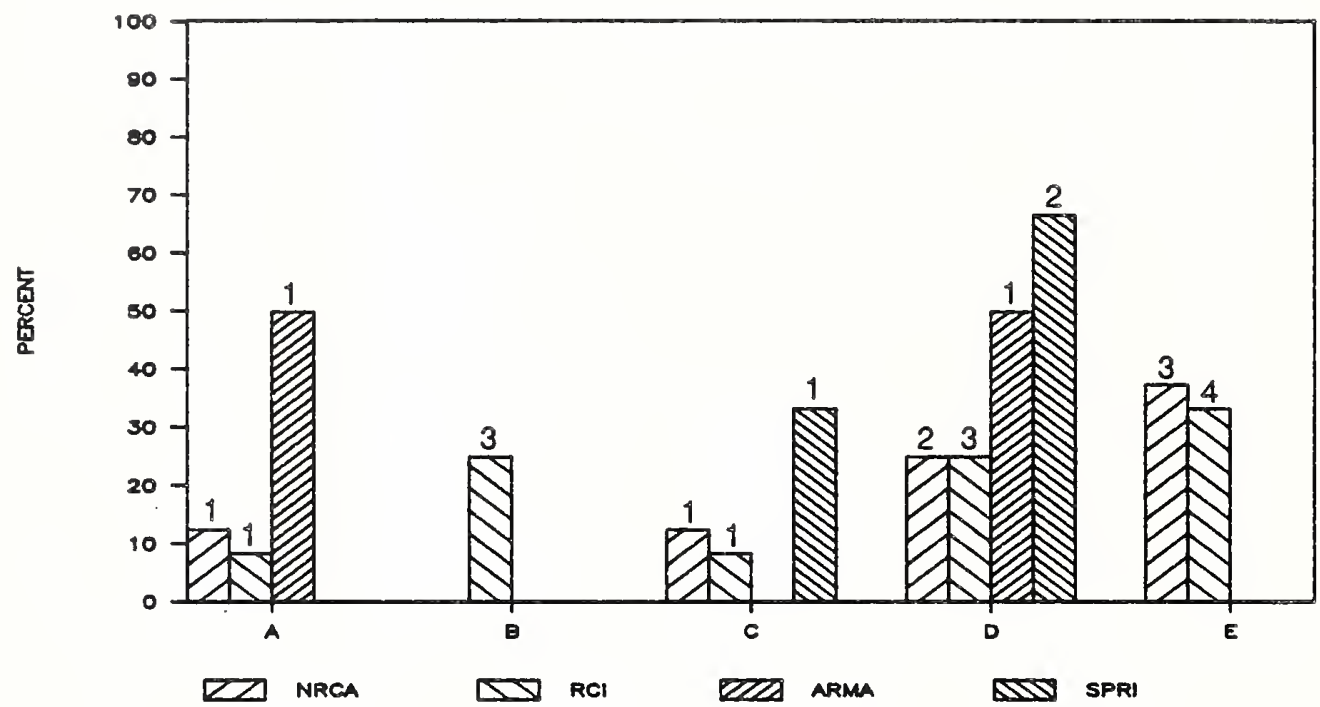

40. Were the membranes generally leaking in cases where corrosion of fasteners was observed: (circle one)
a. do not know
b. always
d. some times
c. frequently
e. seldom
f. never

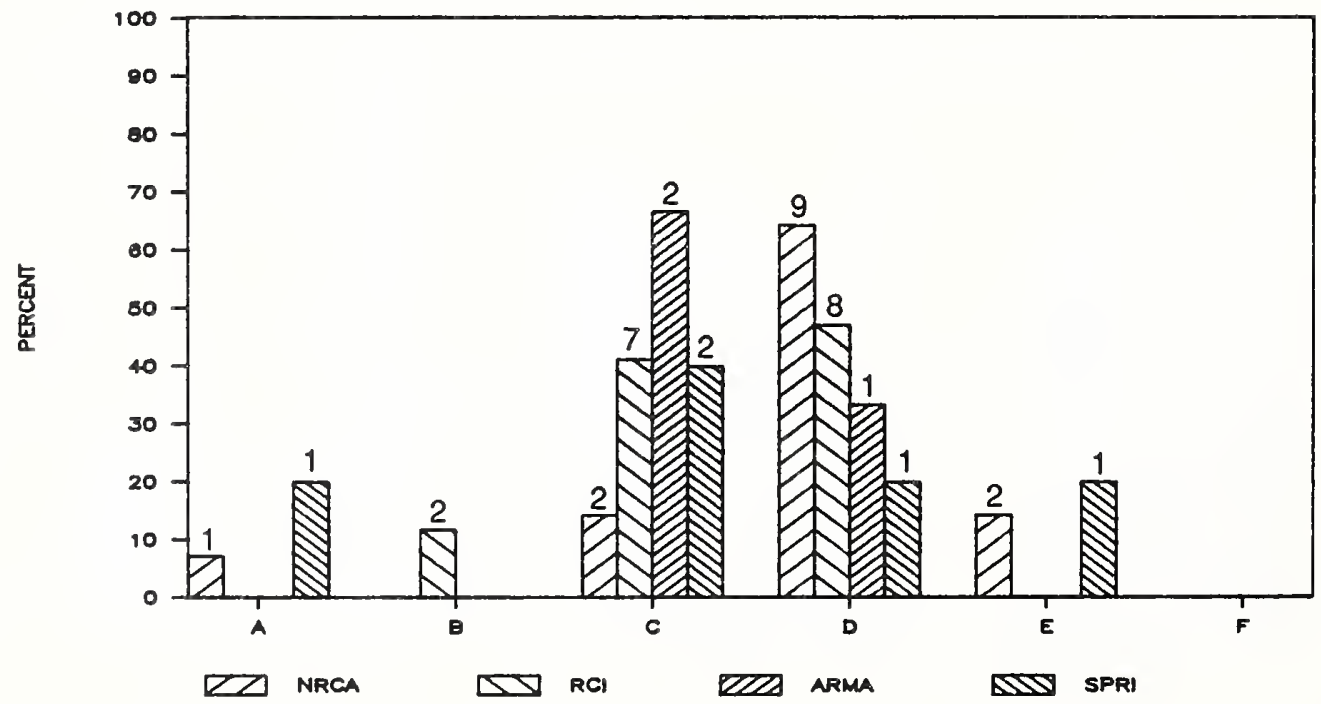


41. Were vapor retarders present in the systems experiencing corrosion of fasteners: (circle one)
a. do not know
b. always
d. some times
c. frequently
e. seldom
f. never

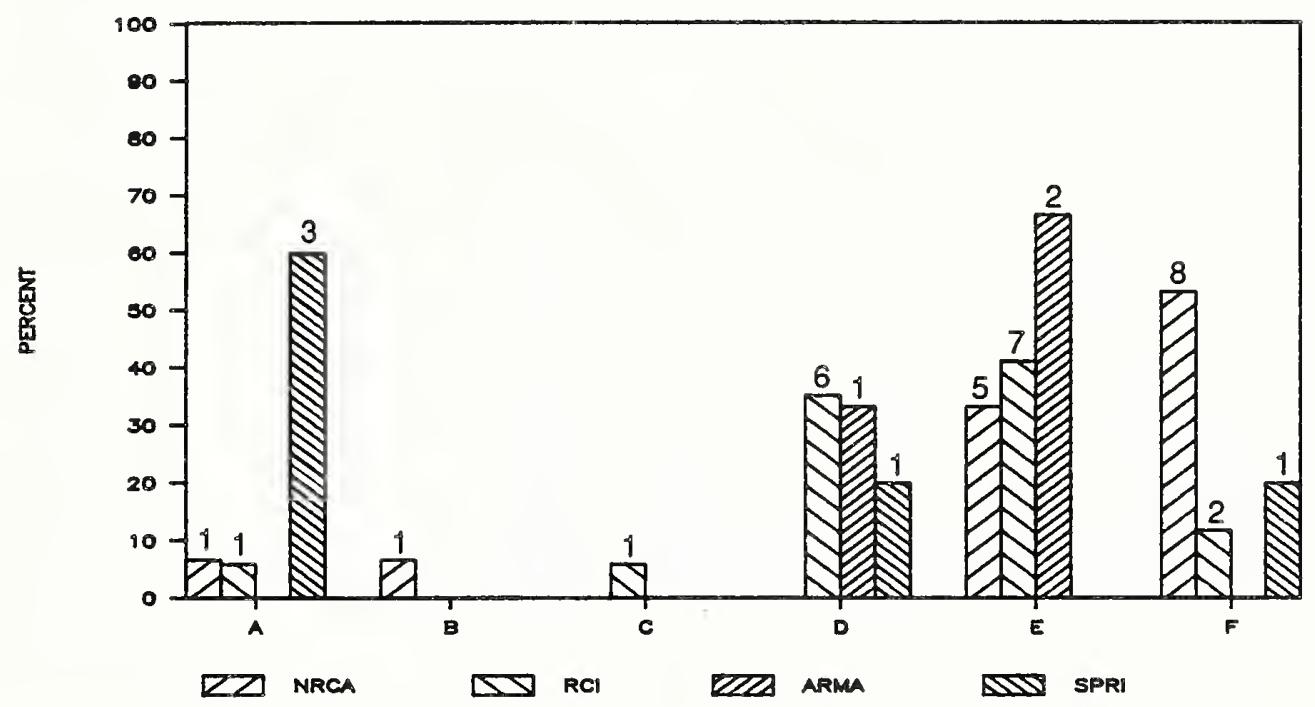

42. What were the types of insulations in the systems experiencing corrosion of fasteners: (circle as many as appropriate)
a. composite board
b. fibrous glass
c. mineral board, e.g., perlite
d. polystyrene
e. polyurethane
g. wood fiberboard
h. phenolic
$i$. more than one type
j. other
k. no insulation
f. polyisocyanurate

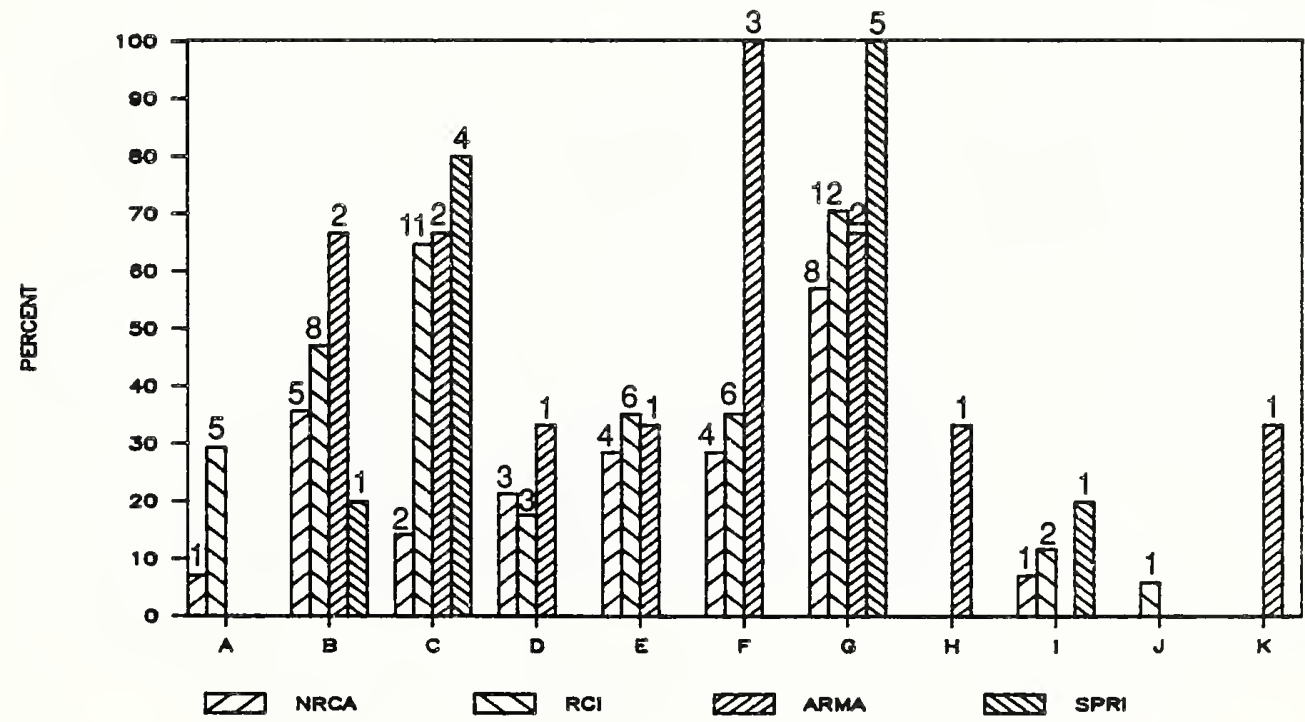


43. If, in the previous question, you circled more than one answer, please indicate the one type of insulation most often found in systems experiencing corrosion of fasteners: (circle one)
a. composite board
b. fibrous glass
c. mineral board, e.g., perlite
g. wood fiberboard
d. polystyrene
e. polyurethame
h. phenolic
i. more than one type
$j$. other
k. no insulation
f. polyisocyanurate
1. none predominated

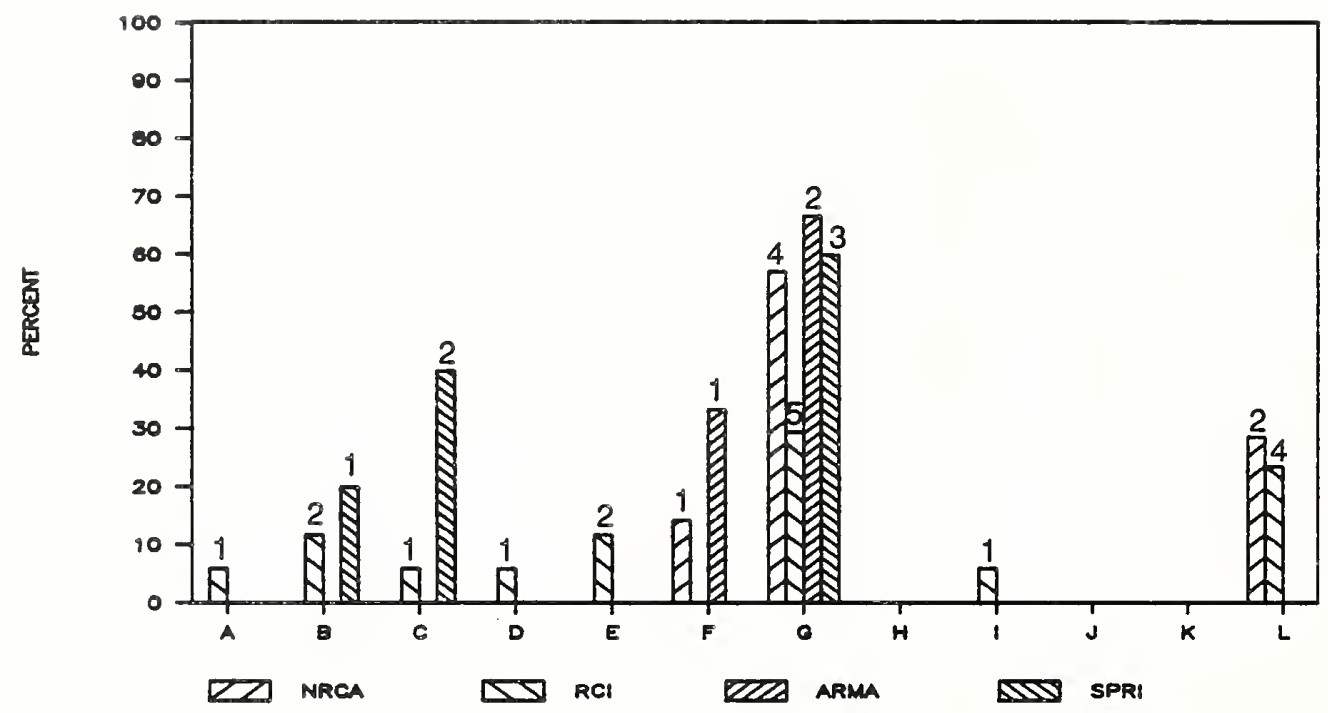

44. When corrosion was observed, did you find that the insulation was wet: (circle one)
a. did not know
b. always
d. some times
c. frequently
e. seldom
f. never

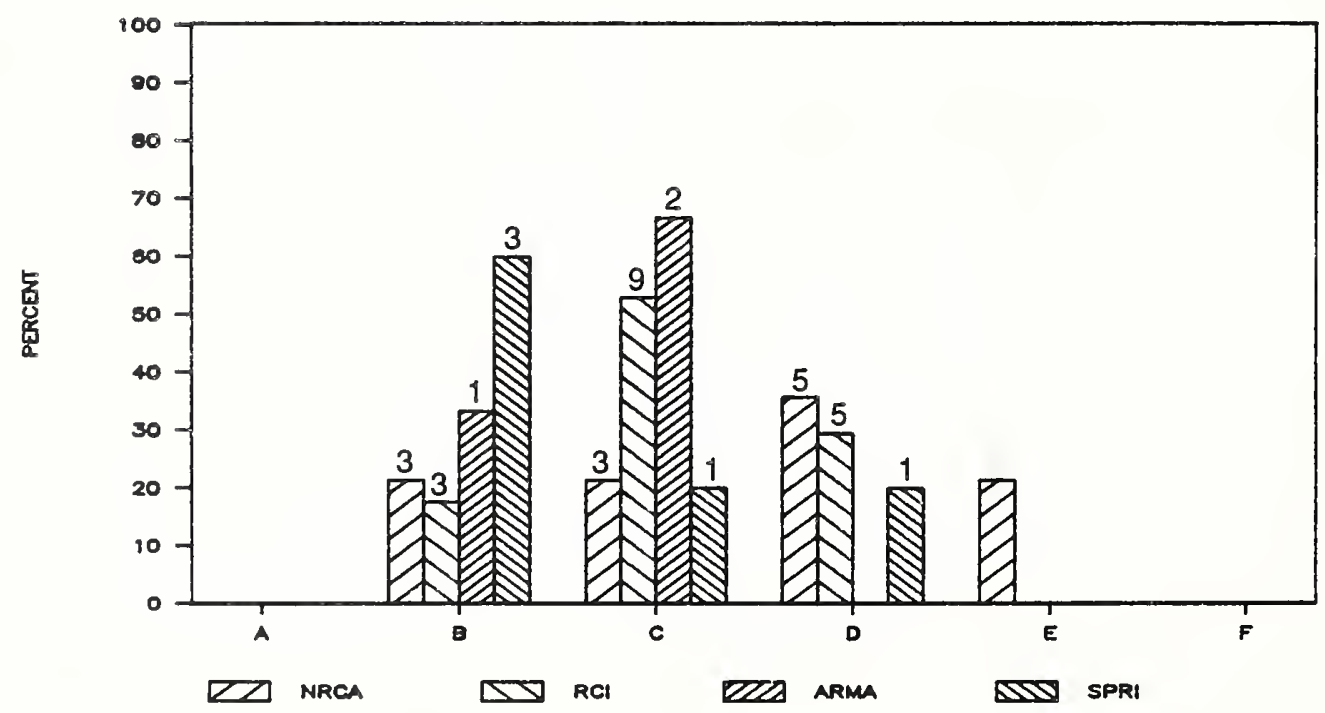


45. When corrosion of fasteners and stress plates were observed in insulated roof systens, in your opinion, to what extent in general did the insulation contribute to the corrosion: (circle one)
a. major factor
c. not a factor
b. minor factor
d. do not know

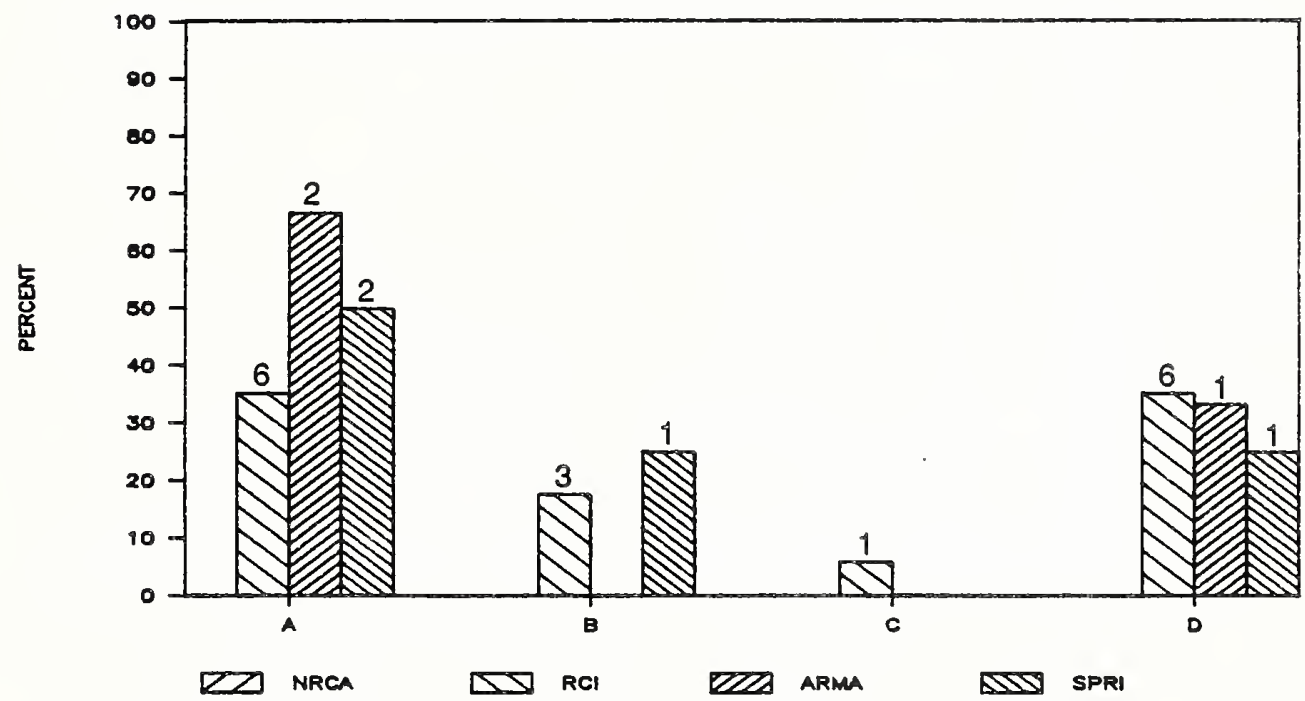

46. What were the deck types when corrosion of fasteners was observed: (circle as many as appropriate)
a. metal
b. plywood or wood
c. concrete (normal density)
d. concrete (lightweight)
e. gypsum
f. composite
g. other

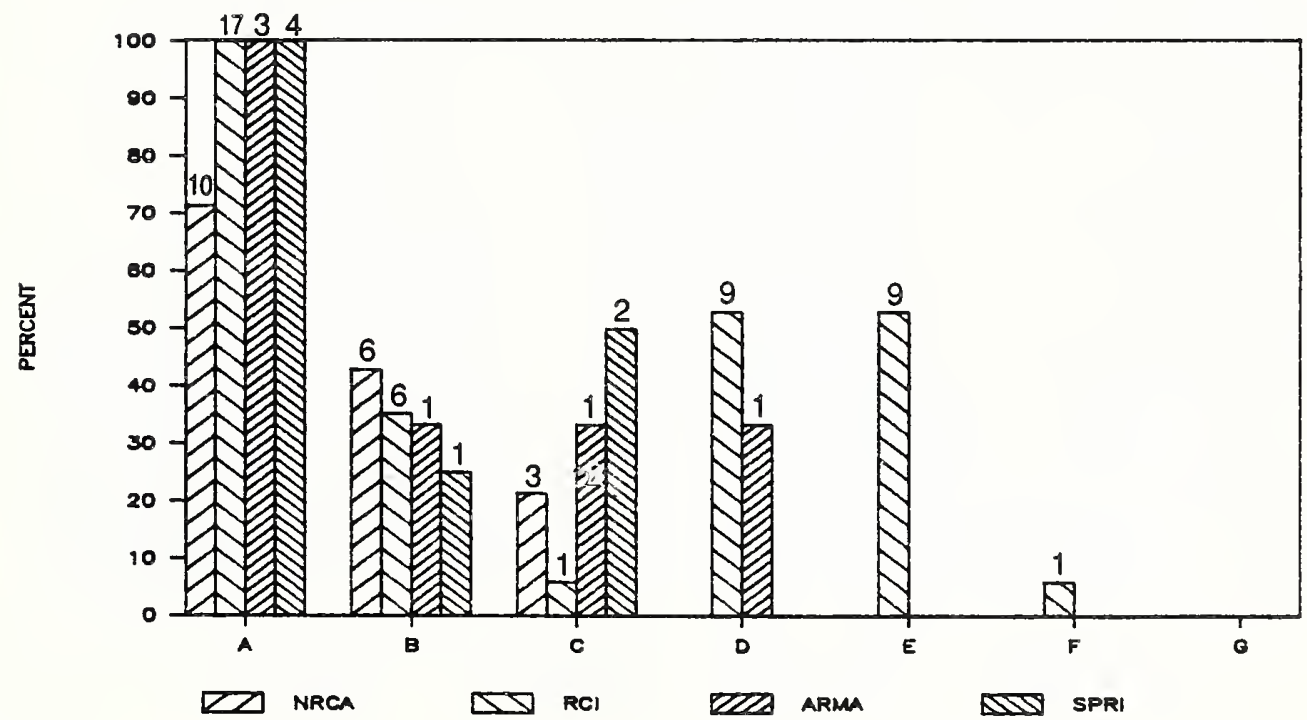


47. If, in the previous question, you circled more than one answer, please indicate the one type of deck most often found in systems experiencing corrosion of fasteners: (circle one)
a. metal
b. plywood or wood
c. concrete (nomal density)
d. concrete (lightweight)
e. gypsum
f. composite
g. other
h. none predominated

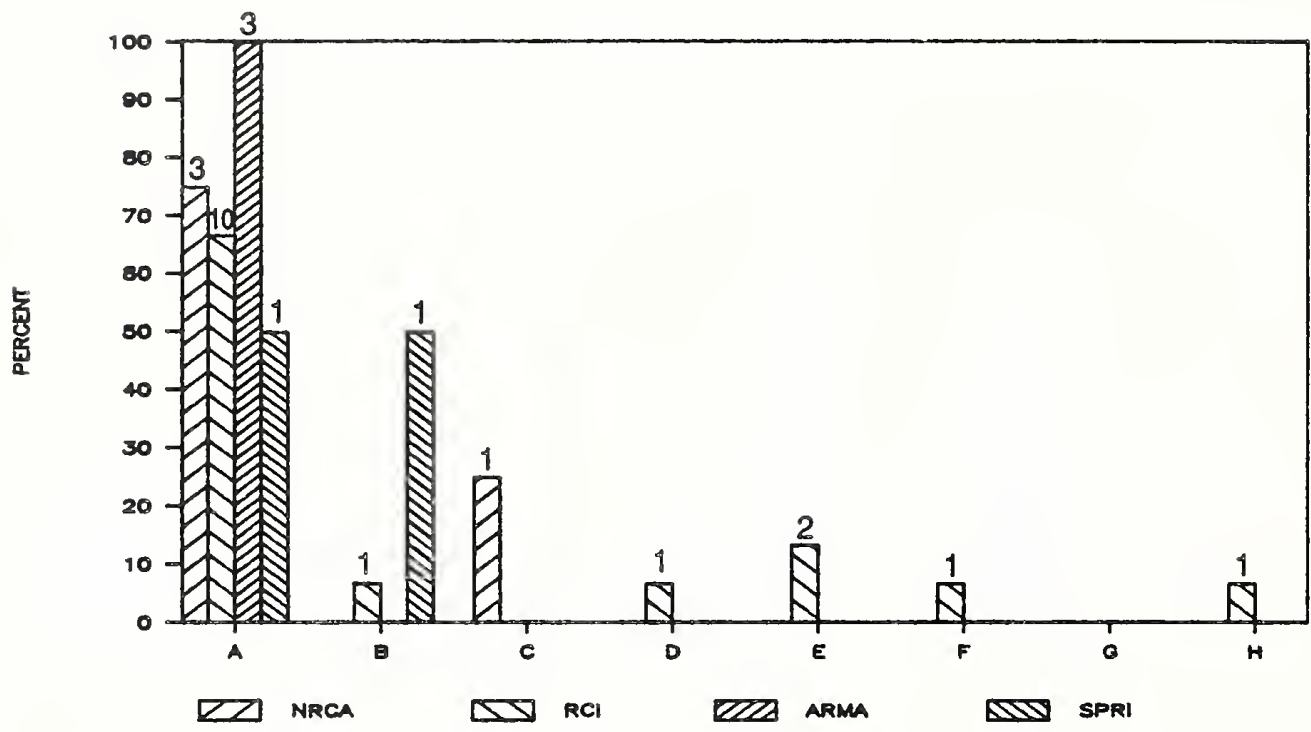

48. In cases where you observed corrosion of fasteners in metal deck systems, were you able to observe the deck at locations where the fasteners penetrated: (circle one)

a. could not observe the decks

b. could generally observe the decks

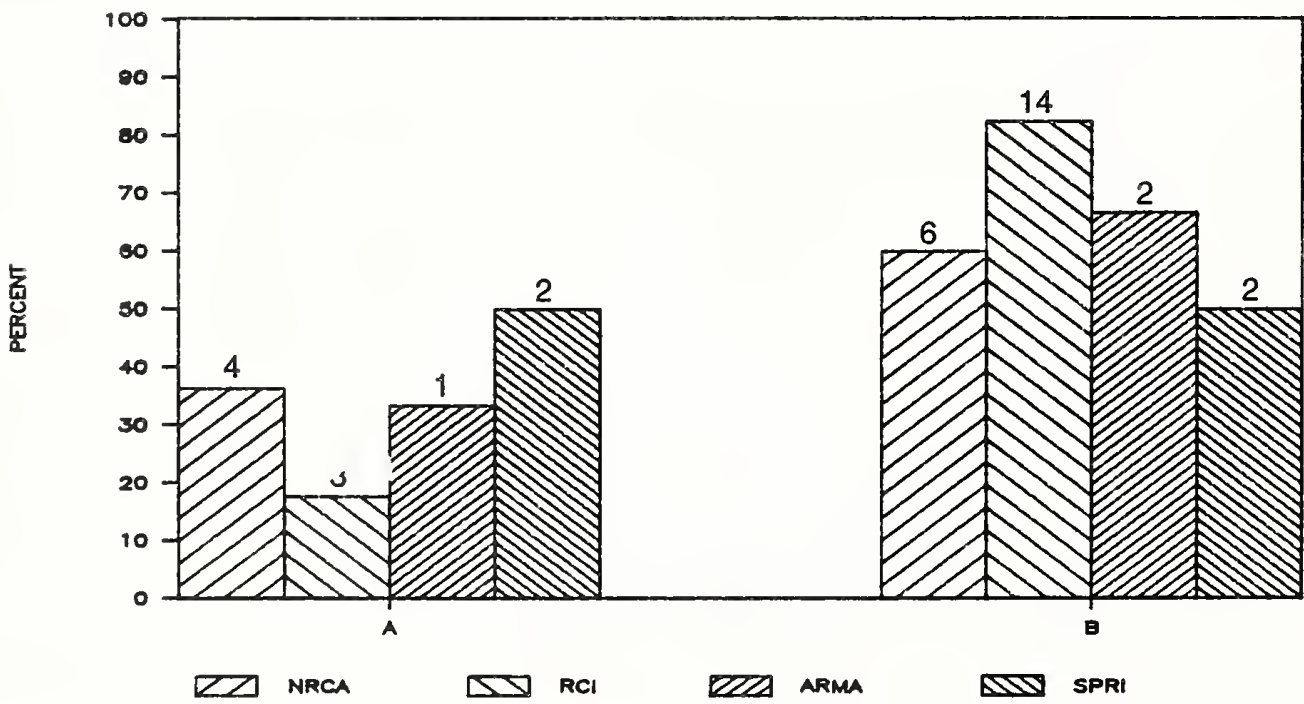


49. In cases where you were able to observe the metal deck, did you find that the deck was also corroded at locations where the fasteners penetrated: (circle one)
a. always
d. seldom
b. frequently
e. never
c. some times

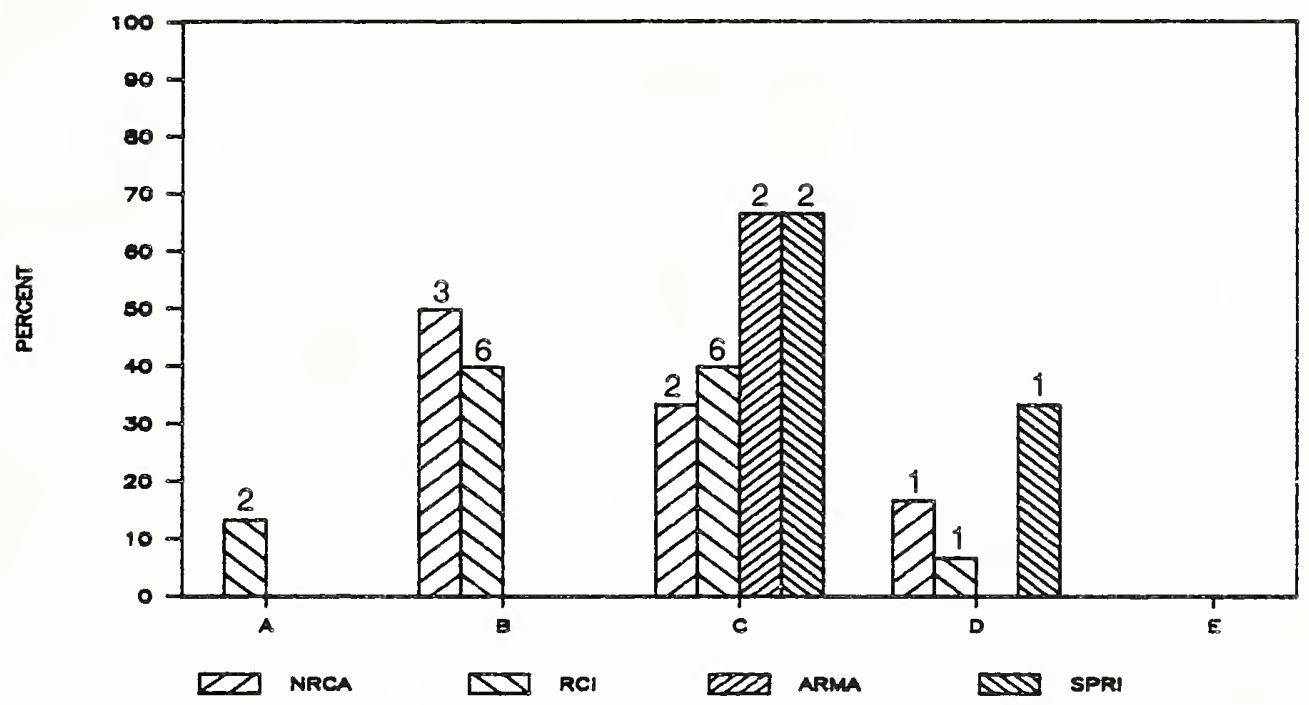

50. When you have observed corrosion of fasteners, how would you describe the humidity within the buildings: (circle one)
a. unusually low
b. normal
c. unusually high

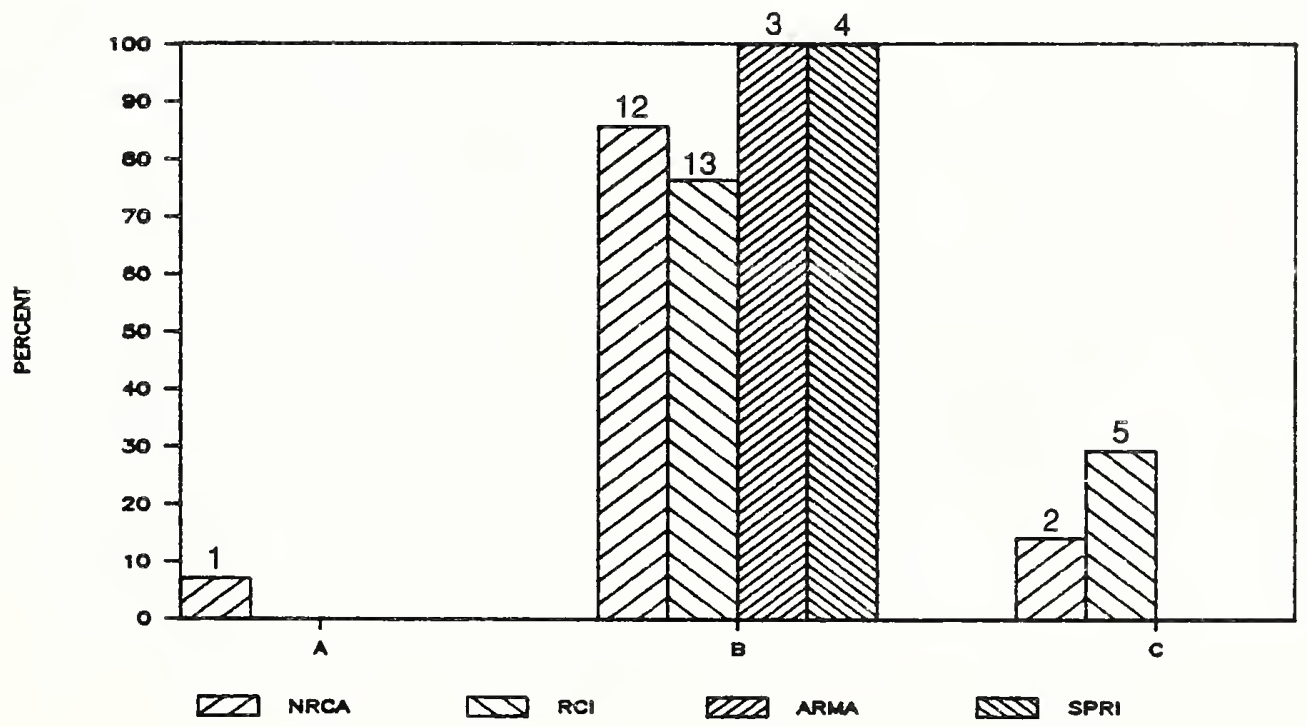


51. Do you think that the introcuction of the Factory Mutual test for evaluation of the corrosion resistance of fasteners has improved the fasteners presently available to the roofing industry: (circle one)
a. yes
c. do not know
b. no

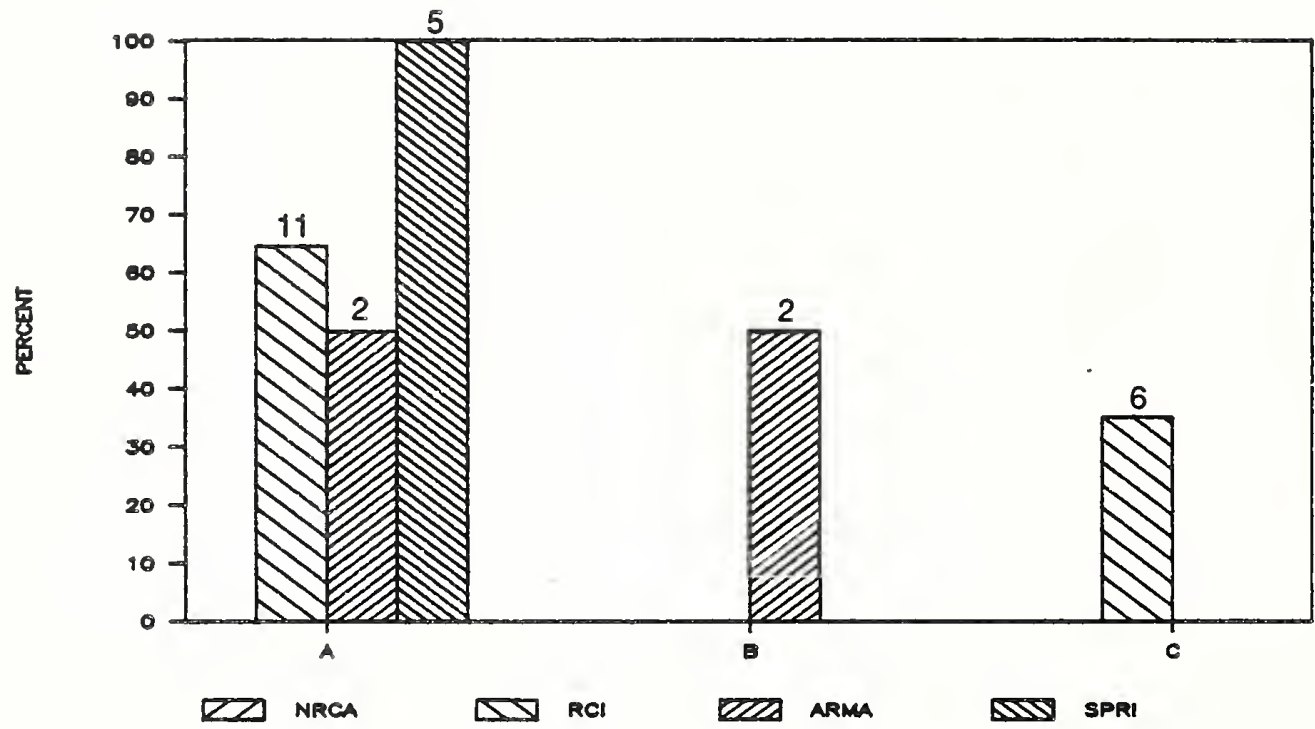

52. In your experience, have fasteners corroded in service after passing the Factory Mutual test procedure for corrosion resistance: (circle one)
a. yes
c. do not know
b. no

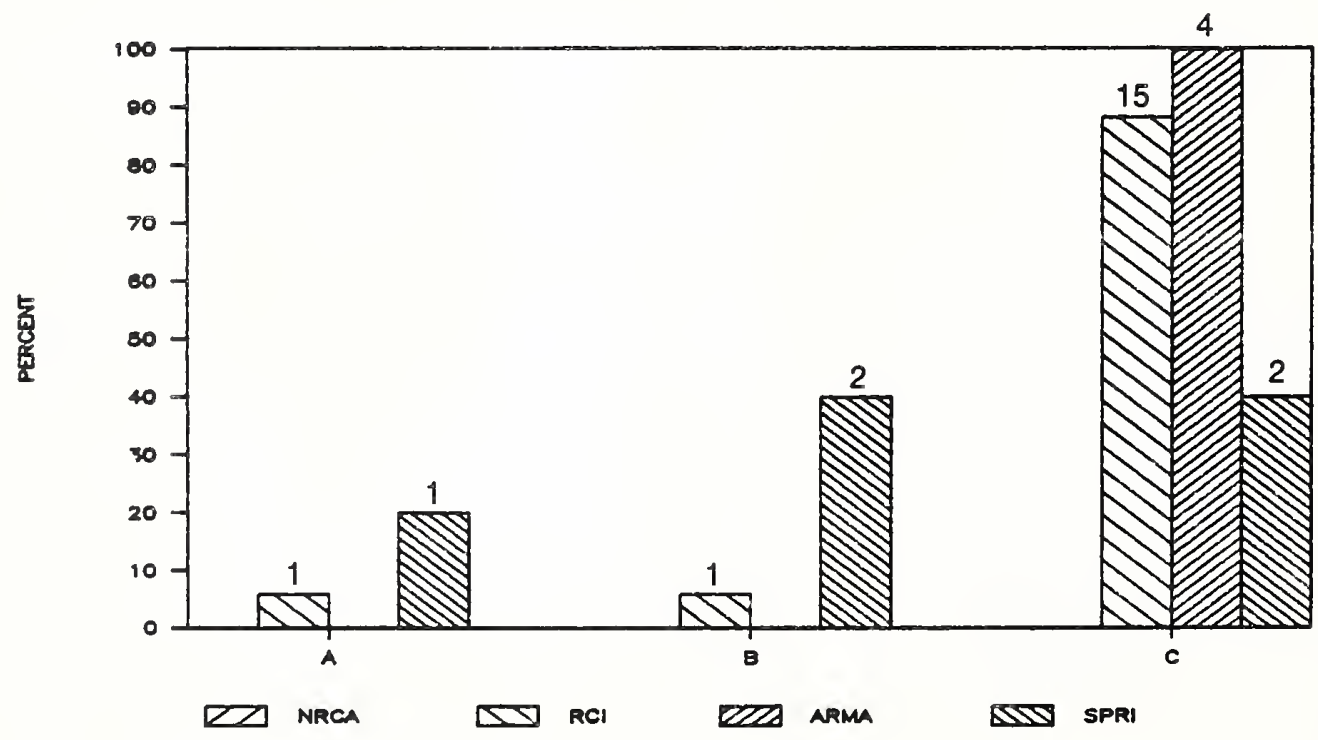


53. Do you know of correlations that have been developed between the results of the Factory Mutual test procedure, conducted in the laboratory, and the long-tem field performance of fasteners: (circle one)
a. yes
b. no

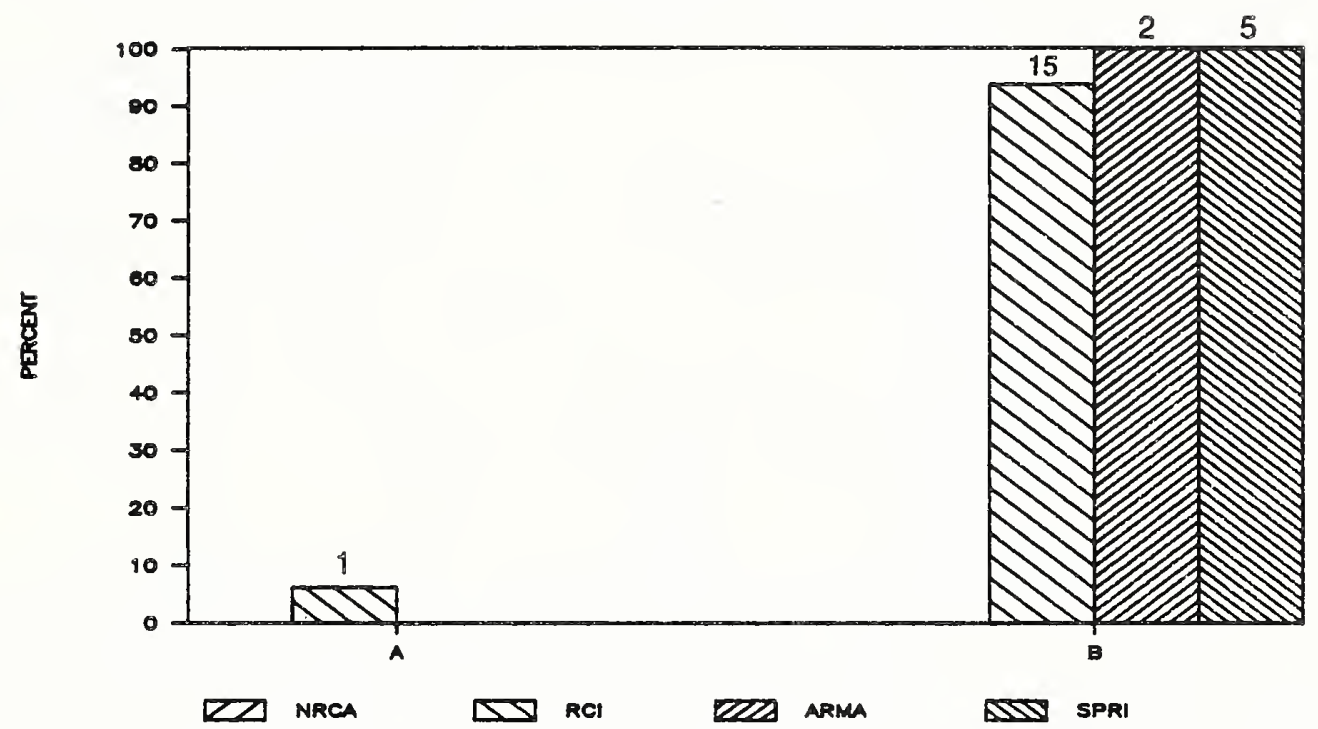

54. In your experience, have fewer cases of corrosion been observed with currently available fasteners than those available a decade or so ago when mechanical fastening became common: (circle one)
a. yes
c. do not know
b. no

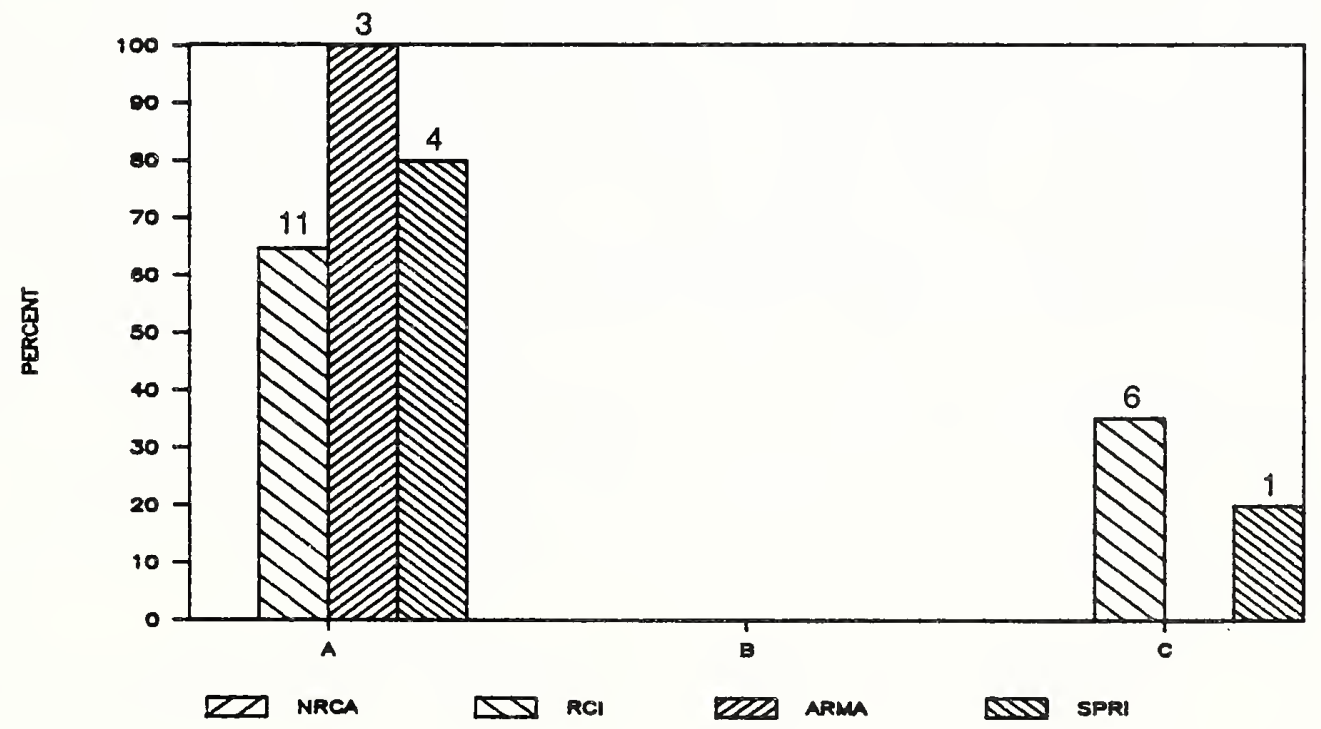


55. Do you think that there has been a progressive improvement in the performance of mechanically fastened systems over the last decade: (circle one)
a. yes
c. no opinion

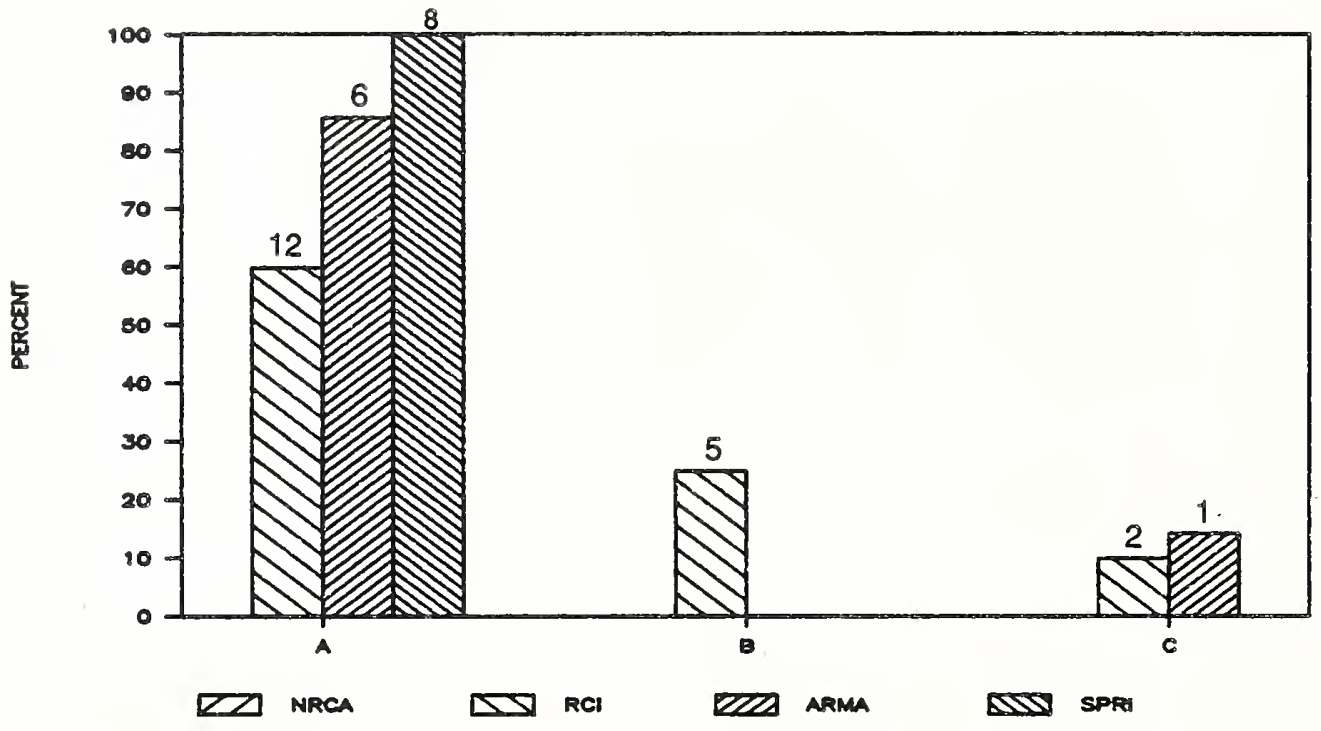


VBS-114A (REV. 2-8C)

U.S. DEPT. OF COMM.

BIBLIOGRAPHIC DATA

SHEET (See instructions)

1. PUBLICATION OR REPORT NO. NISTIR $88-4008$
2. Performing Organ. Report Nof 3. Publication Date

FEBRUARY 1989

4. TITLE AND SUBTITLE

Corrosion of fletallic Fasteners in Low-Sloped Roofs: A Review of Available

Information and Indentification of Research Needs

5. AUTHOR(S)

Walter J. Rossiter, Jr., Michael A. Streicher, and Willard E. Roberts

6. PERFORMING ORGANIZATION (If joint or other than NBS. see in structions)

\section{NATIONAL BUREAU OF STANDARDS \\ U.S. DEPARTMENT OF COMMERCE \\ GAITHERSBURG, MD 20899}

9. SPONSORING ORGANIZATION NAME AND COMPLETE ADDRESS (Street, City, State, ZIP)

U.S. Department of Energy

Office of Energy Utilization Research

1000 Independence Ave., S.W.

Washington, DC 20585

10. SUPPLEMENTARY NOTES

Document describes a computer program; SF-185, FIPS Software Summary, is attached.

11. ABSTRACT (A 200-word or less foctual summary of most significant informotion. If document includes a significant bibliogroohv or literoture survey, mention it here)

The use of mechanical fasteners for securing membranes or both insulation and membranes to the structural deck of low-sloped roofing systems is a common practice in the United States. The fasteners have been observed to corrode in service. Depending upon the extent of corrosion, loss of securement may result, making the roofing vulnerable to damage during high winds. Systematic studies to elicit the factors affecting the corrosion of fasteners in service have not been conducted.

This paper presents the results of a study conducted to summarize available information on the corrosion issue, and to identify research needed to correct problems. On the basis of the available information, it was not possible to estimate the extent of the corrosion problem. In particular, the incidence of loss of fastener securement due to corrosion could not be established because of the inaccessibility of installed fasteners within roofs. In reviewing factors affecting fastener corrosion, water was the only one that stood out on the basis of the information obtained. Uniform corrosion (rust on some or all of the surface) was the predominant type that inspectors have observed in service. Nevertheless, some evidence of localized corrosion processes (e.g., crevice corrosion) has also been observed. Both types of corrosion may lead to loss of fastener securement in service. The results of the study indicated that there are three major gaps in the knowledge base: 1) evaluation test procedures for the corrosion resistance of fasteners are limited and need to be improved, 2) a data base on field performance of fasteners is lacking, and 3) non-destructive diagnostic procedures for assessing the condition of inplace fasteners are not available. Research needed to overcome these

limitations was identified.

12. KEY WORDS (Six to twelve entries: alphabetical order: capitalize only proper names: and seporate key words by semicolons) corrosion; durability; metallic fasteners; low-sloped roofs; membrane attachment; research needs; review; roof performance; securement.

13. AVAILABILITY

Unlimited

For Official Distribution. Do Nor Release to NTIS

Order From Supepintendent of Documents, U.S. Government Printing Office, Washington, D.C. 20402.

Order From National Technical Information Service (NTIS), Springfield, VA. 22161
14. NO. OF PRINTED PAGES

104

15. Price

$\$ 19.95$ 
$\checkmark$ 
